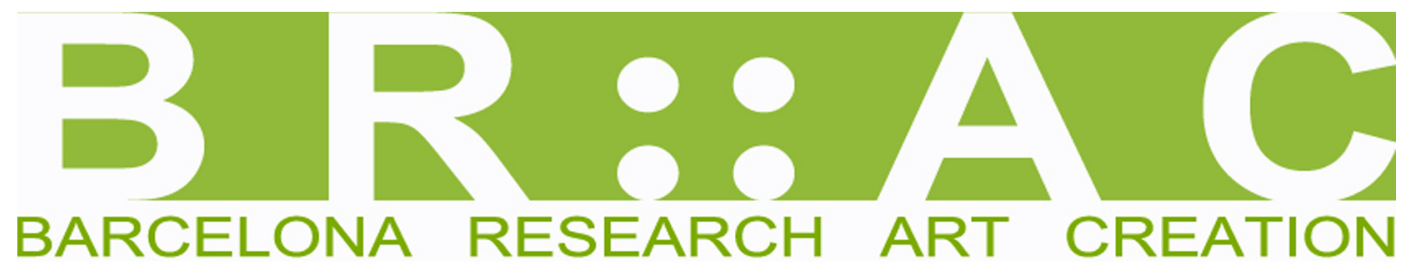

\title{
Volume 1, Number 1
}

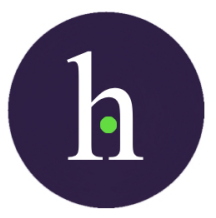

Editorial. BR::AC; Barcelona, Research, Art, CreationEquipo editorial- 1

Word sense discrimination using statistic analysis of textsRogelio Nazar- 5

Articles

¿Contra sí mismas? Mujeres artistas en los orígenes de la abstracciónMaria Lluïsa Faxedas- 27

Escultura sonora Baschet: universal design, pedagogía e inclusiónMartí Ruiz \& Robert Ruiz- 62

El Bulli: contemporary intersections between food, science, art and late capitalism- 100

Review La cascarilla cerámica como material escultóricoCarmen Marcos- 127 


\section{BARCELONA RESEARCH ART CREATION}

Instructions for authors, subscriptions and further details:

http://brac.hipatiapress.com

\section{Editorial}

Equipo editorial Revista BRAC ${ }^{1}$

1) University of Barcelona, Spain.

Date of publication: June 3rd, 2013

To cite this article: Editorial, E. (2013). Editorial. Brac: Barcelona, Research, Art, Creation, 1(1), 1-4. doi: 10.4471/brac.2013.00.

To link this article: http://dx.doi.org/10.4471/brac.2013.00

\section{PLEASE SCROLL DOWN FOR ARTICLE}

The terms and conditions of use are related to the Open Journal System and to Creative Commons Non-Commercial and Non-Derivative License. 
BRAC - Barcelona Research Art Creation Vol. 1 No. 1 June 2013 pp. 1-4

\section{Editorial}

Equipo Editorial BR::AC

University of Barcelona

1 es un placer para nosotros introducir en esta editorial el primer número de la revista BR::AC; Barcelona, Research, Art, Creation.

Nos complace presentarla como una revista electrónica de acceso abierto que nace con la voluntad de publicar artículos relevantes en el área del pensamiento $\mathrm{y}$ las prácticas artísticas, potenciando la colaboración internacional de artistas y teóricos del arte, en particular en el marco de las Facultades de Bellas artes.

Aún no hace un año que emprendimos esta aventura de tratar de crear un espacio en el que posibilitar la publicación científica, una plataforma rigurosa en el entorno del arte para contribuir a una normalización de la cual tradicionalmente ha carecido; de generar un espacio propio con entidad y credibilidad, conscientes también de las propias especificidades.

La revista, de carácter cuatrimestral, somete todos los artículos a una doble evaluación anónima con el objetivo de aparecer indexada en las principales bases de datos de Humanidades y Ciencias Sociales, tales 
como Journal Citation Reports, Arts \& Humanities Citation Index (A\&HCI), Social Sciences Citation Index (SSCI), Latindex, InRECS, ERIH, ERIC, the Social Science Citation Index, Current Contents (Thomson ISI), Scopus, Elsevier Bibliographic Databases, ISOC (CINDOC, Consejo Superior de Investigaciones Científicas), Social Scisearch, entre otras.

En este primer número os presentamos 4 artículos originales de 5 autores de los Estados Unidos y España; el primero de los artículos, Word Sense Discrimination using Statistic Analysis of Texts, apunta a la vocación multidisciplinar de la revista que considera el arte como una hibridación entre el conocimiento científico, sociológico y antropológico que aporta visiones diferentes de la realidad. El autor, Rogelio Nazar, inmerso en el contexto del reto actual que supone acceder a la información almacenada en formato digital, aborda en su artículo la problemática a la que se enfrentan los sistemas automáticos de análisis de textos cuando intentan discriminar entre palabras polisémicas que designan distintas entidades con el mismo nombre. Propone en su articulo un método estadístico que consigue, sin tener ningún conocimiento externo del texto ni del idioma, discernir el sentido de la palabra en función de los grupos de unidades léxicas que tienen tendencia a aparecer en el contexto de dicha palabra.

El segundo artículo de Lluïsa Faxedas, ¿Contra sí mismas? Mujeres artistas en los orígenes de la abstracción, se centra en el papel de las artistas que a principios del siglo XX optaron por la abstracción como vía de trabajo y pensamiento. La autora aborda el tema en el marco de exclusión general de la mujer en la historia del arte y en particular del arte moderno. Presenta de este modo, ciertos aspectos específicos relacionados con la teoría que sustentó los propios orígenes de la abstracción y la propia práctica. Teoría basada en el pensamiento dualista en el que "lo femenino" representaba "lo otro" aspecto este a purificar y, en el peor de los casos, eliminar. La asociación con lo material, lo sensual, es decir lo corporal, derivó en lo meramente decorativo en el campo de las artes aplicadas llevando esto último a una aportación minusvalorada a la cual, según la autora, la historiografía feminista del arte tampoco ha prestado una atención específica a las aportaciones de estas artistas. 
En el tercer articulo, Escultura Sonora Baschet: Universal Design, Pedagogía e Inclusión, sus autores Martí Ruiz y Robert Ruiz, en un acercamiento al Instrumentarium Pedagógico Baschet plantean una lectura inédita a través del punto de vista de Ron Mace y su Universal Design. Nos proponen una doble lectura de sus principios, aplicaciones e implicaciones fundamentada en los más de sesenta años de evolución de Baschet. Evolución que se aborda aquí como ejemplo, como paradigma que nos abre las puertas a la pedagogía y la función social del arte.

Y en el artículo que completa este primer número de la revista, Maria Domene con su aportación El Bulli: Contemporary Intersections Between Food, Science, Art and Late Capitalism, partiendo de la polémica participación o "intervención" de Ferran Adrià en la Documenta de Kassel el 2007, y superadas las sensaciones de confusión, ansiedad, decepción y curiosidad producidas, Maria Domene reflexiona sobre aspectos poliédricos del trabajo de Adrià en particular en tres de ellos: trabajo, performance e incorporación de ciencia y tecnología en la cocina; la llamada "tecno-cocina", llegando así a una clara disolución entre fronteras lo que Fredric Jameson denomina como "desdiferenciación" fruto de la economía del capitalismo tardío.

Estos cuatro artículos conscientemente diferentes en esencia conforman, no obstante, unas líneas de pensamiento que nos permiten abrir caminos plurales de trabajo e investigación dentro de las amplias y variadas posibilidades que cada día se abren ante el arte en relación con otros ámbitos de pensamiento y práctica.

Dentro del arte contemporáneo debemos profundizar en la investigación rigurosa y documentada que revierta asimismo en las propias aulas potenciando una relación directa entre práctica artística, investigación y docencia.

La revista se ha hecho realidad gracias al esfuerzo y entusiasmo del equipo de personas que la componen. Por último, deseamos manifestar nuestro agradecimiento a todas las personas que trabajan y colaboran con Hipatia Press en la puesta en marcha de esta iniciativa. Hipatia Press es una editorial que siempre se ha caracterizado por la excelencia científica dentro las ciencias sociales y por su compromiso democrático. 
4 Equipo editorial Revista BRAC-Editorial

No ha sido nuestra intención hacer un repaso exhaustivo aquí, pero sí os animamos a leer estos artículos en la confianza que serán de vuestro interés.

Equipo editorial Revista BR::AC Universidad de Barcelona, 3 de Junio de 2013 


\section{B. R: : : A C}

Instructions for authors, subscriptions and further details:

http://brac.hipatiapress.com

\section{Word Sense Discrimination Using Statistic Analysis of Texts}

Rogelio Nazar ${ }^{1}$

1) Natural Language Processing Research Group, Dept. of Information and Communication Technologies, Universitat Pompeu Fabra, Barcelona.

Date of publication: June 3rd, 2013

To cite this article: Nazar, R. (2013). Word Sense Discrimination Using Statistic Analysis of Texts. BRAC. Barcelona, Research, Art, Creation, 1(1), 5-26. doi: 10.4471/brac.2013.01.

To link this article: http://dx.doi.org/10.4471/brac.2013.01

\section{PLEASE SCROLL DOWN FOR ARTICLE}

The terms and conditions of use are related to the Open Journal System and to Creative Commons Non-Commercial and Non-Derivative License. 


\title{
Word Sense Discrimination Using Statistic Analysis of Texts
}

Rogelio Nazar

Universitat Pompeu Fabra, Barcelona

\begin{abstract}
For years, computer programs have been working to obtain information about certain entities such as persons, organizations or scientific concepts from the Web or from other sources. However, they have many challenges yet to overcome, for instance when texts refer to different entities that share the same name (e.g., a mouse can be an electronic device or a living creature). This article presents a method to solve this problem based on the frequency analysis of the words that are found in the vicinity of a target word. Each sense of the polysemous word or term will be represented as a different group of other vocabulary units that show a tendency to appear together with the target word in each of its different senses. The interest of the proposal is that it does not require previous knowledge about the language of the corpus or any other form of knowledge from the external world.
\end{abstract}

Keywords: computational linguistics, information extraction, word sense induction. 
BRAC - Barcelona Research Art Creation. Vol. 1 No. 1 June, 2013 pp. 5 26

\section{Discriminación de Sentidos Basada en Análisis Estadístico de Textos}

Rogelio Nazar

Universitat Pompeu Fabra, Barcelona

\section{Resumen}

Durante años han existido programas que de manera automática obtienen información acerca de entidades como personas, organizaciones o conceptos científicos a partir de repositorios de texto en formato digital tales como la Web u otras fuentes. Sin embargo, todavía existe una serie de dificultades que no se han podido resolver, por ejemplo cuando distintas entidades son designadas con un mismo nombre (como el ratón, que puede ser un dispositivo periférico en computación o bien un mamífero). El presente artículo propone un método para resolver este problema basado en el análisis de la frecuencia de las palabras que se encuentran en el contexto de aparición de la palabra ambigua.

Cada uno de los sentidos de una palabra polisémica se representan mediante los correspondientes grupos de otras unidades léxicas que muestran tendencia a aparecer en el contexto de esta palabra. El interés de esta propuesta reside en que no requiere ningún tipo de conocimiento externo al corpus, como conocimiento del mundo o de la lengua de los textos.

Palabras claves: extracción de información, inducción de sentidos, lingüística computacional.

2013 Hipatia Press

ISSN 2014-8992

DOI: $10.4471 /$ brac.2013.01 
here currently exists a wide variety of computer programs ${ }^{1}$ that are scanning the Web or vasts collections of scientific literature with the purpose of collecting information. These programs are designed to obtain data of different degrees of complexity from running text, such as, for instance, attributes of different entities like persons or organizations or information of a more technical nature, like drug-drug interaction or the possible relations between proteins and certain diseases, to name only a few possibilities. Of course, human beings are much more skilled than most computer programs in the task of reading and understanding a written document. However, the massive amount of text that is accumulating these days has reached such a point where it becomes difficult for a single individual or a group of researchers to retrieve all the relevant documents produced in their corresponding fields and assimilate the information in the traditional way, i.e., taking the time to read the documents one by one.

As a result of the massive grow experienced by the collections of technical and scientific literature, more and more researchers from different fields are using computers to search and extract information from electronic documents, offering a significant opportunity of application for the algorithms developed in computational linguistics, which is the general denomination of the field of research on semantic analysis of text by automatic means.

Information Retrieval (IR; cf. Manning et al., 2008) and Information Extraction (IE; cf. Grishman, 2012) are complex tasks that still have many challenges to be addressed by computational linguists. One of the most difficult problems is faced when different entities mentioned in the texts share the same name. This is the problem that is introduced in the present article, along with a proposal for a methodology to solve this kind of ambiguity by means of statistical analysis. More specifically, the article will show how the meaning of a word can be modeled using other words occurring in the vicinity of the ambiguous one. The article advocates for the use of statistical methods instead of rule based systems for a number of reasons that will become apparent later.

Let us first clarify the terminology used to circumscribe the problem: 
Word Sense Disambiguation (WSD) is defined as the operation by which an automaton assigns a determined sense to an ambiguous word in context from an inventory of senses available to the system. Word Sense Induction (WSI) or Discrimination, in contrast, is the operation of finding those senses from a sample of contexts of occurrence of a given word. Both operations are related, but they are often treated as independent problems in the literature (Ide \& Véronis, 1998; Navigli, 2009).

The present article is focused on WSI only, and it discusses a methodology for its application to the results of a search on the Web or on other corpus. The paper reports promising results of experiments that were conducted to test if one can acquire the senses of acronyms in English and proper nouns in Spanish, although the same idea should also be useful for other languages and scenarios.

As an example of application of this algorithm, consider the case of a search engine like Google, which has not yet been able to find a proper solution to the problem of homographs in the search results. The problem of homographs is especially acute in the Google Alerts service, which provides an email alert when a new document appears on the Web containing a given query expression that has been set beforehand by the user. Of course, this user will only be interested in one of the possible senses or references of such query and not the noise produced by email alerts triggered by irrelevant documents.

There is increasing interest in this type of email alert services because of their relation to the field of "reputation management", which is usually in the hands of public relations and communication professionals who are in turn creating a demand for IE technologies and motivating research in the extraction of information about persons and organizations (Artiles et al., 2010). In an increasingly digital world, the circulation of information about a given institution or individual can be of strategic importance, and we can expect to see a market of software solutions for the extraction of, for instance, the most frequent opinion of consumers about a certain brand or product. In order to fulfill this purpose, however, applications must be able to distinguish between different people that share the same name or different referents that are designated by the same acronym.

The present paper thus argues that clustering algorithms based on co- 
occurrence graphs can be useful to resolve different kinds of ambiguity. It proposes an original algorithm that is based on graphs of lexical cooccurrence which takes an expression as input and retrieves contexts of occurrence from a corpus (a collection of documents from the Web or from any other source) and produces a graph based clustering of the contexts. This output, in turn, can serve as a representation (or a discrimination) of the different senses that the ambiguous word may have. The proposed model produces, for each input word, a representation of the syntagmatic associations of such word, i.e., those that have a significant frequency of co-occurrence with the analyzed word in the same sentence, paragraph, or in a context window of an arbitrary size. These are the units that are taken as disambiguation clues, disregarding all external sources of explicit linguistic or ontological knowledge.

The units found in the contexts are referred to as the vocabulary, which is represented as words and sequences of up to $n$ orthographic words (called $n$-grams), with $n=2$ in the case of these experiments. This vocabulary is organized in a graph that represents the co-occurrence between the vocabulary units. Every node in the graph is a unit and the links between the nodes represent the associational strength between the words given by the number of times they appear together in the same contexts.

The graph is created from an input word (or term) $A$, thus the graph represents n-grams occurring with $A$ with a significant frequency, set denoted as $\bar{A}$. The arcs of the graphs are not only between $A$ and the nodes $A_{i}$, they are also created between nodes $A_{i}$ and $A_{j}$ if both tend to appear together in the contexts of $A$. The idea of applying these graphs to WSI is to travel through such graph to extract subgraphs and to treat them as separate clusters, each one representing a different sense of the analyzed word.

With a minimum number of contexts of occurrence of a given target word (experiments in this paper included 100 contexts per trial) representing different senses of such word, then the resulting graph of $A$ will show different hubs, which are regions of densely interconnected nodes. Thanks to their singular geometric properties, co-occurrence graphs can be useful in the case of polysemous expressions. There are regions of the graph that attract a group of nodes related to one of the 
senses, and this phenomenon can be used as a natural way to cluster contexts according to word senses. Some obvious examples are the cases of homographs such as the computer mouse and the animal mouse. In the graph for mouse, one region will be populated with computer-related terminology and the other with words related to the biological creature.

In the case of proper nouns, homonymy can be resolved because the names of related people serve as hubs in the network of a given proper noun, separating the references to different persons because it is unlikely that homonyms will share the same friends and acquaintances. One would rather expect each person to know different people, which results in the creation of independent networks within the graph generated with the name of the homonyms. It is the same process as with words: every sense of a polysemous word has its own group of "word friends", according to a famous Firthian principle (Firth, 1957).

This paper is organized as follows: next section offers a brief comment of related work on the field of WSD and WSI; Section 3 outlines the proposed methodology while Section 4 discusses the results of two kinds of experiments designed to test the method. Finally, Section 5 draws some conclusions and lines for future research.

\section{Related Work}

Research in WSD has been carried out for many decades and it has long been regarded as one of the most difficult problems in Machine Translation (MT) since its early days (Weaver, 1949; Pierce et al, 1966). First attempts were based on hand-crafted disambiguation rules (Kelly \& Stone, 1975). Lesk (1986), for instance, tried to disambiguate words using the definition of senses listed in machine readable dictionaries. In the same way, manually constructed lexical resources have been used in the attempt to disambiguate words, like Yarowsky (1992) with Roget's thesaurus or Voorhees (1993) with the WordNet ontology.

In contrast to rule based techniques, different statistical approaches have also been proposed. Gale et al. (1992) used parallel corpora (collections of documents with their translations to another language) to learn the different senses of a word, since ambiguous words are 
translated to different words in the aligned sentences according to their different word senses. Thus, one sense of the English word sentence will be aligned with the French word peine and in another sense with the word phrase. Also in the statistical trend, Yarowsky (1995) later discovered that collocations are useful to disambiguate because there usually is only one sense per collocation.

In the present days, we are living a sort of critical moment in the history of the WSD field. After several decades of research and many competitions organized for comparing precision figures (such as the Senseval/Semeval competitions, Agirre \& Soroa, 2007; Manandhar et al., 2010), signs of a loss of optimism have begun to appear, both in the theoretical and practical levels. The reliability of many common assumptions is now being scrutinized, such as if there really is such thing as an inventory of word senses (Kilgarriff, 1997). In the theoretic level, there is still a great amount of confusion around the topic of polysemy and ambiguity. At the same time, the levels of inter-annotator agreement -which measure how different persons agree upon the discrimination of senses of a word- are lower than one would expect (Véronis, 1998).

Probably as a consequence of the great complexity of the problem, WSD methods are often ignored in many real world applications (Ide \& Wilks, 2007). In MT, for instance, disambiguation is done in an implicit manner, as a consequence of the fact that MT researchers in general use statistical models trained on parallel corpora to associate equivalent sequences of words in two languages, with the phrase context playing the role of a disambiguating factor. In IR, a debate exists on whether WSD modules can or not improve results, but no consensus has yet been reached (Sanderson, 1994; Voorhees, 1993; Véronis, 2004; Agirre \& Edmonds, 2007).

The work on WSD has been criticized mainly from the lexicographic front for the rather naïve assumptions that underlie most approaches, mainly the already mentioned idea that words have a limited number of discrete senses that can be listed in a dictionary. Many authors have expressed that such an approach would only be useful for certain levels of word-sense distinctions such as homographs (Kilgarriff, 1997; Hanks, 2006; Jezek \& Hanks, 2010). Regarding this debate, one has to raise the question of what is exactly the purpose of the research in WSD. As 
pointed out by Ide \& Wilks (2007), for the purpose of practical applications, it is just the homograph-type distinction that is really needed in NLP:

We argue that there is rarely a need to make distinctions below the homograph-like level for understanding, human or automated; and in the unusual circumstance where it becomes necessary to explicitly throw one of the sub-senses away, we can expect there to be contextual clues that will enable both humans and machines to do so. (Ide \& Wilks, 2007:66).

The application of unsupervised approaches of WSI could be the appropriate response to the objections raised by critics of the inventorybased WSD, because this approach is less rigid and would not need previous inventories. Many authors have been working in this direction since the early nineties, with the application of vector space models as used in IR to perform WSD oriented clustering (Schütze, 1992, 1998; Schütze \& Pedersen, 1995; 1997; Purandare \& Pedersen, 2004; among others). The interest on the vector based approach begun to decay, however, when Small World Graphs (Watts \& Strogatz, 1999) were introduced in linguistics under the name of Co-occurrence Graphs (Ferrer-i-Cancho \& Solé, 2001). According to a growing number of publications, different versions of the Co-occurrence Graph approach are the most promising solution for both WSI and WSD (Widdows \& Dorow, 2002; Véronis, 2004; Biemann, 2006; Klapaftis \& Manandhar, 2010, among many others).

The line of research that is explored in the present paper could be categorized in the same trend as the latter studies. The novel contribution, in comparison to related work, is that the proposed method is much more simple both in the conceptual and computational level and that it disregards all external sources of knowledge (both linguistic and ontological).

\section{Methods}

As briefly sketched in the introduction, for the experiments to take 
place, this approach assumes that we have a determined polysemous word and a corpus where this word is instantiated. When the analyzed corpus is downloaded from the Web, a series of routines are needed to convert the format of the files (e.g., HTML, PDF, Word documents, etc.) to plain text documents. The conversion process is not strictly relevant to the design of the algorithm and is therefore not discussed in detail here.

Once the corpus is available in plain text format, each vocabulary unit of the contexts is represented as a node. A vocabulary unit, however, may have different surface realizations on the corpus due to inflectional derivation or other types of term variation. A proper solution to this problem would be to apply full text-handling, including tokenization, lemmatization, Part-of-Speech tagging and a series of operations some of which are of great complexity, such as the identification in text of named entities and technical terminology. For simplicity, and to allow for the application of the algorithm to different languages, the methodology disregards these sources of information and only performs a sort of "pseudo-lemmatization", using an orthographic similarity measure based on the Dice coefficient $(1)$, which takes two strings $(i, j)$ as arguments and returns a value between 0 and 1, representing how similar they are on the basis of how many sequences of two letters they have in common.

$\operatorname{Dice}(i, j)=2|\mathrm{I} \cap \mathrm{J}| /(|\mathrm{I}|+|\mathrm{J}|)$

For instance, if we compare the French bigrams détentions provisoires and détention provisoire, the resulting similarity would be 0.9 . It is important to mention, however, that this procedure is only justified for the purpose of evaluating this method without the benefits provided by services such as lemmatization and Part-of-Speech tagging. Of course, in a real world application, nothing would prevent the use of all available resources.

The next step is to reduce the vocabulary of the corpus in order to keep only the most informative units (i.e., to eliminate non-content words, words that are not conceptually related to the input word, or more precisely, words that could appear in any text, regardless of the topic). This is done by using a reference corpus of the analyzed 
language. Reference corpora are expected to represent general vocabulary and should be a balanced collection of genres and registers. Instead of this, in the experiments the reference corpora consisted of collections of press articles of approximately two million tokens per language used, downloaded from the Wortschatz-Portal (Quasthoff et al., 2006).

Strictly speaking, it cannot be said that a corpus of press articles is representative of general vocabulary, but using the frequency of the analyzed words in this reference corpus, it is possible to filter out the least informative vocabulary units. This operation is undertaken with the help of association measures. In the case of these experiments, Pointwise Mutual Information (2) is used (Church \& Hanks, 1990), calculating the score between the target word and each of the cooccurring $n$-grams. In this context, $X$ would be the input word and $Y$ each co-occurring word. $\mathrm{P}(X, Y)$ would be the relative frequency of cooccurrence in the analyzed corpus while $\mathrm{P}(X)$ and $\mathrm{P}(Y)$ represent their independent relative frequency in the reference corpus. Deleting nodes with an association score below a threshold produces an efficient reduction of the vocabulary.

$\operatorname{PMI}(X, Y)=\log 2 \mathrm{P}(X, Y) / \mathrm{P}(X) \mathrm{P}(Y)$

In order to reduce computational effort, a further filtering of the vocabulary is performed by the construction of the co-occurrence graph. Arcs between nodes are created when the words in the nodes appear in the same context. Each arc is weighted according to Equation (2), where $\left(A_{i} A_{j}\right)$ denotes the frequency of co-occurrence of nodes $A_{i}$ and $A_{j}$ while $N$ is the total number of contexts.

$\mathrm{R}\left(A_{i}, A_{j}\right)=\left(A_{i} A_{j}\right) / N$

Once the graph for a given input word is constructed, the process of WSI consists of a clustering process of the graph by identifying and extracting hubs. Each extracted subgraph or cluster represents a sense of the analyzed word. If a given cluster shows a similarity over a given threshold (details of the overlapping function are given later), then the two clusters are merged into a single cluster and this process continues 
until no more clusters are created.

Table 1 shows the pseudo code for the WSI algorithm. Perhaps the most suitable way to explain this algorithm is by means of an example. Consider, for instance, the Spanish word ratón (mouse) in a corpus consisting of 50 contexts of occurrence of ratón in a Computer Science corpus and 50 contexts from a Genomics corpus.

\section{Table 1}

Pseudo-code for the proposed WSI algorithms

Word Sense Induction Algorithm

For each word $j$ co-occurring with input word $t$ \{

Initialize counter;

Initialize rank;

Create cluster $s$ with documents containing $j$;

Next if first cluster;

For each previously created cluster $p\{$

$\mathrm{o}=$ overlap $(p, s)$;

if $(o>k)\{$

$\operatorname{rank}(p)=0$;

counter++;

\}

\}

if (counter $>1)\{$

destroy cluster s;

\} else if ( counter $==1)\{$

collapse ( $\max ($ rank), $s$ );

\}

\}

Do pairwise comparison of clusters; 
The process of word sense induction starts in the first loop with the word icono (icon) as the value of the variable $j$, because it is the word with the most significant frequency of co-occurrence with the target word. Since it is the first word, the loop ends here, creating a first cluster with pointers to all the contexts of ratón that also contain the word icono. The next value of $j$ is the word teclado (keyboard), another word frequently found in the contexts of ratón when the word is used to designate the computer device. In this case, since there already is a cluster created, the new cluster of contexts teclado + ratón is compared to determine the number of contexts they share using the overlap function (4).

$\operatorname{overlap}(i, j)=|\mathrm{I} \cap \mathrm{J}| / \min (|\mathrm{I}|,|\mathrm{J}|)$

The result of the comparison between the two clusters of teclado and icono yields a coincidence of $33 \%$ of the contexts (i.e., in $33 \%$ of the cases, the word ratón occurs both with teclado and icono. Since the arbitrary threshold $k$ of the overlap was set precisely to $33 \%$, these clusters are considered different and therefore they are not merged and, as a consequence, a new cluster for the contexts of the word teclado is thus created. This is a somewhat unfortunate decision, since both terms are indeed related. However, as we will see in a moment, the algorithm is robust enough to recover later from this "mistake": when the clusters grow in number of members, then there is sufficient overlapping to allow for their assimilation into a single, larger cluster.

For the moment, let us continue with the simulation of the process. The next word to be the value of $j$ is transgénico (transgenic). Again, the same process unfolds: the cluster of contexts of transgénico is compared with each of the two clusters recently created and the result in both cases is that the overlap is zero. Consequently, the contexts of transgénico are treated as a new cluster. The following word is seleccionar (to select). Again, the cluster of contexts of this word is compared with the three clusters previously created. This time, the comparison shows an overlap of $20 \%$ with the first cluster, the one for icono, but since it is again below the threshold $k$, a new cluster is created. In the case of the following cycle, with the word puntero (pointer), the overlap with the first cluster is $75 \%$, thus the new cluster 
is collapsed with the first one.

The process goes on like this until there are no more co-occurring words or no more contexts of occurrence. When this is the case, the algorithm performs a pairwise comparison of each of the created clusters, with the purpose of collapsing those clusters that, again, surpass the overlap threshold (as in the already mentioned case of teclado and icono). The mechanism is the same as in the comparison just described: a cluster $s$ will be collapsed to another cluster $p$ if the overlap between $s$ and $p$ is greater than $k$ and if there is no other cluster apart from $p$ that $s$ has such an overlap with. For illustration, figures 1 and 2 depict fragments of the two clusters or sub-graphs representing each of the two uses of the word ratón.

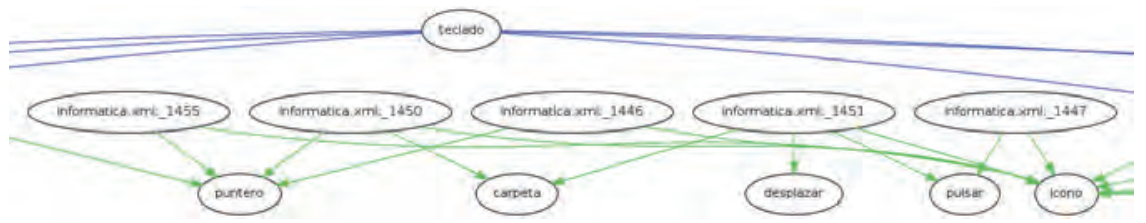

Figure 1. One of the regions of the graph for the Spanish word ratón meaning computer mouse.

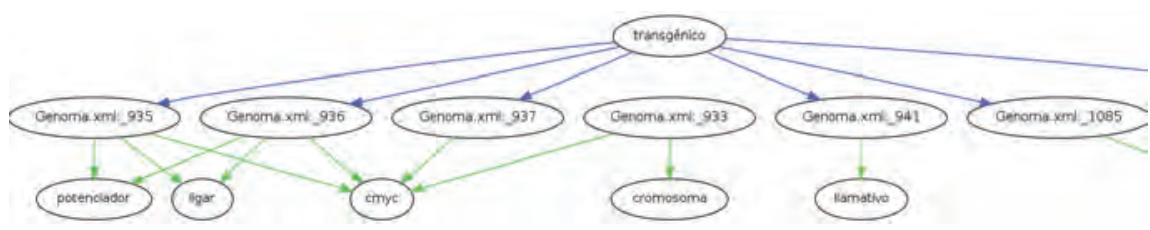

Figure 2. Another region of the graph of ratón, now representing the animal sense.

\section{Experimental results}

\section{Analysis of acronyms}

The first experiment was undertaken with a set of acronyms in English, in order to cluster documents downloaded from the Web according to the different referents of these symbols. The case of the acronyms is interesting because their disambiguation with a previously available 
inventory of senses (or references, in this case) is virtually impossible. The number of entities that can be referred to by these symbols in large digital corpora such as the Web would make it very difficult to keep those inventories updated. Thus, the ideal solution would be a WSI technique such as the present proposal, because it would take nothing for granted apart from a given input word and a corpus where this word is instantiated.

This first run of experiments was conducted using English acronyms of an extension of three and four letters, randomly sampled from Wikipedia (e.g. ASG, NCO, PCR, etc.). For each acronym, the algorithm downloaded 100 documents from the Web and generated clusters as subgraphs. In total, 25 experiments like these were undertaken.

Table 2

Results of the experiment in the case of the acronym AASC

\begin{tabular}{lccccc}
\hline Clusters & Docs & Errors & $\begin{array}{c}\text { Omissions } \\
\text { Precision } \\
(\%)\end{array}$ & $\begin{array}{c}\text { Recall } \\
(\%)\end{array}$ \\
\hline $\begin{array}{l}\text { Asian American } \\
\text { Studies }\end{array}$ & 9 & 2 & 0 & 66 & 100 \\
$\begin{array}{l}\text { American } \\
\begin{array}{l}\text { Association of } \\
\text { State }\end{array}\end{array}$ & 4 & 1 & 0 & 75 & 100 \\
$\begin{array}{l}\text { Climatologists } \\
\text { Arizona }\end{array}$ & 3 & 0 & 0 & 100 & 100 \\
$\begin{array}{l}\text { Association of } \\
\text { Student Councils }\end{array}$ & & & & & \\
\end{tabular}

After a thorough examination of the results, it became apparent that each generated cluster represents a different entity referred to by the acronym. Table 2 is an example of the clusters generated for the acronym $A A S C$. There we can see that the algorithm correctly identified three distinct clusters: the Asian American Studies Center, the American Association of State Climatologists and the Arizona Association of 
Student Councils. There were also two other referents, however, that the algorithm could not discriminate. These are two groups of three documents each, referring to the Asian American Students Center and the Academic Assembly Steering Committee. The rest of the documents, up to 100 , is a long tail of single references to different uses of the expression, a very stable pattern in acronyms that is naturally not seen in general vocabulary units because, normally, general vocabulary units do not have so many senses.

Table 3

Examples of the overall results of the experiment with English acronyms

\begin{tabular}{ccc}
\hline Acronym & Detected Uses & Undetected Uses \\
\hline AASC & 3 & 2 \\
APCS & 5 & 1 \\
ASG & 2 & 0 \\
BVM & 4 & 0 \\
CKD & 2 & 0 \\
DDO & 3 & 0 \\
ETN & 1 & 1 \\
FYI & 2 & 0 \\
IED & 4 & 0 \\
JUB & 6 & 1 \\
KPS & 7 & 0 \\
KSP & 5 & 1 \\
LEP & 4 & 1 \\
$\ldots$ & $\cdots$ & 11 \\
Total & 93 & \\
\hline
\end{tabular}

Table 3 reports more details on the number of detected vs. nondetected senses for some of the 25 trials. There we can see that, in general, the number of detected senses in each case is far larger than those that went undetected. After 25 experiments, the algorithm was able to detect 93 senses ( $89 \%$ of the total). 


\section{Analysis of homonyms}

The second experiment is a case of disambiguation of homonyms in proper nouns. In this case, the analyzed unit refers to two different persons who share the same uncommon name. What makes this case interesting from a WSI perspective is that, by pure chance (since they are not related), both have approximately the same age and were born and raised in the same city. Because of their professions, both have raised a certain public profile, being present on the Web and the media (names were deleted to preserve anonymity).

This case makes any attempt of automatic disambiguation difficult because these two persons share an important number of vocabulary items in the texts that refer to them, due to their common origin and circumstances. The idea, as in the previous experiments, is to take a collection of documents referring to both persons (the first 100 documents served by Google with their name used as a query expression) and to separate this collection in coherent clusters of documents according to each person.

Despite the complexity of the problem, the results obtained using the same algorithm as in the previous experiment were very promising. Table 4 presents the distribution of contexts per cluster. Each context of occurrence is labeled as $A$ or $B$, depending on the subject, along with a context identification number. Ideally, we would have expected only two clusters (one per person) instead of six. However, the subdivision is meaningful, as it will be seen shortly, and the internal consistency of the clusters is very high. As table 4 shows, there is no single cluster that mixes documents referring to both persons. There is only one context in cluster 1 which is labeled as $\mathrm{N}$, that is, neither $A$ or $B$, and is just an irrelevant document -not related with any of the two persons- that was returned by the search engine.

The reason why there are more than two clusters is that each one is devoted to a particular aspect of the life of these individuals. For 
Table 4

Clusters of documents generated from a corpus of two homonym subjects (A and $B$ )

\begin{tabular}{lll}
\hline Cluster 1 & Cluster 2 & Cluster 3 \\
\hline Subject_A_34 & Subject_A_11 & Subject_B_13 \\
Subject_A_42 & Subject_A_19 & Subject_B_16 \\
Subject_A_46 & Subject_A_27 & Subject_B_21 \\
Subject_A_5 & Subject_A_32 & Subject_B_22 \\
Subject_A_71 & Subject_A_46 & Subject_B_23 \\
Subject_A_73 & Subject_A_55 & Subject_B_48 \\
Subject_N_53 & Subject_A_57 & Subject_B_58 \\
& Subject_A_69 & \\
& Subject_A_71 & \\
& Subject_A_72 & \\
\hline Cluster4 & Subject_A_75 & Cluster6 \\
\hline Subject_B_13 & Cluster5 & Subject_A_1 \\
Subject_B_14 & Subject_B_15 & Subject_A_24 \\
Subject_B_29 & Subject_B_64 & Subject_A_62 \\
Subject_B_39 & Subject_B_67 & Subject_A_65 \\
Subject_B_44 & Subject_B_70 & Subject_A_8 \\
Subject_B_52 & & \\
\hline
\end{tabular}

instance, one of the clusters is related to the professional life of one of the subjects, while others are related to his social life, with many of the nodes representing the names of friends or places where he usually goes. Similarly, in the case of the other man, it can be seen that the division in clusters reflect the different domains in which he has worked, with many of the nodes representing the names of places, colleagues and friends.

Another aspect that should be mentioned about these results is that, from 100 documents downloaded from the web, only a limited proportion (40) was assigned to a cluster. This, however, is not really a problem in this case because the task was to infer senses (referents in this case) and not to perform an exhaustive classification of the downloaded documents. This could be done indeed, assigning each remaining document to the most likely cluster based on shared 
vocabulary but, again, this attempt was not undertaken because it was not the purpose of the experiment (it would be, indeed, a kind of WSD operation).

\section{Conclusions}

This paper has presented a co-occurrence graph based approach for WSI which does not demand great conceptual or computational complexity and disregards external knowledge such as lemmatization, Part-ofSpeech tagging as well as dictionaries, ontologies or other semantic resources. In the practical level, the result is a fast and flexible algorithm that can be adapted to different languages and domains. Moreover, the paper can be of theoretical interest as well, as it may model or at least offer clues on how humans use contextual information to disambiguate words or to acquire word-senses, as a complement to other types of psycholinguistic evidence.

Despite the complexity of the problem, the results obtained in general in both experiments are very promising. The results presented here are not those of a ready-to-use tool, and much work is still needed to refine and further evaluate these results. However, there is no doubt that this algorithm, as it is in its present state, could already be an important improvement for the email alert services of most mainstream search engines, as well as for other multiple uses such as the improvement of Web searches in general and the automatic creation of glossaries, among other possibilities.

At the moment, it has only been tested on a few European languages, and much more experiments have to be undertaken before claiming the algorithm is language independent. The evidence already gathered, however, suggests that co-occurrence patterns are a property of language in general.

Co-occurrence graphs have proven to be useful tools for the linguistic analysis of polysemy, but the number of possible practical applications 
in lexicography and related domains are very diverse. One of them, which is a line of future work for this research, is to apply cooccurrence graphs to the study of semantic neology, i.e., to detect novel senses in known words, which can be seen as a special case of polysemy. Other directions of future work would be to conduct more experimental research comparing the performance of this method with language-specific approaches and, moreover, to try to seek ways to integrate different solutions to the problem (both statistical and knowledge-based).

\section{Notes}

${ }^{1}$ This paper is partially based on a chapter of the author's Ph.D. Thesis.

\section{References}

Agirre, E. \& Edmonds, P. (2007). Word Sense Disambiguation:

Algorithms and Applications. Dordrecht, Springer.

Agirre, E. \& Soroa, A. (2007). SemEval 2007: Evaluating Word Sense

Induction and Discrimination Systems. Proceedings of the 4th

International Workshop on Semantic Evaluations (pp. 7-12).

Prague.

Artiles, J. \& Borthwick, A., Gonzalo, J., Sekine, S., Amigó, E. (2010).

WePS-3 Evaluation Campaign: Overview of the Web People

Search Clustering and Attribute Extraction Task. Proceedings of

Conference on Multilingual and Multimodal Information Access Evaluation (CLEF).

Biemann, C. (2006). Chinese Whispers - an Efficient Graph Clustering

Algorithm and its Application to Natural Language Processing

Problems. Workshop on TextGraphs at HLT-NAACL (pp. 73-80).

Church, K. \& Hanks, P. (1990). Word association norms, mutual information and lexicography. Computational Linguistics 16(1), 22-29. 
Ferrer-i-Cancho, R. \& Solé, R. (2001). The Small World of Human

Language. Proceedings of the Royal Society of London 268, 2261-2265.

Firth, J. (1957). Papers in Linguistics 1934-1951. London: Oxford University Press.

Gale, W., Church, K. \& Yarowsky, D. (1992). A Method for

Disambiguating Word Senses in a Large Corpus. Technical report, AT\&T Bell Laboratories.

Grishman, R. (2012). Information Extraction: Capabilities and

Challenges. [Lecture Notes]. Retrieved from

http://cs.nyu.edu/grishman/tarragona.pdf

Hanks, P. (2006). The Organization of the Lexicon: Semantic Types and Lexical Sets. Proceedings of XII Euralex (pp. 1165-1168), Prague.

Ide, N. \& Véronis, J. (1998). Introduction to the special issue on word sense disambiguation: the state of the art. Computational Linguistics, 24(1), 1-40.

Ide, N. \& Wilks, Y. (2007). Making Sense About Sense. In Agirre \& Edmonds (eds.) Word Sense Disambiguation, Algorithms and Applications, (pp. 47-73). Springer.

Jezek, E. \& Hanks, P. (2010). What Lexical Sets Tell us about Conceptual Categories. Lexis 4, 7-22.

Kelly, E. \& Stone, P. (1975). Computer Recognition of English Word Senses. North-Holland, Amsterdam.

Kilgarriff, A. (1997). I don't Believe in Word Senses. Computers and the Humanities 31(2), 91-113.

Klapaftis, I., Manandhar, S. (2010). Taxonomy Learning Using Word Sense Induction. Proceedings of Human Language Technologies: The 2010 Annual Conference of the North American Chapter of the ACL, Los Angeles, USA, ACL.

Lesk, M. (1986). Automatic Sense Disambiguation: How to Tell a Pine

Cone from an Ice Cream Cone. Proceedings of the 1986 SIGDOC Conference.

Manandhar, S., Klapaftis, I., Dligach, D. \& Pradhan, S. (2010) SemEval-2010 Task 14: Word Sense Induction \& Disambiguation. Fifth International Workshop on Semantic Evaluation, (pp. 63- 68) Uppsala, Sweden. 
Manning, C., Raghavan, P. \& Schütze, H. (2008) Introduction to Information Retrieval. Cambridge University Press.

Navigli, R. (2009). Word Sense Disambiguation: a Survey. $A C M$ Computing Surveys, 41(2), 1-69. ACM Press.

Pierce, J., Carroll, J., Hamp, E., Hays, D., Hockett, C., Oettinger, A. \& Perlis, A. (1966). Language and machines computers in translation and linguistics: A Report. Automatic Language Processing Advisory Committee. Division of Behavioral Sciences. National Academy of Sciences. National Research Council. Washington, D. C.

Purandare, A. \& Pedersen, T. (2004). Word sense discrimination by clustering contexts in vector and similarity spaces. Conference on Computational Natural Language Learning (pp. 41-48). Boston, USA.

Quasthoff, U., Richter, M. \& Biemann, C. (2006). Corpus portal for search in monolingual corpora. Proceedings of the LREC 2006 (pp- 1799-1802) Genoa, Italy.

Sanderson, M. (1994). Word sense disambiguation and information retrieval. Proceedings of ACM SIGIR Conference (pp. 142-151).

Schütze, H. (1992). Dimensions of Meaning. Proceedings of Supercomputing (pp. 787-796).

Schütze, H. (1998). Automatic Word Sense Discrimination. Computational Linguistics, 24(1), 97-123.

Schütze, H. \& Pedersen, J. (1995). Information Retrieval Based on Word Senses. Proceedings of the 4th Annual Symposium on Document Analysis and Information Retrieval (pp. 161-175). Schütze, H. \& Pedersen, J. (1997). A Co-occurrence-based Thesaurus and Two Applications to Information Retrieval. Information Processing and Management, 33(3), 307- 318.

Véronis, J. (1998). A study of polysemy judgments and inter-annotator agreement. Senseval Workshop, Herstmonceux Castle, UK.

Véronis, J. (2004). HyperLex: Lexical Cartography for Information Retrieval. Computer Speech \& Language, 18(3), 223-252.

Voorhees, E. (1993). Using WordNet to Disambiguate Word Senses for Text Retrieval. Proceedings of the 16th ACM SIGIR conference on Research and Development in Information Retrieval (pp. 171180). 
Watts, D. \& Strogatz, S. (1998). Collective Dynamics of 'Small- World' Networks. Nature, 393, 440-442.

Weaver, W. (1949). Translation. Reprinted in Readings in Machine Translation, Nirenburg et al. (eds.), MIT Press, 2003.

Widdows, D. \& Dorow, B. (2002). A Graph Model for Unsupervised

Lexical Acquisition. Proceedings of the 19th International

Conference on Computational Linguistics (pp. 1093-1099). Taipei.

Yarowsky, D. (1992). Word-sense Disambiguation using Statistical

Models of Roget's Categories Trained on Large Corpora.

Proceedings of Coling-92 (pp. 454-460). Nantes.

Yarowsky, D. (1995). Unsupervised Word Sense Disambiguation

Rivaling Supervised Methods. Proceedings of the 33rd annual meeting on Association for Computational Linguistics (pp. 189196). Stroudsburg, PA, USA.

Rogelio Nazar Natural Language Processing Research Group Dept. of Information and Communication Technologies Universitat Pompeu Fabra, Barcelona, Spain.

Contact Address: Roc Boronat, 138. 08018 Barcelona. Spain. Email: rogelio.nazar@upf.edu. 
Instructions for authors, subscriptions and further details:

http://brac.hipatiapress.com

\section{Against Themselves? Women Artists in the Origins of Abstract Art}

Maria Lluïsa Faxedas ${ }^{1}$

1) University of Girona, Spain.

Date of publication: June 3rd, 2013

To cite this article: Faxedas, LI. (2013). Against Themselves? Women Artists in the Origins of Abstract Art Brac: Barcelona, Research, Art, Creation, 1(1), 27-61. doi: 10.4471/brac.2013.02.

To link this article: http://dx.doi.org/10.4471/brac.2013.02

\section{PLEASE SCROLL DOWN FOR ARTICLE}

The terms and conditions of use are related to the Open Journal System and to Creative Commons Non-Commercial and Non-Derivative License. 


\section{Against Themselves? Women Artists in the Origins of Abstract Art}

Lluïsa Faxedas

University of Girona

\section{Abstract}

This article is about women artists who created abstract art in the early decades of the twentieth century. Within the broad context of exclusion of women from the history of art, and particularly from modern art, its case has some specific features relating to the nature of the theory that underpinned the origins of abstraction, and the artistic practice that it supported. This theory was based on a dualistic thinking in which the feminine represented the 'other' to purify and remove, in association with the material, the sensual, the body and finally the decorative. The abstract artists met the contradiction of working in a language that was based on the rejection of the feminine, which culminated in great difficulties to do his work, often retreating to the field of applied arts. Feminist historiography of art, meanwhile, has not paid specific attention to these contributions.

Keywords: abstract art, women artists, Modernity, decoration. 


\title{
¿Contra sí Mismas? Mujeres Artistas en los Orígenes de la Abstracción
}

\author{
Lluïsa Faxedas \\ University of Girona
}

\section{Resumen}

Este artículo trata sobre las mujeres artistas que se dedicaron al arte abstracto durante las primeras décadas del siglo XX. Dentro del contexto general de exclusión de las mujeres de la historia del arte en general y del arte moderno en particular, su caso presenta algunas especificidades que se relacionan con la propia naturaleza de la teoría que sustentó los orígenes de la abstracción, y la práctica que se desprendió de la misma. Esta teoría se fundamentaba en un pensamiento dualista en el cual lo femenino representaba lo 'otro' a purificar y eliminar, en asociación con lo material, lo sensual, lo corporal y finalmente con lo decorativo. Las artistas abstractas se encontraron con la contradicción de trabajar en un lenguaje que se basaba en el rechazo a lo femenino, lo cual se concretó en grandes dificultades para realizar su obra, y en muchas ocasiones en su retirada al campo de las artes aplicadas, lo que contribuyó a que su aportación fuera minusvalorada. La historiografía feminista del arte, por su parte, tampoco ha prestado una atención específica a estas aportaciones.

Palabras claves: arte abstracto, mujeres artistas, feminismo, decoración, Modernidad. 
"La naturaleza es un hecho externo al hombre, es múltiple, difusa, generalmente inasible. Nosotros necesitamos sistemas conformes a nuestro estado, ante todo límites, medidas, orden" Ozenfant / Le Corbusier (1993, p. 16)

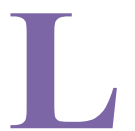

a historia del arte del siglo XX es en buena medida inseparable, al menos hasta los años setenta, de la historia de la modernidad; y el de la modernidad es, pese al género del sustantivo, un relato que se ha escrito desde, por y en lo masculino (Felski, 1995).Como han teorizado numerosos autores, los propios valores fundacionales de la modernidad son básicamente valores masculinos, hasta el punto que lo 'otro' respecto a lo cual la modernidad se autodefine y determina ha podido ser descrito, en gran medida y desde diversas perspectivas, como lo femenino ${ }^{1}$. Si a ello añadimos que la propia construcción de la figura del artista moderno se ha basado en el arquetipo del creador como héroe romántico, luchador solitario por la originalidad y la innovación frente a la tradición y la convención, no es de extrañar que el canon del arte moderno esté formado casi exclusivamente por artistas hombres (Wolff, 2000 y Pollock, 2010).

En las últimas décadas, las mujeres artistas de las primeras vanguardias han sido ya objeto de abundantes estudios monográficos o colectivos que han demostrado muy claramente sus importantes y numerosas aportaciones ${ }^{2}$; pero pese a ello, su papel como sujetos activos en la historia de la Modernidad ha continuado siendo prácticamente irrelevante, $\mathrm{y}$ esto se debe precisamente a este carácter fundamentalmente masculino de la misma que hemos apuntado, más que a los habitualmente citados mecanismos de exclusión y marginalización de la mujer de la práctica artística. Cómo escribió Carol Duncan en un análisis detallado de la museografía del MOMA, "since the heroes of this ordeal are generically men, the presence of women artists, in this mythology, can only be an anomaly"3 (Duncan, 1989, p. 172). Sin embargo, también es particularmente evidente que incluso esta misma "anomalía" se articula mediante diferencias significativas; y es que resulta obvio que algunas artistas y tendencias han sido más y mejor estudiadas que otras: la implicación de las mujeres en el Surrealismo, por ejemplo, ha sido mucho más investigada que, como veremos enseguida, su participación en el surgimiento de la abstracción. Esta situación ha sido agudamente señalada por Estrella de Diego en estos términos: " $¿[\mathrm{O}]$ será, acaso, que a una mujer se le permite ser bailarina, 
"surrealista", inconsciente, pero no ser matemática, precisa, incorruptible?" (De Diego, 2009, p. 18); esta dualidad que vincula el Surrealismo con la sensualidad y la irracionalidad, por una parte, y la abstracción con el intelectualismo geométrico, por otra, apunta al corazón de la cuestión que abordaremos inmediatamente. De Diego parece señalar el hecho de que el concepto del Surrealismo pudo actuar como una especie de escudo protector para aquellas artistas que investigaban en el campo de una figuración cuanto menos dudosa, y que en cualquier caso para las mujeres artistas la etiqueta de surrealista parecía menos peligrosa que la de abstracta (De Diego, 2008, p. 29). Sea como sea, y más allá de lo que hemos expuesto sobre la vinculación entre masculinidad y modernidad, es necesario preguntarse el porqué de esta distinta consideración, ya que es evidente que existen cuestiones específicas que se relacionan con el propio papel que el concepto de lo femenino jugó en el contexto teórico y artístico concreto del nacimiento de la abstracción. En este artículo examinaremos algunas de estas cuestiones, centrándonos básicamente en las décadas de los años diez, veinte y treinta, la etapa a la que podríamos cualificar de más propiamente moderna de la historia de la abstracción ${ }^{4}$.

\section{Las mujeres artistas en los orígenes de la abstracción}

En este sentido, el primer paso debe ser constatar que existió un gran número de mujeres que se dedicó al arte abstracto durante el período señalado: algunas de ellas han sido muy estudiadas individualmente, otras han sido valoradas más bien en el contexto de los grupos con los que se vincularon, y otras son aún muy poco conocidas. En cualquier caso, hasta ahora no se ha abordado la cuestión de la relación entre arte abstracto y género de una forma global ${ }^{5}$; empezamos pues reseñando (sin ánimo exhaustivo) los nombres de algunas de ellas, centrándome en las mujeres que nacieron durante las dos últimas décadas del s. XIX, y que por lo tanto llegaron a su madurez creativa en las décadas señaladas. Así podemos citar los nombres de Sonia Delaunay-Terk (1885-1979), Marthe Donas (1885-1967), Sophie Taeuber-Arp (1889-1943), Florence Henri (1893-1982), Marcelle Cahn (1895-1981), Jeanne Coppel (18961976), Franciska Clausen (1899-1986) o Nelly van Doesburg (1899- 
1975) entre las que estuvieron relacionadas con distintos grupos y círculos artísticos abstractos europeos, y de Marlow Moss (1889-1958) o Charmion von Wiegand (1896-1983) entre las que se dedicaron a la abstracción geométrica procedentes del contexto anglosajón; en el ámbito de la Bauhaus encontramos también un nutrido grupo de mujeres, entre ellas Gunta Stölzl (1891-1983), Marianne Brandt (18931983) o Anni Albers (1899-1994). No podemos olvidar a las mujeres de las vanguardias rusas: artistas como Natalia Goncharova (1881-1962), Alexandra Exter (1882-1949), Olga Rozanova (1886-1918), Nadeshda Udaltsova (1886-1962), Liubov Popova (1889-1924), Vera Ermolaeva (1893-1938), Varvara Stepanova (1894-1958) y Anna Leporskaya (1900-1982), a las que podríamos añadir a Katarzina Kobro (18981951), de origen ruso aunque trabajó sobre todo en Polonia, y la también polaca Maria Nicz-Borowiak (1896-1944).

Todas ellas fueron coetáneas de los primeros artistas abstractos, y por lo tanto estuvieron e incluso convivieron con ellos en muchos de los lugares en los que se desarrolló la abstracción: unos y otras se encontraron en la Bauhaus, en diversos grupos y organizaciones de la Rusia pre- y posrevolucionaria, en la Académie Moderne de Léger y Ozenfant o en algunos de los colectivos de artistas abstractos que surgieron en el París de los años 30, como Abstraction-Création o Cercle et carré. Su participación en el grupo más o menos estable reunido entorno a De Stijl y en la abstracción geométrica de la primera época, en cambio, fue mínima ${ }^{6}$, aunque aumentó a partir de los años 30; quizá el lugar más refractario a su presencia fuera significativamente el grupo organizado alrededor de Kandinsky y Marc: el almanaque Der Blaue Reiter sólo incluyó la obra, figurativa, de dos mujeres: Gabrielle Münter, compañera de Kandinsky, y Natalia Goncharova ${ }^{7}$.

Es necesario también constatar claramente que, pese a que todas ellas trabajaron más o menos durante el mismo período artístico, existen enormes diferencias entre sus respectivas trayectorias, las obras que realizaron y el reconocimiento que obtuvieron por las mismas; por ello no podemos caer en la simplificación de valorarlas globalmente con una mirada única, como no lo haríamos con sus compañeros masculinos. Sin embargo es cierto que la obra de estos, también muy diversa, ha acabado integrándose en una narrativa coherente de la historia de la abstracción 


\section{Maria Llü̈sa Faxedas - ¿Contra si Mismas?}

en la que cada uno ha ido encontrando su lugar (que a su vez se ha convertido en una parte fundamental del relato del arte moderno ${ }^{8}$ ), mientras que la de ellas en ningún caso ha pasado a formar parte con normalidad y naturalidad de esta historia ${ }^{9}$. Ciertamente, el reto para una historia del arte feminista en este momento ya no puede ser el de simplemente intentar incorporar sus nombres a una genealogía que se ha revelado tan claramente excluyente, ni el de reclamar mayor valoración de su trabajo en función de nuevos parámetros. Pero también lo es que para avanzar en una adecuada comprensión y contextualización de su obra se hace imprescindible identificar qué estrategias han hecho posible este aislamiento de su aportación.

Así, hay que recordar que una de las características esenciales de la lectura moderna de la historia del arte abstracto es la definición de los artistas protagonistas de la misma (Kandinsky, Mondrian, Robert Delaunay, Kupka, Klee, Van Doesburg o Malevich, entre muchos otros) como los "pioneros"10 de un nuevo camino de investigación para el arte, lo que se corresponde plenamente con la mitificación romántica de la figura del artista moderno que ya hemos citado. En comparación al empuje de estos pioneros, las figuras de sus colegas o compañeras femeninas permanecen notablemente veladas; y así no debe extrañarnos que cuando encontramos menciones a las obras de ellas sea a menudo en términos poco apreciativos: en el caso de Sonia Delaunay, por ejemplo, no son excepcionales comentarios como "[a] close collaborator of her husband... under his influence" (Dabrowski, 1985, p. 249), o "par ailleurs la femme de Robert Delaunay, Sonia Terk, se consacra pendant longtemps aux arts appliqués" (Nigro Covre, 2002, p. 52) ${ }^{11}$, en las que lo más relevante resulta ser su condición de "esposa de". Es verdad que en algunas ocasiones también ellas han recibido apelativos que ponen el acento en el aspecto más atrevido y arriesgado de su trabajo; es el caso del concepto de la "amazona", que Benedikt Livchits aplicó a las artistas de la vanguardia rusa (Livchits, 1971) ${ }^{12}$ y que también se utilizó en el París de los años 20 en el entorno de la escritora Natalie Barney, creadora del "Salón de la amazona". Pero en muchos casos, sobre todo en el de las artistas rusas, el impacto de sus aportaciones individuales se diluye en la fuerza del grupo: aunque sus nombres aparecen en cualquier estudio que considere la creación artística en la Rusia de los años diez y 
veinte, casi siempre es en virtud de su relación con los distintos colectivos de artistas del momento. Sucede algo parecido con las mujeres de la Bauhaus ${ }^{13}$, siempre agrupadas bajo la poderosa marca de la escuela y pocas veces consideradas en su individualidad. Finalmente, también hay que indicar que en algunos casos (como el de las artistas más vinculadas a la abstracción geométrica), sencillamente han sido ignoradas y muy poco estudiadas ${ }^{14}$.

En cualquier caso, estas consideraciones podrían también aplicarse a artistas pertenecientes a movimientos distintos del de la abstracción, y por lo tanto debemos seguir preguntándonos por las razones específicas del poco reconocimiento del trabajo de las artistas abstractas. Para ello será necesario dirigirnos directamente hacia los orígenes y el significado de la propia idea de abstracción y a su desarrollo teórico y práctico, y preguntarnos por cómo encaja ahí la cuestión del género. En la extensión de este artículo es imposible desarrollar el tema en toda su magnitud, y por lo tanto en lo sucesivo nos centraremos en algunos aspectos concretos que no son relevantes para todas las artistas citadas en la misma medida (en particular, dejamos de lado el caso de las artistas eslavas, que tiene sus propias singularidades), pero que pueden ayudarnos a entender los procesos ejercidos sobre algunas de ellas.

\section{El lugar de lo femenino en la teoría de la abstracción}

Una de las características comunes entre los artistas que hemos citado anteriormente y generalmente conocidos como los "pioneros" de la abstracción es el hecho de que todos, aún con diferencias importantes entre ellos, concedieron a su trabajo lo que podríamos cualificar de un cierto valor trascendental, tal y como plasmaron en numerosos textos y reflexiones. Podemos afirmar que, en general, para estos artistas la pintura abstracta ofrecía la posibilidad de constituirse en un medio a través del cual transformar y hacer evolucionar el mundo y la humanidad: renunciando a la representación figurativa de la realidad, el arte (particularmente la pintura) adquiría la capacidad de convertirse en un lenguaje universal que hiciera posible tanto la comunicación directa entre el artista y el espectador, como el constituirse en un modelo para la evolución humana hacia sociedades menos materialistas y más 
espirituales. En distintos grados y niveles de aceptación y desarrollo, subyace en todos ellos una concepción profundamente idealista del mundo según la cual éste se fundamentaría en una serie de principios universales duales que a menudo se oponen o contraponen entre ellos, habiéndose generado con el tiempo ciertos desequilibrios que, a su modo de ver, debían ser corregidos. De estas dualidades, la que nace de la contraposición entre los elementos masculino y femenino es fundamental, en correspondencia casi equivalente a la que confronta lo espiritual y lo natural, o lo mental y lo corpóreo ${ }^{15}$. Como los simbolistas, de los que su teoría y práctica artísticas es heredera $\left(\right.$ Faxedas, 2007) ${ }^{16}$, los abstractos privilegiaron claramente la dimensión espiritual e intelectual (que corresponde al elemento masculino) de la existencia, menospreciando la dimensión natural, corporal y material (equivalente a la dimensión femenina) de la misma. Ésta obviamente debía existir, pero tenía que ser corregida y reducida, pues a su juicio tanto el individuo como las sociedades contemporáneas se encontraban excesivamente escorados hacia lo materialista. La dualidad masculino femenino articula pues una oposición en el que el polo de la mujer es siempre el inferior, y debe ser purificado para evolucionar hacia un estado que podríamos describir como de mayor espiritualidad; como ejemplo de este discurso cito unas palabras de Mondrian, aunque son muchos otros textos los que podríamos traer a colación (Faxedas, 2010):

Ancient wisdom identified the physical, the natural, with the female, and the spiritual with the male element. To achieve pure naturalness, the natural must be interiorized, that is, stripped as far as possible of the most capricious outwardness that obscures perfect naturalness; in other words, it must perfect itself [...]. For this, it is only necessary that the new mentality develops freely: that it anhilites the old mentality and domination by the individual, natural (or female) element; that it frees itself of tradition and dogma (...)" ("The New Plastic in Painting", 1917; en Holtzman y James, 1993, pp. 56-57; cursivas en el original) ${ }^{17}$ 
Es necesario considerar que esta concepción teórica y especulativa encontraba su equivalencia en las discusiones sobre los aspectos más estrictamente formales de la práctica artística. Así, al menos desde el siglo XVII los debates sobre los méritos relativos del dibujo y el color se mantuvieron en buena medida en términos de género, de forma que en el siglo XIX el dibujo y el diseño, con sus connotaciones de linealidad y racionalidad, ya se habían establecido como masculinos, mientras que el color, con sus connotaciones de contingencia, fluidez y superficialidad, se consideraba firmemente anclado en lo femenino (Garb, 2007); el teórico francés Charles Blanc lo expresó con claridad en su muy leído libro Grammaire historique des arts du dessin (1876), en el que escribió lo siguiente:

Le dessin est le sexe masculin de l'art; la couleur en est le sexe féminin. [...] L'union du dessin et de la couleur est nécessaire pour engendrer la peinture, comme l'union de l'homme et de la femme pour engendrer l'humanité; mais il faut que le dessin conserve sa prépondérance sur la couleur. S'il en est autrement, la peinture court à sa ruine; elle sera perdue par la couleur comme l'humanité fut perdue par Ėve." (Blanc, 2000, p. 53). ${ }^{18}$

La cuestión decisiva es que estos ejemplos demuestran claramente que la arquitectura conceptual y plástica de la abstracción se construyó sobre unos cimientos en los que el concepto de lo femenino no era ni excluido, ni se situaba en un lugar marginal o residual: bien al contrario, en este discurso lo femenino (junto con los demás conceptos del esquema dual que le son equivalentes) se sitúa en un lugar central e imprescindible en tanto que alteridad en contraposición a la cual se va definiendo, en positivo, la novedad y el nuevo mensaje de la abstracción. Es cierto que como hemos comentado al inicio de este texto esta visión de lo femenino como alteridad puede extenderse a toda la modernidad en su conjunto; pero en ninguno de los movimientos, grupos o tendencias que la constituyen se hace tan evidente esta caracterización, ni juega un rol tan fundamental, como en los discursos teóricos vinculados a la abstracción. Este planteamiento tampoco fue 
exclusivo, como hemos indicado, de uno u otro artista en concreto, sino que en mayor o menor grado fue compartido por todos los agentes que trabajaron alrededor de la abstracción desde sus inicios hasta, como mínimo, la II ${ }^{\mathrm{a}}$ Guerra Mundial. Así, por una parte hubiera podido parecer que el ideal utópico y universal de una abstracción pura podía facilitar el acceso de las mujeres a la práctica artística, evitando la confrontación con la representación figurativa que puede ser más fácilmente connotada como de género (Schor, 2006, p. 10); pero en realidad la misma teoría caracterizaba este supuesto universalismo como masculino: aspirar a la universalidad implicaba reducir lo 'femenino', en todas sus dimensiones, a la mínima expresión.

La radicalidad de esta propuesta teórica hace que debamos formularnos de nuevo la pregunta inicial, ya que la cuestión ya no es tan sólo sobre como y porqué las artistas abstractas no han sido apenas incluidas en la historia de la abstracción, sino más bien sobre la misma posibilidad de su participación en la misma. Así pues, podríamos plantearlo así: ¿cómo y de qué maneras trabajaron estas artistas con un lenguaje como el de la abstracción que, en su formulación teórica, más que excluirlas denigraba la propia condición de su feminidad? En otras palabras, ¿era posible para una mujer desarrollar una obra en el ámbito del arte abstracto, teniendo en cuenta que, como hemos señalado, en la conceptualización del mismo ella representaba lo otro a purificar y superar? ¿Cómo afectó este hecho a la escasa repercusión y valoración de su trabajo por parte de sus colegas masculinos, la crítica artística y la historiografía posterior?

Ciertamente, responder completamente a estas preguntas necesitaría de un estudio individualizado de cada una de las artistas y de cómo su trabajo se adaptó en cada caso al campo de juego delimitado por las primeras definiciones de la abstracción. Sin embargo, a riesgo de generalizar, puede afirmarse que tanto la trayectoria como la recepción crítica de gran parte de las artistas citadas demuestran claramente las enormes dificultades y resistencias que encontraron para desarrollar su trabajo artístico; y el hecho de que estas dificultades fueran sobre todo de tipo conceptual es un elemento específico que distingue su posición de la de sus coetáneas modernas: las artistas abstractas partían, en virtud de su género y su opción artística, de una clara desventaja. Ellas no participaron al mismo nivel que los hombres de algunos de los 
principales foros y espacios de debate teóricos sobre la abstracción, especialmente en su primera etapa (como hemos dicho sus aportaciones están prácticamente ausentes tanto de Der Blaue Reiter como de De Stijl, y tampoco formaron parte del claustro de profesores de la Bauhaus); tampoco publicaron ningún texto teórico relevante e influyente, como sí hicieron sus colegas masculinos, y esto se debe en buena medida al hecho de que el mismo lenguaje en el que trabajaban les impedía tomar la palabra. Así mismo, y sobre todo en las décadas de los años diez y veinte, para muchas de ellas fue complicado incluso el acceso en igualdad de condiciones a las prácticas artísticas privilegiadas por sus compañeros masculinos, especialmente a la pintura. El hecho de que éste fuera el formato preferente para las investigaciones más radicales del nuevo lenguaje abstracto, como veremos, convirtió a la pintura en una especie de campo de batalla en el que se libraba la guerra por la purificación del arte; y este combate desplazó a muchas de las artistas hacia los márgenes de la actividad artística, más concretamente al ámbito de lo que llamamos artes decorativas. Así, en un círculo totalmente vicioso, el hecho de haber desarrollado la mayoría o una parte muy significativa de su trabajo en estos medios serviría como excusa para situar críticamente su trabajo en escalones inferiores al de sus compañeros masculinos, los maestros pintores abstractos. En este sentido, la relación entre el doble binomio hombre/mujer y arte/artesanía en relación a las prácticas de la abstracción emerge como una de las claves para entender la configuración del propio discurso de la misma.

\section{Ornamento y abstracción}

El papel de las distintas teorías y visiones sobre el ornamento como fuente teórica para la justificación y desarrollo de la abstracción ha sido bien estudiado (Morgan, 1992). Sin embargo, no hay ninguna duda de que los primeros artistas abstractos vieron al ornamento como un espectro atemorizador ${ }^{19}$ : la posibilidad de caer en la decoración superficial era una amenaza real para los artistas que investigaban sobre una pintura basada en formas y colores sin referencia figurativa aparente, ya que pese a los presupuestos intelectuales anteriormente 
citados, su obra corría el grave riesgo de ser malentendida y considerada como un simple ejercicio decorativo. Esto no significa que no puedan identificarse relaciones, especialmente a nivel formal, entre el elemento ornamental y el arte abstracto; pero como ha sido señalado, el primero funcionó sobre todo como un "polizón" en un proyecto, el de la abstracción, que para muchos de sus practicantes tenía una dimensión que iba más allá de lo estrictamente plástico (Brüderlin, 2001).

En este sentido resulta de crucial importancia distinguir rigurosamente entre el temor a lo decorativo, y el hecho más que contrastado de que muchos de los artistas vinculados a la abstracción se interesaran profundamente por la relación de las artes entre sí y por los vínculos entre el arte y la vida. Todos ellos desarrollaron distintos proyectos en este ámbito: las composiciones escénicas de Kandinsky, la integración y posterior disolución de arte y arquitectura que plantea el Neoplasticismo, o los numerosos proyectos vinculados al diseño y a las artes aplicadas propuestos en toda Europa, por ejemplo. En todos estos casos se trata de alcanzar, mediante el cruce o fusión a varios niveles de diversas disciplinas y prácticas artísticas, una obra que adquiere unos valores superiores (de índole plástica o incluso espiritual) precisamente en virtud de este carácter interdisciplinar. $Y$ ello se opone profundamente a su comprensión del concepto de decoración, que no implica más que un acercamiento superficial entre el arte y el objeto. Así, Mondrian quiso dejar claro que es en la pintura de caballete, y no en la decorativa, dónde se da la posibilidad de vincularse con las problemáticas esenciales de la vida contemporánea: "The growing profundity of the whole of modern life can be purely reflected in painting. In painting - in pictorial, not decorative painting - naturalistic expression as well as naturalistic plastic means become more inward, are essentialized into the abstract" ("The New Plastic in Painting", 1917; Holtzman y James, 1993, p. 29; cursivas en el original) ${ }^{20}$. En esta misma línea, Kandinsky escribió lo siguiente sobre el ornamento y la decoración en De lo espiritual en el arte:

Si destruyéramos hoy los lazos que nos unen a la naturaleza y nos dirigiéramos por la fuerza hacia la libertad, contentándonos exclusivamente con la combinación de color puro y forma 
independiente, crearíamos obras que parecerían una ornamentación geométrica, o, dicho de otra manera, parecerían una corbata o una alfombra. La belleza del color y de la forma no es (...) un objetivo suficiente para el arte. [...]. Desde luego, el ornamento no es una entidad sin vida. Por el contrario, posee vida interior, pero que no comprendemos (ornamentación antigua) o que constituye un tumulto alógico, un mundo donde los adultos y los embriones reciben el mismo trato y juegan socialmente iguales papeles, donde seres con miembros arrancados se sitúan sobre un mismo plano con narices, dedos y ombligos independientes. Esta es la confusión del calidoscopio determinada por la casualidad material y no por el espíritu". (Kandinsky, 1995, p. 100)

La vinculación de lo ornamental y lo decorativo con conceptos como lo material, lo confuso o lo irracional, y su contraposición al espíritu, marca claramente la distancia extrema que lo aleja de la pureza asociada al auténtico arte abstracto; una pureza que es, a su vez, condición necesaria para la interrelación de las artes a la que nos hemos referido (Faxedas, 2007). No cabe duda que el de la pureza es uno de los conceptos clave en el vocabulario de la abstracción, tal y como aparece reiteradamente en los textos de sus representantes más destacados. En este sentido, para comprender mejor el abismo que separa lo abstracto de lo decorativo en virtud de esta distinción entre lo puro y lo confuso que propone el mismo Kandinsky, resulta ilustrativo remitirnos al trabajo de la antropóloga Mary Douglas, que en su fundamental obra Pureza y peligro. Un análisis de los conceptos de contaminación y tabú mostró el sentido y uso compartido de las ideas de pureza, contaminación y purificación en distintas culturas y religiones de todo el mundo. En su interpretación, "las ideas acerca de la separación, la purificación, la demarcación y el castigo de las transgresiones tienen por principal función la de imponer un sistema a la experiencia, que de por sí es poco ordenada. Sólo exagerando la diferencia entre adentro y afuera, encima y debajo, macho y hembra, a favor y en contra se crea la apariencia de un orden." (Douglas, 1973, p. 17) Así, la purificación debería comprenderse como esta misma operación de imponer un orden sobre el caos del mundo, encarnado en la materia, la suciedad, la confusión y la transgresión de la norma, ya que "la reflexión sobre la 
suciedad implica la reflexión sobre el nexo que existe entre el orden y el desorden, el ser y el no-ser, la forma y lo informe, la vida y la muerte" (Ibíd., p. 19). Así mismo, la pureza también se relaciona con la divinidad y especialmente con la santidad, cualidad que en muchas culturas coincide con la idea de la integridad, el ser uno; por ello la impureza se vincula con la fragmentación, y la pureza con la reconstrucción.

Esta comparación y asimilación entre los conjuntos de conceptos pureza / unidad / arte abstracto versus suciedad / fragmentación / arte decorativo fue detectada ya por las primeras artistas y teóricas feministas que, a finales de los sesenta, iniciaron una investigación más profunda alrededor de todo lo relacionado con la situación y el papel de las mujeres en la historia del arte. Así, en su artículo "Art Hysterical Notions of Progress and Culture" las artistas Valerie Jaudon y Joyce Kozloff (1978) ya demostraron ampliamente como el lenguaje de la modernidad en general y el de la abstracción en particular se habían construido sobre esta distinción radical entre el arte y la decoración con el único objetivo de sublimar el primero y denigrar la segunda. Esta distinción nacía de una perspectiva que quería presentarse como estrictamente artística o estética, pero en realidad tenía raíces profundamente ideológicas $\mathrm{y}$, sin duda, connotaciones de género, puesto que históricamente estaba claro que el de las artes aplicadas había sido un espacio femenino por excelencia. De entre los numerosos ejemplos que evidencian la persistencia de este tópico entre los autores que reflexionaron y escribieron sobre la cuestión, destacamos a Adolf Loos, que en su artículo "Ornamento y delito" (1908), en el que lo decorativo se equiparaba a lo degenerado e incluso a lo criminal, escribió lo siguiente:

\footnotetext{
"Soporto los ornamentos del cafre, del persa, de la campesina eslovaca, los de mi zapatero, ya que todos ellos no tienen otro medio para alcanzar el punto culminante de su existencia. Pero nosotros tenemos al arte, que ha sustituido al ornamento. Después del trabajo del día, vamos al encuentro de Beethoven o de Tristán" (Loos, 1908).
} 
Es consecuente con todo lo expuesto, pues, que en el esquema conceptual dual de la primera abstracción lo decorativo, vinculado a lo material y sensual como opuesto a lo espiritual y racional, quedara agrupado en el mismo ámbito que lo exótico, lo primitivo y lo femenino; como advierte Buci-Glucksmann en su Philosophie de l'Ornement, lo decorativo ha sido por mucho tiempo excluido de la modernidad debido a "ses affinités avec un féminin voué aux tissus, textures, tapis et autres travaux manuels"21 (Buci-Glucksmann, 2008, p. 14). De aquí que la vinculación de un buen número de artistas abstractas con las artes aplicadas, y la lectura de su trabajo en las mismas como decorativo, no sea una cuestión más o menos circunstancial relacionada con la trayectoria de cada una de ellas en particular; al contrario, deriva directamente de este planteamiento teórico tan restrictivo que las empujaba claramente hacia este espacio, condicionando notablemente su recepción y evaluación. Vamos a explorar ahora algunas de estas afinidades a través de tres casos concretos de artistas cuyo trabajo se movió precisamente en este espacio situado entre lo artístico y lo decorativo.

\section{Sonia Delaunay y el diseño de moda}

Un buen ejemplo de todo ello nos lo ofrece el caso de Sonia Delaunay, cuya vida y trayectoria artísticas son de las más reveladoras entre las artistas del s. XX por las tremendas presiones y contradicciones provocadas por las distintas facetas de su personalidad como mujer, esposa, madre y artista. En sus pocas declaraciones sobre su trabajo, realizadas sobre todo después de la temprana muerte de su marido Robert (acaecida en 1941), se observa siempre una actitud ambigua y ambivalente hacia el mismo: oscila entre un deseo de reconocimiento hacia su obra personal y la voluntad de poner en primer plano la de Robert, a la difusión de la cual se dedicó con gran entusiasmo, aún a costa de la suya propia. Así, por ejemplo, en algunas entrevistas recalcó como para Robert la valoración pública de su obra era fundamental, pero no para ella: "I didn't take it so seriously - though it was quite serious [...]. It was my life and I worked the whole time, but I wasn't working - I was living - and that is the difference [con el trabajo de 


\title{
42 Maria Llü̈sa Faxedas - ¿Contra si Mismas?
}

Robert]" (Nemser, 1975, p. 31)22. Así mismo, niega ningún sustrato teórico para su obra, mientras que Robert si lo elaboró: "First I didn't feel it was necessary to speak of my art. I made it very much for myself [...] When I make these things up I need to make them. I don't think of it" (Ibid., pp. 32-37) ${ }^{23}$. En su autobiografía escribió lo siguiente:

\begin{abstract}
"Robert avait tiré ses fusées dans tous les sens; moi, sur terre, j'avais recueilli les retombées du feu d'artifice, j'avais allumés des feux plus intimes, plus éphémères dans la vie de tous les jours, tout en pursuivant l'œuvre profonde, silencieusement" (Delaunay, 1978, p. $45)^{24}$.
\end{abstract}

En efecto, Sonia ya contaba con una formación y una carrera propias como pintora cuando conoció a Robert en 1909, y sus respectivas propuestas artísticas a partir de ese momento se entrelazaron de una forma muy sugestiva e interesante; es evidente por ejemplo lo que Sonia le aportó en lo que se refiere a la sensibilidad respecto al color, que se convertiría en uno de los elementos distintivos del trabajo de Robert. Pero lo cierto es que él desarrolló una trayectoria consistente en el campo de la pintura, mientras que Sonia, sin dejar nunca del todo la pintura ni sus experimentaciones personales, dedicó gran parte de sus energías a lo que podríamos llamar artes aplicadas o decorativas (Godefroy, 2003/04). Desde la famosa colcha de patchwork para su bebé Charles, las cajas de madera pintadas o las encuadernaciones de libros, hasta los diseños de moda y tejidos la creatividad y el arte de Sonia se movieron, sobre todo de cara al público, en el espacio de lo decorativo, cuya valoración estética y artística en comparación a la pintura de su marido era sin ninguna duda mucho menor. Que todas estas actividades eran cosa de mujeres lo tenía claro incluso la propia Sonia, que en una carta dirigida al galerista Josep Dalmau para comentar una exposición que tenían prevista escribió que en ella quería presentar "des objets d'art avec un décor adéquat, par exemple une table de salle à manger mise avec un arrangement tout à fait nouveau et inattendu d'autres compositions d'objets d'intérieur qu'on peut intituler l'art de la femme et qui intéresse beaucoup le public" (carta de Sonia Delaunay a Josep Dalmau, 3 de marzo de 1916; Godefroy, 2003/2004, 
p. 56 , nota 30$)^{25}$.

En el contexto que hemos ido dibujando, resulta especialmente significativo el trabajo de Sonia en el diseño de moda femenina y tejidos, al que se dedicó a partir de 1917 (por la necesidad de mantener económicamente a la familia y liberar a Robert de este deber, permitiéndole dedicar todo su tiempo y talento a la pintura) a través de distintas marcas comerciales y con un gran éxito, en general, de crítica y de ventas (Figura 1). Los años veinte fueron un momento clave del

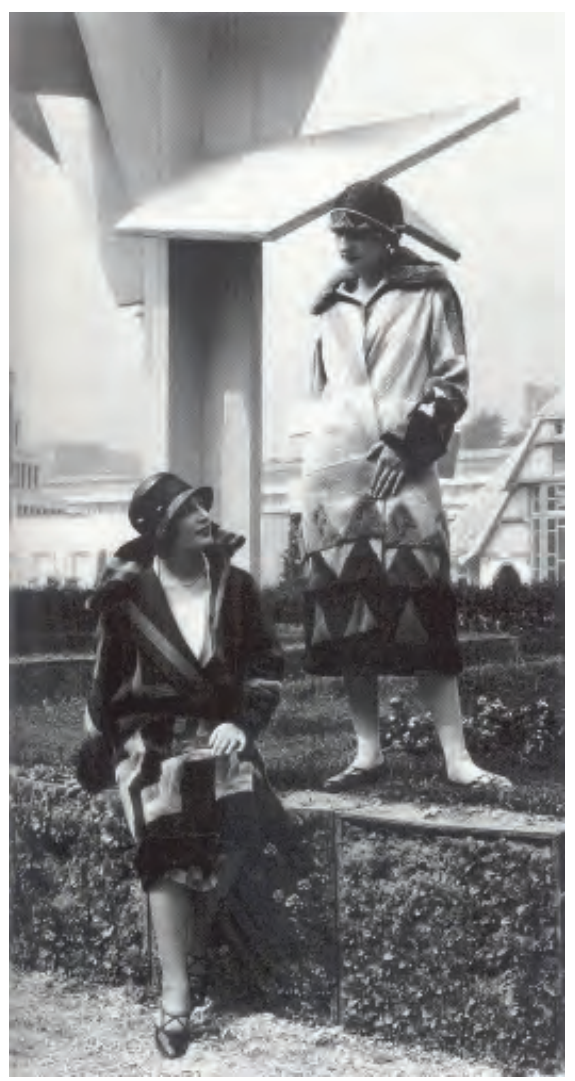

Figura 1. Modelos vistiendo conjuntos de Sonia Delaunay en la exposición de París de 1925. Impresión de gelatina de plata, 1925. L\&M services B.V. Amsterdam 20020402. 
encuentro entre el diseño de moda de alta costura y su comercialización en tiendas y grandes almacenes, lo que supuso el salto a la fama de diseñadores como Paul Poiret y el acceso de muchas mujeres a la posibilidad de vestir modelos de calidad a un precio mucho más asequible. Las propuestas de Sonia (abrigos, vestidos, sombreros,...), basadas en un corte más o menos convencional y en estampados geométricos, abstractos y muy coloristas, supusieron una aportación muy singular a la nueva moda del momento. Este auge de la moda femenina contrasta notablemente con lo que algunos autores han llamado la generalización de la Gran Renuncia Masculina, o el abandono progresivo por parte de los hombres del elemento ornamental en su indumentaria que se había ido produciendo desde principios del siglo $\mathrm{XIX}^{26}$. Autores como Loos, por ejemplo, aplaudieron este proceso (adoptando ellos mismos un estilo de vestuario casi militar) y se aplicaron, como hemos visto, a eliminar el ornamento de cualquier ámbito de la vida cotidiana, incluidas las artes. Artistas y arquitectos como Tatlin, Oud o Gropius también trabajaron sobre esta idea de la uniformidad simple y funcional de la ropa moderna masculina (Wollen, 1987). Este contraste entre la moda de diseño femenina y el vestido estándar e industrial masculino ejemplifica otra faceta de las dualidades fundadoras del Modernismo, estrechamente vinculada con las que hemos ido indicando: la que enfrenta la máquina y el cuerpo, o una estética funcionalista y racionalista frente a otra más figurativa, en el sentido más estricto de la palabra. El trabajo de Sonia en el diseño de moda demostró que era capaz de aplicar sus conocimientos pictóricos y el resultado de sus experimentaciones vanguardistas a nuevos medios y espacios; así hizo realidad, quizá más que ningún otro artista de su generación, el tan anhelado deseo de vincular estrechamente el arte y la vida. Pero al mismo tiempo, su dedicación a este trabajo sirvió también para anclar su obra del lado de lo decorativo, que el Modernismo rechazaba abiertamente.

\section{Sophie Taeuber-Arp y la abstracción aplicada}

Otro caso muy interesante en este contexto lo ofrece la trayectoria de Sophie Taeuber-Arp (1889-1943); Sophie estudió en diversas escuelas y talleres de artes aplicadas y decorativas, y una vez obtuvo su diploma 
fue nombrada profesora en la Escuela de Artes Aplicadas de Zurich, donde dirigió la sección textil hasta que dejó la docencia, en 1929, para dedicarse más libremente a su trabajo artístico. Su obra abarca un gran número de medios: dibujo, bordado, tapiz, gouache, pintura, escultura, danza, escenografía, decoración de interiores y arquitectura. Aunque en su producción plástica no renunció completamente a la figuración (en 1934 abandonó el grupo Abstraction-Création, en la fundación del cual había participado activamente, por su rechazo dogmático de la misma), su trabajo se desarrolla fundamentalmente y desde sus primeras obras en el contexto de la abstracción. Casada con Jean Arp desde 1922, aunque se conocieron y trabajaron juntos desde 1915, Sophie Taeuber se relacionó con todas las personas relevantes en el mundo del arte abstracto de las décadas de los veinte y los treinta; y tomó parte también en algunos proyectos emblemáticos, desde grupos y revistas (además del ya citado Abstraction-Création también formó parte de Cercle et Carré y codirigió la revista Plastique/Plastic), hasta la ejecución de obras como el Café Aubette.

Pese a todo lo dicho, el estatuto de Sophie Taeuber en la historia del arte abstracto ha sido siempre extremadamente precario; aunque Michel Seuphor (uno de los primeros teóricos e historiadores de la abstracción) dijo de ella que "je considere Sophie Taeuber comme une très grande figure, une des éminences de l'art de ce siècle, je la place au même niveau que son mari Arp, que Mondrian, Van Doesburg, Kandinsky" (Jaeger y Weil-Seugeot, 2007, p. 90) ${ }^{27}$, lo cierto es que pocas veces su obra y su persona han sido realmente tan valoradas en libros, catálogos o exposiciones. Diversas razones explican esta escasa visibilidad: en primer lugar, y como en el caso de Sonia Delaunay, el hecho de ser la esposa de un artista importante probablemente contribuyó al desarrollo de proyectos o al establecimiento de contactos comunes, pero sin duda ocultó e invisibilizó su obra detrás de la de su marido. Significativamente, las palabras de Seuphor que acabamos de citar continúan así:

J'ai même une légère préférence pour Sophie qui était singulièrement modeste et effacée. Elle était utile dans l'entourage de Arp, elle était présente et serviable. Presque tous les personnes 
qui venaient chez Arp ignoraient qu'il y avait au dessus de son atelier, un autre atelier de même dimension qui était celui de Sophie et que personne ne visitait. Elle faisait des oeuvres remarquables qui se trouvent maintenant dans des musées, mais que seules trois ou quatre personnes connaissaient alors. Pourtant Arp recevait de nombreuses visites, tous les jours (ibid., p. 90-91) ${ }^{28}$

Taeuber (llamada siempre por su nombre de pila, a diferencia de su marido) aparece aquí pues como modesta, eclipsada, servicial, ignorada; en otros comentarios escritos por personas que la conocieron bien aparecen los adjetivos (en referencia tanto a su persona como a su obra) calmada, invisible, silenciosa, serena, juiciosa, comedida, laboriosa, meticulosa, equilibrada,... En fin, todo lo contrario al ímpetu y visibilidad que se le suponen al artista radical, innovador $y$ revolucionario, modelado según el patrón romántico del genio, y aplicable en buena medida, como hemos visto, a los pioneros de la abstracción. Y todo ello pese a que tanto Arp como muchos de los autores que escribieron sobre ella se esforzaron en remarcar que la relación de su obra con la de su marido no era en ningún caso de subordinación creativa, sino de interdependencia e influencia mutua; así lo prueban estas palabras de Arp que evocan el momento en qué descubrió la obra de Taeuber: "le calme limpide qui se dégageait des compositions verticales et horizontales créées par Sophie Taeuber influença la facture baroque, la structure en diagonale de mes "configurations abstraites"' (Ibid.., p. 22). ${ }^{29}$

Con todo, la poca visibilidad de Taeuber en el contexto de la historia de la abstracción tiene mucho que ver también, sin duda, con su vinculación a las artes aplicadas y a su asimilación con lo decorativo. Como hemos comentado trabajó durante mucho tiempo como profesora de textil, y no pocas de sus composiciones abstractas son bordados, estampados o tejidos (Figura 2). También escribió un par de textos para sus alumnas en los que reflexiona, entre otros temas, sobre la cuestión del ornamento; desde su punto de vista éste responde a una propensión interna y profunda del ser humano hacia la belleza y a una aspiración a la perfección, que le lleva a intervenir en los objetos para mejorarlos. E1 ornamento, pero, no debe responder ni a ansias materialistas ni a la 
simple imitación, sino que debe crecer orgánicamente de la superficie del objeto a embellecer; en "Observaciones sobre la enseñanza del diseño ornamental" escribe:

"Cada línea, cada forma, cada color de las flores o de los insectos ha nacido de una profunda necesidad. Toda expresión realmente viva es bella o interesante. Los objetos fabricados desde el afán de imitación, de la ambición o de sentimientos similares son repulsivos" (De Diego, 2009, p. 163).

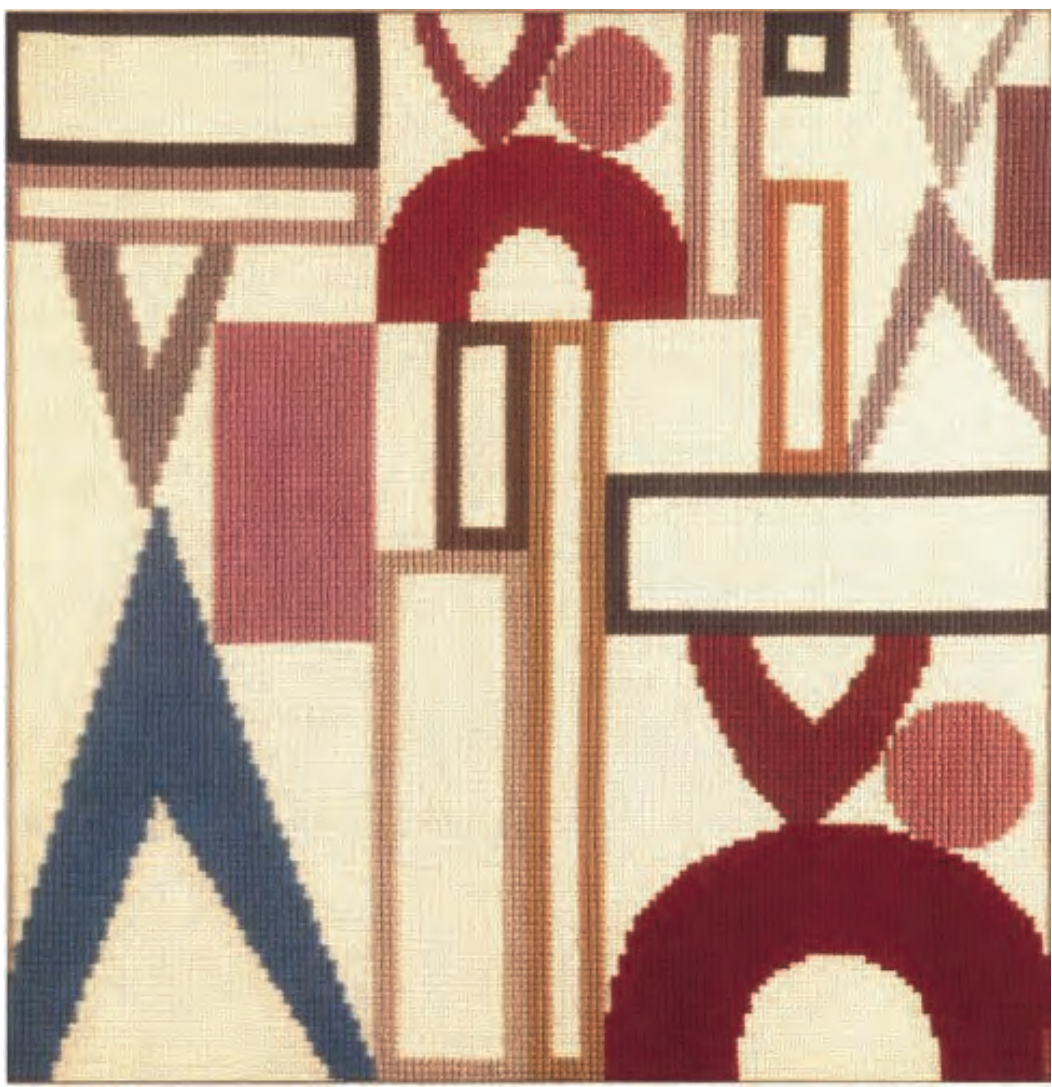

Figura 2. Sophie Taeuber, Tapisserie Dada. Composition à triangle et partie d'anneau, 1916. Bordado, 41 x $41 \mathrm{~cm}$. 
Nótese como esta idea de la necesidad profunda a la que debe obedecer el ornamento es muy similar al concepto de 'necesidad interior' que, según Kandinsky, debe ser el único impulso creador al que obedezca el artista:

"El artista debe ser ciego a las formas reconocidas o no reconocidas, sordo a las enseñanzas y los deseos de su tiempo. Sus ojos abiertos deben mirar hacia su vida interior y su oído prestar siempre atención a la necesidad interior [...]. Todos los medios son sagrados, si son interiormente necesarios. Todos los medios son sacrílegos si no brotan de la fuente de la necesidad interior." (Kandinsky, 1995, p. 75).

Kandinsky reservaba el concepto para su concepción más elevada del hecho artístico.

La dedicación de Taeuber a la cuestión de las artes aplicadas o decorativas, sin embargo, le pasó factura al menos en dos frentes distintos: por una parte, aunque llevó a cabo algunos proyectos de decoración de interiores, el hecho de no conseguir desarrollar totalmente ningún proyecto arquitectónico mantuvo su trabajo en un plano de valoración inferior. En este sentido es muy relevante la importancia que la integración de las artes en la arquitectura tuvo para algunos de los abstractos, muy en especial para Mondrian y el Neoplasticismo. De hecho, para el holandés el arte del futuro sería precisamente el surgido de la asimilación de los principios pictóricos neoplásticos por parte de la arquitectura hasta su integración total, como lo muestran sus escritos: "La arquitectura sólo tiene que realizar en el dominio tangible lo que la pintura ha demostrado en la Nueva Plástica. Son el arquitecto y el ingeniero quienes deben hacer posible, en el futuro, una armonía real entre nosotros y nuestro entorno." (Mondrian, 1989, p. 81); "Architecture, sculpture, painting, and decorative art will then merge, that is to say, become architecture-as-our-environment. The less material arts will be realized in life. [...] The Neo-plastic conception will go far beyond art in its future realization" ("The Realization of Neo-plasticism in the Distant Future and in Architecture Today", 1922; Holtzman y James, 1993, p. 168; cursivas y negritas en el original) ${ }^{30}$. Taeuber tuvo de hecho una oportunidad para realizar un gran proyecto, 
puesto que el encargo de la reforma del famoso Café Aubette de Estrasburgo se lo hicieron a ella, que a su vez contactó con Theo Van Doesburg para que la ayudara; diversas circunstancias llevaron sin embargo a que finalmente fuera él quien gestionara el proyecto, y quién haya acabado apareciendo en los libros de historia del arte como su principal responsable. A ello no puede ser ajena de ninguna manera la dificultad ancestral y aún ahora muy real que han tenido las mujeres para acceder a la arquitectura, pero en cualquier caso limitó considerablemente la repercusión de la obra de Taeuber.

Por otra parte, la desvalorización de las artes aplicadas en el contexto de lo abstracto a la que ya nos hemos referido anteriormente fue sin duda un gran hándicap a superar para alguien gran parte de cuya obra puede clasificarse bajo esta etiqueta. En este sentido es muy significativo que incluso quienes querían defender histórica y teóricamente su obra se sintieran obligados a hacerlo a partir del rechazo de lo decorativo. Un ejemplo es el siguiente texto del mismo Jean Arp: “(...) parfois on a qualifié ses oeuvres d'art appliqué. La bètise autant que la méchanceté sont à l'origine de cette appellation. L'art peut aussi bien s'exprimer au moyen de la laine, du papier, de l'ivoire, de la céramique, du verre que par la peinture, la pierre, le bois, l'argile. [...] L'art est toujours libre et libère l'objet auquel il s'applique" (Jaeger y Weil-Seugeot, 2007, p. 90) ${ }^{31}$. Por más que podamos estar de acuerdo con Arp en la necesidad de borrar distinciones entre una idea de Arte en mayúsculas y otra denigrativa de artes aplicadas, su propia insistencia en no querer que la obra de Taeuber se sitúe bajo este concepto demuestra que él mismo lo consideraba inferior. Quiero concluir con un ejemplo mucho más reciente de esta misma incomodidad respecto a la obra de Taeuber que nos proporciona Hal Foster, quién formulando unas preguntas sobre su obra que jamás se formularía ante la de otros artistas abstractos, evidencia hasta qué punto su trabajo resulta problemático para determinadas visiones de la Modernidad:

Por ejemplo, ¿cómo debemos clasificar las cuadrículas de Sophie Taeuber, que a veces basaba estas obras (que son anteriores a las primeras abstracciones modulares de Mondrian) en las disposiciones casi espontáneas de los cuadrados formados como collages de Hans 
Arp? Por su parte, Arp dijo que eran "probablemente los primeros ejemplos de "arte concreto", a la vez "puros e independientes" y “elementales y espontáneos". ¿Son arte elevado? ¿Bajo? ¿Trascendentales en ambición? ¿Decorativos? ¿Programáticos? ¿Aleatorios? Estas obras complicaron estas oposiciones jerárquicas casi antes de que existieran." (Foster, 2006, p. 119).

\section{Mujeres en la Bauhaus}

Un último ejemplo nos lo proporciona el caso de la Bauhaus, la célebre escuela de artes aplicadas fundada en Weimar en 1919 por Walter Gropius. En el documento fundacional de la misma está clara la vocación de interdisciplinariedad entre lo que podríamos llamar bellas artes y artes aplicadas: "¡Arquitectos, escultores, pintores, todos debemos volver a la artesanía! Pues no existe un arte como profesión (...) ¡Formemos pues un nuevo gremio de artesanos sin las pretensiones clasistas que querían erigir una arrogante barrera entre artesanos y artistas! Deseemos, proyectemos, creemos todos juntos la nueva estructura del futuro, en que todo constituirá un solo conjunto, arquitectura, plástica, pintura" (Gropius, 1919). Así mismo, en el programa también queda bien claro que la oferta formativa de la escuela debía dirigirse a hombres y mujeres por igual: "Serán admitidas todas las personas sin antecedentes, sin limitaciones de edad ni sexo, cuya preparación sea considerada suficiente por el consejo de maestros de la Bauhaus y mientras se disponga de plazas" (Ibíd.); como resultado, 84 mujeres y 79 hombres solicitaron matricularse en la Bauhaus en su primer semestre lectivo, en 1919 (Müller, 2009, p. 9; con el tiempo y la inclinación de la escuela hacia una formación más tecnológica, la proporción de mujeres matriculadas bajó hasta llegar a un $25 \%$, aproximadamente). Gran parte de la bibliografía existente sobre la escuela pone énfasis en la participación de las mujeres en las actividades formativas del centro, así como en las extra académicas, que tanto contribuyeron a forjar lo que se ha dado en llamar el espíritu de la Bauhaus.

Pese a todo ello, la situación de estas mujeres en la escuela distó mucho, no ya de ser idílica, sino de ser comparable a la de sus compañeros masculinos. Para empezar, las alumnas que se matricularon 
en los primeros cursos fueron calurosamente invitadas (aunque no formalmente obligadas) a realizar sus estudios de taller u oficio en una clase específicamente para mujeres, que pronto se fundió de forma natural con el taller textil de tapiz y tejido; muy pocas lograron a la larga integrarse en otros talleres, y tenían específicamente prohibido participar en el de arquitectura. Por lo que se refiere a los docentes, de los cuarenta y cinco profesores de la Bauhaus de Weimar y los treinta y cinco de Dessau, sólo seis en cada caso fueron mujeres, mientras que en Berlín sólo hubo una mujer entre doce profesores. De entre todas ellas, sólo tres (Helene Börner, Gunta Stölzl y Lilly Reich) llegaron a asumir el puesto de maestra de taller, el más alto de la jerarquía académica de la Bauhaus, y todas en el taller de tejido. Marianne Brandt llegó a ser la directora ayudante del taller de metal en 1928, después de haber sido la primera mujer que estudió en dicho taller. Además, la actitud general de los diversos profesores y maestros de la escuela, incluido el propio Gropius, sobre las relaciones entre género, arte y creatividad remitían claramente al tipo de pensamiento dualista al que hemos hecho referencia con anterioridad. Por ello se aplicaron diversas estrategias para evitar la presencia de las mujeres en los distintos talleres, desde un proceso de selección más estricto, pasando por un asesoramiento sesgado hasta prohibirles directamente vender sus obras (Baumnhof, 1999). Un último apartado lo configuran las historias de las mujeres de los maestros, muchas de las cuales, como la fotógrafa Lucia Moholy, jugaron un papel muy significativo en la historia de la escuela, pero cuya contribución ha quedado una vez más oculta detrás de la de sus maridos.

La historia del taller de tejido de la Bauhaus y de las mujeres que participaron en él es pues muy reveladora de cual era el papel que la Bauhaus preveía para ellas. El taller, dirigido al principio por Helene Börner, existía ya antes de que naciera la escuela (que se fundó a partir de la unión de dos centros preexistentes). En mayo de 1920 se convirtió como hemos visto, en la práctica, en un departamento específico para mujeres, dirigido por Börner y con Johannes Itten como responsable de la dirección artística (sustituido más adelante por Georg Muche). Pronto surgieron las diferencias entre Börner, cuyas referencias estéticas no pasaban del Jugendstil, y las estudiantes más jóvenes, entre ellas Gunta Stölzl, que querían aprender técnicas y formas nuevas, más en línea con 


\section{Maria Llü̈sa Faxedas - ¿Contra si Mismas?}

lo que se trabajaba en los departamentos artísticos de la escuela. Cuando la Bauhaus se mudó a Dessau, Stölzl empezó a ejercer como nueva maestra de taller, aunque sólo en 1927 fue formalmente nombrada como tal; en 1931 fue forzada a dimitir y su cargo lo ocupó Lilly Reich, quien intentó dar al taller una orientación más vinculada a la arquitectura.

Pese a ser considerado el menos prestigioso de los talleres de la Bauhaus se mostró a la larga como uno de los más productivos y de los que más contribuyeron a consolidar la imagen exterior de la escuela. A pesar de la losa de tradicionalismo asociada con lo textil, las estudiantes de la Bauhaus lograron introducir un considerable grado de innovación tanto en los materiales como en los diseños de sus tejidos. Muchas de ellas aplicaron a sus trabajos (por ejemplo alfombras, cobertores o textiles para colgar en la pared) principios formales derivados de lo que aprendían en las clases de Itten o Klee, dos de los profesores que más influyeron en las estudiantes, prescindiendo completamente de los elementos figurativos característicos de la decoración textil hasta ese momento. Las obras de Stölzl (Figura 3), Ida Kerkovius o Anni Albers, por citar algunos nombres, son creaciones tan puramente abstractas como las de sus profesores o compañeros, aunque estas se ejecutaran en otros materiales y formatos. Algunas de ellas trabajaron también en estrecha colaboración con colegas de otros departamentos; Stölzl, por ejemplo, elaboró tejidos para algunas de las sillas diseñadas por Marcel Breuer. Por todo ello, como hemos indicado, las producciones del taller textil fueron de las que mejor se comercializaron; pero, paradójica y significativamente, esto fue así en buena medida porque, debido tanto a su técnica como a su autoría, no eran percibidas por el público y los críticos como piezas de arte abstracto del mismo tipo que las obras pictóricas o artísticas de los artistas abstractos del momento. En los materiales textiles lo abstracto se acepta porque se vincula una vez más con lo decorativo, ornamental o superficial, y por lo tanto se ve desprovisto de un sentido trascendente como el que sus autores proclamaban que se podía encontrar en el arte abstracto pictórico y escultórico. En este sentido, el confinamiento de las mujeres de la Bauhaus al taller textil es muy revelador, una vez más, de que incluso en un centro dedicado completamente a la cuestión de la integración entre lo artístico y lo aplicado se construyeron categorías que sirvieron para limitar el desarrollo creativo de las mujeres. 


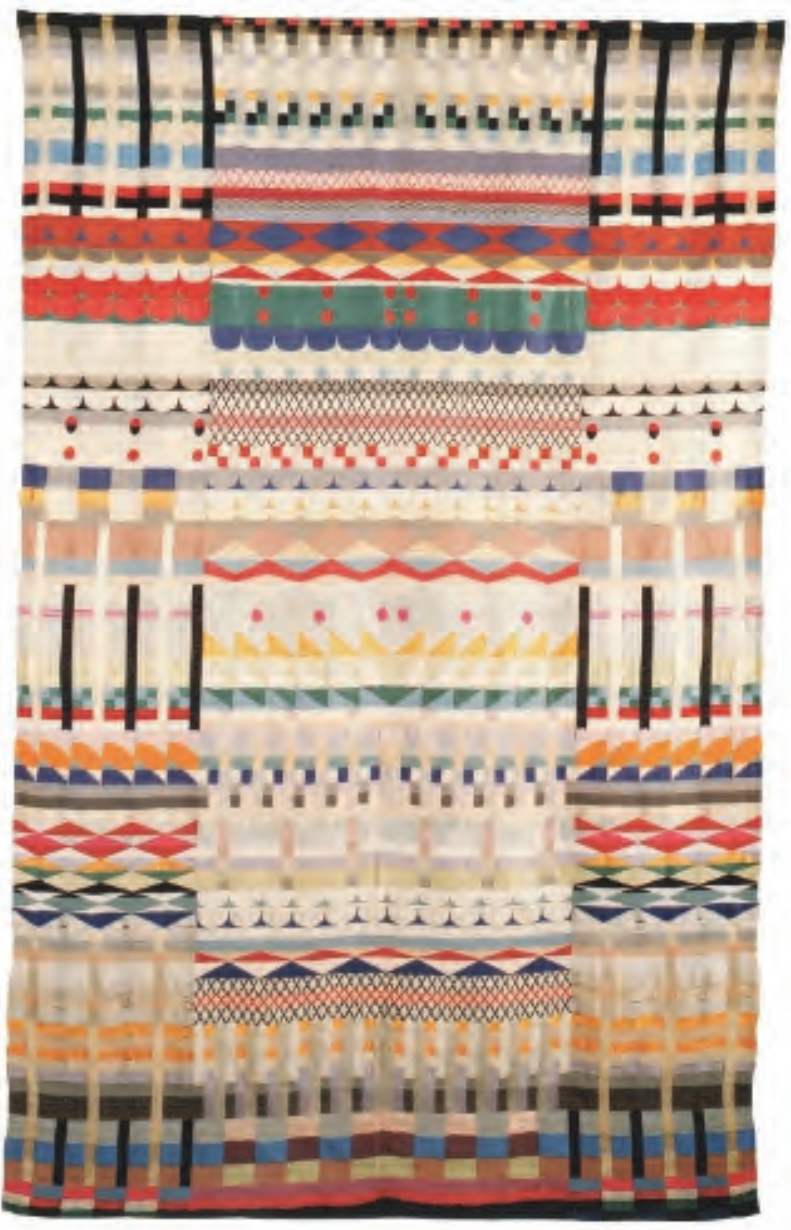

Figura 3. Guntha Stölzl, 5 Chöre, 1928. Jacquard para colgar en la pared; algodón, lana, rayón y seda. 229 x $143 \mathrm{~cm}$. 


\section{Conclusiones}

A lo largo de este artículo hemos esbozado algunas cuestiones que permiten aproximarnos a una realidad concreta, la de la práctica artística de un buen número de mujeres en el contexto de la abstracción plástica, que estuvo sometida a una serie de restricciones que situaron su trabajo en un marco conceptual y práctico muy estrecho y difícil de superar. Hemos apuntado que tanto el pensamiento teórico que sirvió de sustrato para la abstracción como su materialización formal se constituyeron en términos de género, haciendo muy compleja la integración de aquello realizado desde y en lo femenino, que se vio relegado a las prácticas artísticas de las artes aplicadas, consideradas sólo en su vertiente decorativa. De algún modo, y parafraseando el comentario de Greenberg sobre lo decorativo, se podría sugerir que la definición que se hizo del arte abstracto en sus primeras décadas de existencia obligó a las mujeres artistas a trabajar 'contra sí mismas', o al menos contra la lectura de lo femenino que impregnaba el lenguaje con el que trabajaban.

Estas cuestiones están abiertas a una investigación más profunda que singularice de forma más pertinente la situación y trayectoria de cada una de las artistas, lo que queda para un futuro próximo. Sin embargo, este texto no puede dejar de cerrarse con nuevas preguntas: las razones esgrimidas pueden ayudarnos a entender porqué la historiografía del Modernismo no ha sabido articular las aportaciones de las mujeres abstractas, pero, ¿cómo explicar que tampoco la historiografía feminista se haya ocupado de estas artistas en su conjunto, y menos aún cuanto más abstracta fue su obra? ¿Es posible que también desde este ámbito se haya caído en la trampa de la supuesta universalidad de la abstracción, lo que haya dificultado la lectura de sus obras desde una vinculación específica a su experiencia femenina? ¿Hasta qué punto el proyecto político del feminismo ha percibido la abstracción como menos instrumental, y por lo tanto menos relevante para la consecución de sus objetivos, que la figuración? (Schor, 2006). En cualquier caso, nos encontramos ante un campo abierto en el que aún tenemos mucho por cuestionar. 


\section{Notas}

${ }^{1}$ Por ejemplo en lo que se refiere a la oposición gran arte / cultura de masas, como propone Huyssens (2002); la historiadora del arte feminista Griselda Pollock (1988) planteó un análisis similar en lo que se refiere a los espacios de la modernidad, caracterizados en buena medida por la contraposición entre lo público y lo privado, equivalente a la oposición masculino-femenino.

2 Se puede encontrar una buena bibliografía en Deepwell (1998); así mismo, los respectivos catálogos de las exposiciones Elles@centrepompidou: artistes femmes dans les collections du Musée National d'Art Moderne (2009), y Modern Women. Women artists at the Museum of Modern Art (2010) actualizan la información y las referencias.

3 "Ya que los héroes de esta dura prueba son genéricamente hombres, la presencia de mujeres artistas, en esta mitología, sólo puede ser una anomalía" (trad. de la autora)

${ }^{4}$ Aunque ciertamente, y en parte por los mismos motivos, la menor valoración del papel de las mujeres en el arte abstracto siguió en las siguientes décadas, como nos lo muestran los ejemplos del Expresionismo abstracto norteamericano o la expansión de la abstracción geométrica.

${ }^{5}$ No existe bibliografía que analice en general el trabajo de las mujeres artistas dentro de la abstracción, ni prácticamente ninguno de los textos dedicados al tema considera la aportación de las mujeres o la cuestión del género como un tema relevante. Sí existen algunos trabajos importantes que se ocupan de aspectos específicos; entre ellos, destacamos el artículo de Fer (1990) sobre Liubov Popova en el que también se señala la relación entre la tradición femenina del trabajo textil y la obra de las mujeres abstractas; el texto de Gibson (2003), más centrado en desarrollos pictóricos contemporáneos, o el de Schor (2006) sobre la pintora Alice Neel y las artistas del Expresionismo abstracto norteamericano.

${ }^{6}$ La obra de la pintora belga Marthe "Tour" Donas fue publicada en dos números de la revista De Stijl, en 1919. Sophie Taeuber-Arp fue la responsable del proyecto del Café Aubette, obra que acabaría dirigiendo Theo Van Doesburg y que es uno de los hitos del movimiento. Nelly van Doesburg, pianista y bailarina, es autora de algunas pinturas abstractas, bajo el seudónimo "Cupera".

${ }^{7}$ En el volumen también se incluyeron algunos dibujos hechos por una niña, Lydia Wieber; en sendos artículos se cita a Marie Laurencin y Marianne Werefkin, aunque no se reproducen sus obras. Cabe recordar también que se había encargado un artículo a la musicóloga rusa Nadezhda Briusova (1881-1951), quién lo escribió y entregó, pero cuya publicación se descartó en el último momento por cuestiones de espacio; de 14 artículos, pues, ninguno era de una mujer. También es llamativo que Robert Delaunay fuera uno de los artistas más celebrados del volumen, con reproducciones de su obra y un artículo dedicado a la misma, mientras que Sonia no recibió ningún comentario.

${ }^{8}$ De hecho, la historia de los orígenes y evolución del arte abstracto está tan entrelazada con la narración que traza el desarrollo del arte moderno, que desde ciertas perspectivas constituye de hecho su razón de ser fundamental; y esto es así tanto desde la visión más estrictamente formalista que supuso el punto de partida para la historiografía del arte moderno, como desde planteamientos más recientes e inclusivos respecto a las distintas fuentes e influencias que fueron confluyendo en el trabajo de los primeros artistas abstractos. 


\section{Maria Llü̈sa Faxedas - ¿Contra si Mismas?}

${ }^{9}$ Por ejemplo, Michel Seuphor incluye en su Dictionnaire de la peinture abstraite unos párrafos dedicados a "l'apport des femmes", que considera un apartado no despreciable de la fenomenología del arte abstracto pero claramente diferenciado, e introduce a algunas de ellas en el diccionario, aún preguntándose: "Sont-elles moins créatrices que l'homme? Ont-elles moins de force, moins d'invention, connaissent-elles moins la mesure? En toute sincerité, je ne le crois pas." (Seuphor, 1957, pp. 69-70). Es significativo que ponga el énfasis precisamente en los conceptos de creación, invención, fuerza y medida, en tanto que como hemos visto están fuertemente asociados a valores masculinos.

10 Esta palabra ha sido utilizada en numerosos estudios sobre los orígenes de la abstracción en referencia a la idea del (hombre) explorador o el aventurero que avanzan valerosamente por un terreno desconocido, hollando por primera vez aquello que ningún ser humano había conocido anteriormente, sea en un sentido físico o espiritual. Walt Whitman publicó un poema titulado precisamente "Pioneers! Oh, pioneers!" en Leaves of grass (1865), en qué lanza una llamada a los jóvenes para que empuñen sus armas y se lancen a la conquista del mundo y del futuro, sorteando todos los peligros: "O you youths, Western youths, So impatient, full of action, full of manly pride and friendship" 11 "[Una] colaboradora muy cercana de su marido... bajo su influencia", y "por otro lado la mujer de Robert Delaunay, Sonia Terk, se consagró durante largo tiempo a las artes aplicadas" (trad. de la autora). En ambos trabajos, escritos por mujeres, éstas son las únicas alusiones a su obra. En Contrasts of form aparece una reproducción de la misma; en Art abstrait se incluyen además unos párrafos dedicados a la pintora sueca Hilma Af Klint, a la que sin embargo se opta por vincular más con la historia de la teosofía que con la del arte.

12 Este texto sugirió el título de la exposición Amazonas de la vanguardia (2000), Guggenheim Museum.

13 Diversos textos y estudios se han ocupado de ellas, entre otros Baumhof (1999) o Müller (2009)

${ }^{14}$ Una de las pocas exposiciones y su relativo catálogo que incluyeron con normalidad el trabajo de las mujeres artistas abstractas fue Art concret (2000), celebrada en el Espace de l'art concret.

15 La distinción cuerpo/mente es uno de los elementos fundamentales del platonismo, que a su vez es la fuente de la que surge el idealismo que, asumido a través de múltiples vías, pondrán en juego estos artistas (Spelman, 1982).

${ }^{16}$ Un ejemplo nos lo ofrece el escritor simbolista Albert Aurier: "El amor es la única forma posible de penetrar en algo. Para entender a Dios, hay que amarle; para entender a una mujer hay que amarla; el entendimiento es proporcional al amor. Así pues, la única manera de entender una obra de arte es llegar a amarla. [...] Incluso es más fácil sentir verdadero amor por una obra de arte que por una mujer, pues en la obra de arte lo material existe mínimamente, y casi nunca permite que el amor degenere en sensualidad. [...] El sensualismo del presente siglo nos impide ver en una mujer algo más que un cuerpo apropiado para satisfacer nuestros deseos físicos. Ya no nos es permitido amar a una mujer"; "Ensayo sobre un nuevo método crítico" (Chipp, 1995, pp. 103-104) .

17 "El conocimiento antiguo identificaba lo físico, lo natural, con lo femenino, y lo espiritual con el elemento masculino. Para conseguir la naturalidad pura, lo natural debe ser interiorizado, eso es, desnudado tanto como sea posible de la más caprichosa externalidad que oscurece la perfecta naturalidad; en otras palabras, debe perfeccionarse 
a sí mismo [...]. Para ello, sólo es necesario que la nueva mentalidad se desarrolle libremente: que aniquile la vieja mentalidad y la dominación por parte del elemento individual, natural (o femenino); esto es, que se libere a sí mismo de la tradición y el dogma (...)." (trad. de la autora).

18 "El dibujo es el sexo masculino del arte; el color es el femenino. [...] Es necesaria la unión del dibujo y el color para crear la pintura, como la unión de hombre y mujer para engendrar a la humanidad; pero es necesario que el diseño conserve su posición predominante sobre el color. En caso contrario, la pintura corre a su ruina; se perderá por el color como la humanidad se perdió por Eva" (trad. de la autora). 19 "Si se puede decir que la decoración es el fantasma que acosa a la pintura moderna, parte de la misión formal de esta última es hallar modos de usar lo decorativo contra sí mismo" (Greenberg, 2002, p. 227).

20 "La creciente profundidad del conjunto de la vida moderna puede ser puramente reflejada en la pintura. En la pintura - en la pintura pictórica, no en la decorativa - la expresión naturalista así como la plástica naturalista se interiorizan, se esencializan en lo abstracto" (trad. de la autora)

21 "Sus afinidades con un femenino consagrado a los tejidos, texturas, tapices y otros trabajos manuales" (trad. de la autora)

22 "No me lo tomaba tan en serio - aunque era bastante serio [...]. Era mi vida y yo trabajaba todo el tiempo, pero no estaba trabajando - estaba viviendo - y esta es la diferencia [con el trabajo de Robert]" (trad. de la autora).

23 "Primero no creía necesario hablar de mi arte. Lo hacía en gran parte para mí misma [...]. Cuando hago estas cosas es porque necesito hacerlas. No pienso en ello" (trad. de la autora).

24 "Robert había estado lanzando cohetes en todas las direcciones - en la tierra, yo había recogido las centellas caídas de los fuegos artificiales, había alumbrado fuegos más íntimos y más efímeros, en la vida de todos los días, aún continuando silenciosamente mi obra más profunda" (trad. de la autora).

25 “(...) objetos de arte, con una decoración apropiada, como una mesa de comedor con un arreglo nuevo y composiciones inesperadas de otros objetos de interior que puedan llamarse el arte de la mujer, y de gran interés para el público" (trad. de la autora)

${ }^{26}$ Fue el psicoanalista J. C. Flugel quién propuso este concepto de la Gran Renunciación Masculina para referirse al proceso por el cual los hombres, a partir de la Revolución Francesa, renunciaron "a su derecho a todas las formas de ornamentación más brillantes, llamativas, elaboradas y variadas, dejándolas enteramente para uso de las mujeres, y haciendo con ello de su sastrería la más austera y ascética de las artes. [...] El hombre abandonó su pretensión de ser considerado hermoso. De ahí en adelante se propuso ser sólo útil." (Flugel, 1964, pp. 141-142).

27 "Considero a Sophie Taeuber como una gran figura, una de las eminencias del arte de este siglo, la sitúo al mismo nivel que a su marido Arp, que Mondrian, Van Doesburg, Kandinsky" (trad. de la autora).

28 "Siento de hecho una ligera preferencia por Sophie, quién era singularmente modesta y poco visible. Era útil en el entorno de Arp, estaba presente y era servicial. Casi todas las personas que venían a casa de Arp ignoraban que debajo de su taller había otro taller de las mismas dimensiones que era el de Sophie, y que nadie visitaba. Hacía unas obras remarcables que se encuentran ahora en los museos, pero que sólo tres o cuatro personas conocían entonces. Por el contrario Arp recibía numerosas visitas, todos los días" (trad. de la autora). 
29 "La calma límpida que se desprendía de las composiciones verticales y horizontales creadas por Sophie Taeuber influyó en la factura barroca, la estructura en diagonal de mis "configuraciones abstractas"" (trad. de la autora).

30 "Arquitectura, escultura, pintura y artes decorativas se fusionarán, es decir, se convertirán en arquitectura-como-entorno. Las artes menos "materiales" se realizaran en la "vida". [...] La concepción Neoplástica irá mucho más lejos del arte en su realización futura." (trad. de la autora).

31 "A veces se han cualificado sus obras de arte aplicado. La tontería tanto como la maldad están en el origen de esta denominación. El arte puede expresarse igualmente bien mediante la lana, el papel, el marfil, la cerámica, el cristal que mediante la pintura, la piedra, la madera, la argila [...]. El arte es siempre libre y libera el objeto al que se aplica." (trad. de la autora).

\section{Referencias}

Baumhof, A. (1999). Las mujeres de la Bauhaus: un mito de la emancipación, en Fiedler, J. y Feierabend (Eds.). Bauhaus (pp. 97-107). Colonia: Könemann.

Blanc, C. (2000). Grammaire des arts du dessin. Paris: École Nationale Supérieure des Beaux-Arts.

Broude, N. (1980). Miriam Schapiro and 'Femmage'.Reflections on the Conflict between Decoration and Abstraction in TwentiethCentury Art, Arts Magazine, febrero, 83-87.

Brüderlin, M. (2001). Introduction: Ornament and Abstraction. En

Brüderlin, M. (ed.) Ornament and Abstraction (pp. 16-27).

Basilea: Fondation Beyeler.

Buci-Glucksmann, C. (2008). Philosophie de l'ornement. D'Orient en Occident, París: Éditions Galilée

Chipp, H.B. (ed.) (1995). Teorias del arte contemporáneo. Fuentes artísticas y opiniones criticas. Madrid: Akal.

Dabrowski, M. (1985). Contrasts of form. Geometric Abstract Art 19101980. Nueva York: MOMA.

De Diego, E. (2008). Escribir sobre las mujeres en el arte. Por qué no pueden ser "surrealistas" las "surrealistas". En Casamartina, J. y Jiménez, P., Amazonas del arte nuevo (pp. 16 - 31). Madrid: Fundación Mapfre.

De Diego, E. (2009). Sophie Taeuber-Arp. Caminos de vanguardia. Málaga: Museo Picasso. 
Deepwell, K. (ed.) (1998). Women artists and modernism. Manchester: Manchester University.

Delaunay, S. (1978). Nous irons jusqu'a soleil. París: Eds. Laffont. Douglas, M. (1973). Pureza y peligro. Un análisis de los conceptos de contaminación y tabú. Madrid: Siglo Veintiuno de España Eds.

Duncan, C. (1989). The MOMA's Hot Mamas. Art Journal, vol. 48, 2 , 171-178.

Faxedas, M. L. (2007). Del Simbolisme a l'abstracció. L'ideal de la unitat de les arts en l'obra de Kandinsky i Mondrian, 1886-1936. Tesis doctoral inédita, Universitat de Girona, Girona.

Faxedas, M. L. Mujeres artistas y pintura abstracta. Sobre la marginalización de lo femenino en el discurso de la abstracción del siglo XX (2010) en Actas del XVIII Congreso del CEHA. Mirando a Clío. El arte español, espejo de su historia (pp. 646658) Santiago de Compostela: CEHA.

Felski, R. (1995). The gender of modernity. Cambridge: Harvard Univ. Press.

Fer, B. (1990). What's in a line? Gender and Modernity. Oxford Art Journal, vol. 13, 1, 77-88.

Flugel, J. C. (1964). Psicología del vestido. Buenos Aires: Paidós.

Foster, H., Krauss, R., Bois, Y.-A. y Buchloch, B. (2006). Arte desde 1900. Modernidad, antimodernidad, posmodernidad. Madrid: Akal.

Garb, T. (2007). Berthe Morisot and the Feminizing of Impressionism. En M. Tompkins (ed.). Critical readings in Impressionism and Post-impressionism (pp. 191-201). Berkeley y Los Angeles: University of California Press.

Gibson, A. E. (2003). Color and difference in Abstract painting. The ultimate case of Monochrome. En A. Jones (ed.) The Feminism and visual culture reader (pp. 193-204). Londres y Nueva York: Routledge.

Godefroy, C. (2003/04). Sonia Delaunay et le décor moderne, 19111937. Les Cahiers du Mnam, 86, 40-59.

Greenberg, C. (2002). Arte y cultura. Barcelona: Paidós. Gropius, W. (1919). Manifiesto y programa de la Bauhaus. Recuperado de

http://www.ddooss.org/articulos/textos/Staatliches_BAUHAUS.ht 
60 Maria Llü̈sa Faxedas - ¿Contra si Mismas?

$\mathrm{m}$

Holtzman, H. \& James, M. (eds. y trads.) (1993). The New Art-The New Life. The Collected Writings of Piet Mondrian. Nova York: Da Capo Press.

Huyssens, A. (2002). La cultura de masas como mujer: lo otro del modernismo. En Huyssen, A. Después de la gran división. Modernismo, cultura de masas, posmodernismo (pp. 89-120). Buenos Aires: Adriana Hidalgo.

Jaeger, C. y Weil-Seugeot, C. (eds.) (2007). Sophie Taeuber. Rythmes plastiques, réalités architecturales. Clamart: Fondation Arp. Jaudon, V. y Kozloff, J. (1978). Art Hysterical Notions of Progress and Culture. Heresies, 4, 38-42.

Kandinsky, V. (1995). De lo espiritual en el arte. Colombia: Labor. Lemoine, S. (ed.) (2000). Art concret. París: Espace de l'art concret y RMN.

Livchits, B. (1971). L'Archer à un oeil et démi. Lausanne: L'Age d'homme.

Loos, A. (1908). Ornamento y delito. Recuperado en http://es.scribd.com/doc/17479175/Loos-Adolf-Ornamento-yDelito

Mondrian, P. (1989). Realidad natural y realidad abstracta. Madrid: Debate.

Morgan, D. (1992). The Idea of Abstraction in German Theories of the Ornament from Kant to Kandinsky. The Journal of Aesthetics and Art Criticism, 50, 3, 231-242.

Müller, U. (2009). Bauhaus women. Art, Handicraft, Design. Flammarion: Paris .

Nemser, C. (1975). Art talk. Conversations with 15 women artists. Nueva York: HarperCollins Pub.

Nigro Covre, J. (2002). Art abstrait. Thèmes et formes de l'abstraction dans les avant-gardes européennes. Arles y Milán: Actes Sud / Motta.

Ozenfant, A.(1952). Foundations of modern art. Nueva York: Dover Pub.

Ozenfant / Le Corbusier (1993). "Naturaleza y creación" en Acerca del purismo. Escritos 1918-1926 (pp. 115-125). Madrid: El Croquis ed. 
Pollock, G. (1988). Vision and difference: Femininity, Feminism and the Histories of Art (pp. 50-90). Londres: Routledge.

Pollock, G. (2010). The missing future: Moma and modern women.

Modern Women. Women artists at the Museum of Modern Art (pp. 29-55; p. 38). Nueva York: MOMA.

Schor, M. (2006). Some Notes on Women and Abstraction and a Curious Case History: Alice Neel as a Great Abstract Painter en Differences: A Journal of Feminist Cultural Studies, vol. 17, 2, 132-160.

Seuphor, M. (1957). Dictionnaire de la peinture abstraite. Paris: Hazan. Spelman, E. (1982). Woman as body: ancient and contemporay views.

Feminist Studies, 8, 1, 109-131.

Troy, N.J. (2003). Couture and culture: a study in modern art and fashion. Cambridge y Londres: The MIT Press.

Wolff, J. (2000). The Feminine in Modern Art. Benjamin, Simmel and the Gender of Modernity. Theory Culture Society, 17, 33-53; p.35.

Wollen, P. (1987). Fashion / Orientalism / The body en New Formations, 1, 5-33.

VV.AA. (1982). Kandinsky in Munich, 1896-1914. Nueva York: The Solomon R. Guggenheim Museum.

VV.AA. (2004). La dona. Metamorfosi de la modernitat Barcelona: Fundació Miró.

VV.AA. (2009).Elles@centrepompidou: artistes femmes dans les collections du Musée National d'Art Moderne. París: Centre Georges Pompidou.

VV.AA. (2010). Modern Women. Women artists at the Museum of Modern Art. Nueva York: MOMA.

Lluïsa Faxedas es Lectora en Historia del Arte Contemporáneo. Miembro del Grupo de Investigación Teorías de Arte Contemporáneo. Universitat de Girona, España.

Contact Address: St. Domènec Plaça Ferrater Mora 1 17071 - GIRONA. Despatx: 3. Email: mlluisa.faxedas@udg.edu 
Instructions for authors, subscriptions and further details:

http://brac.hipatiapress.com

\section{Escultura Sonora Baschet: Universal Design, Pedagogía e Inclusión}

Martí Ruiz ${ }^{1}$ \& Robert Ruiz ${ }^{2}$

1) Universitat de Barcelona (UB), España.

2) Universitat de Vic (UVIC), España.

Date of publication: June 3rd, 2013

To cite this article: Ruiz, M., Ruiz i Bel, R. (2013). Escultura Sonora Baschet: Universal Design, Pedagogía e Inclusión. BRAC. Barcelona, Research, Art, Creation, 1(1), 62-99. doi: 10.4471/brac.2013.03.

To link this article: http://dx.doi.org/10.4471/brac.2013.03

\section{PLEASE SCROLL DOWN FOR ARTICLE}

The terms and conditions of use are related to the Open Journal System and to Creative Commons Non-Commercial and Non-Derivative License. 


\section{Baschet's Sound Sculpture: Universal Design, Pedagogy and Inclusion}

Martí Ruiz

Universitat de Barcelona
Robert Ruiz

Universitat de Vic

\section{Abstract}

This paper presents an approach to the Pedagogical Baschet Instrumentarium from the point of view of the Universal Design proposed by Ron Mace. This unprecedented double reading of the principles, applications and implications, draws a promising path that is based on over 60 years of evolution of Baschet Soundsculpture and currently appears as a oparadigm for contemporary reflection on pedagogy and the social function of art.

Keywords: sound sculpture, Baschet, universal design, acoustics, pedagogy. 


\section{Escultura Sonora Baschet: Universal Design, Pedagogía e Inclusión}

Martí Ruiz \& Robert Ruiz

Universitat de Vic

\section{Resumen}

El presente artículo presenta una aproximación al Instrumentarium Pedagógico Baschet des del punto de vista del que Universal Design propuesto por Ron Mace. Esta doble lectura inédita de los principios, aplicaciones e implicaciones, dibuja una trayectoria prometedora que se sustenta en más de 60 años de evolución de la Escultura Sonora Baschet y que actualmente se muestra como un paradigma para la reflexión contemporánea sobre la pedagogía y la función social del arte.

Palabras claves: escultura sonora, Baschet, diseño universal, acústica, pedagogía. 
D $\mathrm{n}$ el presente artículo se plantea un conjunto de reflexiones sobre las dimensiones participativas de la escultura sonora Baschet y sus posibles vínculos con el Universal Design (UD) o "Diseño para todos" en nuestros términos, y el Universal Design for Learning -UDL - (Diseño Universal para el Aprendizaje) con diferentes propósitos.

Nuestro propósito de mayor amplitud es estimar hasta que punto la identificación de estos vínculos podría servir eventualmente para interpretar las aportaciones de Baschet desarrolladas hasta el momento presente y para, en su caso, orientar algunos posibles nuevos desarrollos a partir de esos enfoques.

Estos propósitos se complementan necesariamente con reflexiones de carácter más general dado que lo que abordamos constituye uno de los ejemplos de sinergia mas evidente y logrado entre los ámbitos de la pedagogía y el arte, un caso paradigmático para reflexionar sobre las relaciones entre la cultura, las ciencias, las artes, y la educación: la Escultura Sonora Baschet y su dimensión participativa. Aunque la obra de los Hermanos Baschet es reconocida mundialmente, con una carrera que hoy en día cumple con sesenta años de actividad, sigue siendo necesario divulgar y profundizar en sus principios. En el presente artículo reflexionamos sobre el Instrumentarium Pedagógico y su proximidad con los principios del Universal Design propuestos por Ron Mace. Presentaremos brevemente ambos mundos, puesto que a menudo las personas especializadas o interesadas en unos de estos ámbitos puede desconocer el otro, así como pensamos que todo lo que sea tender puentes entre artistas y pedagogos es necesario y enriquecedor para todos. Escribimos este artículo desde posición de investigadores, docentes, alumnos, artistas y ciudadanos, y las cuestiones que planteamos en el presente son recurrentes, inevitables y compartidas con todo tipo de personas en nuestro contexto social actual. Esperamos pues que sea de interés para todos. Hay mucha información relativa a los dos ámbitos que queremos comparar, así que no pretendemos aquí describir totalmente, ni profundizar en las ideas y las tareas llevadas a cabo por los Baschet ni por Mace y sus colaboradores, ni todo lo que significa 
hoy en día el UD. Mencionaremos lo que consideramos esencial para proceder al desarrollo de la pequeña tesis del artículo.

Desde el Laboratori d'Art Sonor del Departament d'Escultura de la Facultat de Belles Arts de la UB, tenemos la fortuna de trabajar en la actualidad con François Baschet y hemos compartido horas de conversaciones con Bernard Baschet. Por ello nuestra experiencia directa con su trabajo puede ofrecer una perspectiva personal que privilegiada para la consecución de los intenciones planteadas tanto por los Hermanos Baschet como por las ideas que motivan el Universal Design.

Para dar forma a este ensayo hemos contado, pues, con esta "inmersión" personal en las actividades y las premisas inclusivas que los Baschet propusieron, con anterioridad a la formulación los principios del Universal Design, y con la colaboración de los investigadores de la línea en Universal Design del "Grup de Recerca en Atenció a la Diversitat" (GRAD) coordinada por el Dr. Ruiz de la UVic.

Actualmente, en 2013, Bernard y François Baschet tienen noventa y cinco y noventa y tres años respectivamente. Cuando conocimos a François y descubrimos asombrados que estaba dispuesto a comunicarnos, a legarnos metafóricamente su patrimonio intelectual, -como había venido haciendo durante décadas a través de exposiciones y publicaciones-, y a los pocos meses a estar trabajando conjuntamente en un taller en la Facultad de Bellas Artes, empezamos a entender que una especial mezcla de arte y ciencia le habían dado una perspectiva del trabajo en equipo, del valor transmisión y la transformación de los conocimientos digna de su legendaria fama de artista poco corriente, humilde maestro poliédrico. Sus ideas sobre la participación y la función social del arte nos han cautivado, han reforzando intuiciones que ya nos habían puesto en una senda que nos llevaba hasta él y nos proyecta hacia un futuro conjunto. Así pues, puede que el entusiasmo algo soñador que tiñen estas líneas proceda directamente del maestro Baschet. Tanto François como nosotros consideramos que es una suerte que finalmente una Universidad pueda acoger sus planteamientos.

Sesenta años de trabajo reconocido mundialmente no merecen sino el mayor de nuestros esfuerzos y agradecimiento, por la oportunidad de aprender de su trabajo como obra extensa y abierta, oportunidad de desarrollar las ideas y aplicaciones que sean más convenientes para las 
próximas generaciones.

Visto desde nuestra propia perspectiva, y la de los hermanos Baschet, el conocimiento científico -su método y su curiosidad no dogmática-, es inseparable del conocimiento intuitivo, y su plasmación creativa, sus aplicaciones, no tienen sentido sin encauzarse en distintos modos de transmisión y pedagogía. Se trata de la intención, la necesidad evolutiva, de compartir los hallazgos con el máximo número posible de personas. $\mathrm{Su}$ historia dibuja un horizonte prometedor, una ventana abierta de posibilidades para una educación y una participación cívica renovadas. Planteamientos como los propuestos por pensadores como Sir. Ken Robinson, -según los cuales la educación debe servir para que cada persona descubra sus capacidades y su potencial creativo y lo pueda cultivar-, parecen estar hoy en día en auge. Aunque no entraremos en profundidad sobre ello, esta perspectiva parece algo más posible gracias a ejemplos como el de los hermanos Baschet.

\section{Breve reseña histórica de la Escultura Sonora Baschet}

La historia de la obra y las ideas los hermanos Baschet está explicada en numerosas publicaciones, destacando entre ellas el espléndido libro escrito por el mismo François Baschet "Les structures Sonores, The SoundSculptures of Bernard and François Baschet" (Baschet, F., 1999). Dado que este libro se encuentra descatalogado y actualmente es complicado de encontrar en el Estado Español, a continuación relataremos los principales hechos y hallazgos, los más destacables para la comprensión del argumento del presente artículo. Evidentemente recomendamos encarecidamente el visionado de los sucesivos documentales sobre Baschet de Jacques Barzac, Eric Marin y Rudolf Ingo, lamentablemente también inéditos en el Estado Español.

La Escultura Sonora constituye hoy en día una parte importante dentro del amplio mundo del Arte Sonoro. Pero durante la primera mitad del siglo XX, y a lo largo de la segunda mitad, numerosas prácticas experimentales, periféricas, alternativas, desde el campo de la música, la poesía y las artes plásticas fueron conformando atomizadamente un marco que hoy podemos conceptualizar gracias a numerosos estudios, revisiones críticas interdisciplinarias, como las enciclopédicas publicaciones La mosca tras la oreja de Llorenç Barber 
y Sound Art de Alan Licht.

Evidentemente este no es lugar para esbozar tan vasto y generalmente desconocido universo, por lo que animamos al lector neófito a buscar entre las innumerables fuentes: libros, artículos, seminarios, documentales, webs, discos, etc. Aun así, desearíamos apuntar algunas relaciones con otras líneas y artistas sonoros para enmarcar mejor la obra Baschet, entender porqué se les considera como los padres -o por lo menos indiscutibles fundadores- de esto que llamamos Escultura Sonora, y así destacar la singularidad y el valor de su posicionamiento social.

Elegimos para ello el ejemplo de dos artistas - Bertoia, Partchcoetáneos a Baschet, con quien coincidieron en varias ocasiones, y veamos sumariamente hacia donde apuntan sus visiones coincidentes en algunos aspectos pero divergentes en otros.

El escultor Harry Bertoia desarrolló una obra característica y muy reconocible trabajando como Baschet con medios acústicos. Todas sus piezas sonoras muestran una línea de investigación centrada en un tipo de forma y material: Racimos de barras metálicas paralelas soldadas a una base, como grandes cepillos estilizados, o columnas de juncos flexibles, que suenan al chocar y frotarse las unas contra las otras. Cada pieza, cada grupo de barras, tiene un potencial tímbrico y una cadencia rítmica, una marcada dimensión táctil y una limitada posibilidad de control una vez la estructura empieza a moverse. Todas sus piezas sonoras se comportan de algún modo como autómatas cuando son percutidas o empujadas, hasta que la inercia cesa por sí misma. El sentido espacial y de conjunto escultórico -donde varias de las piezas pueden estar activadas simultáneamente- lo acerca a la noción de instalación ambiental y fundamentalmente a lo que llamamos arte sonoro. Probablemente mucha gente negaría a esos sonidos la categoría de música, en gran parte por presentarse siempre en contextos escultóricos y no darle usos ligados a las intenciones, liturgias y escenificaciones musicales. A lo sumo, desde una posición favorable a la lógica difusa podríamos asociar esos fenómenos sonoros a una concepción de la música muy contemplativa, paisajista, azarosa y desvinculada de las tradiciones musicales occidentales. Así pues, podemos ver en este compañero de exposiciones de Baschet, un extremo de la escultura sonora física e interactiva, pero que no pretende ser más 
instrumento de lo que es como escultura, ni buscar versatilidades musicales.

Desde el ámbito de la música contemporánea, el gran Harry Partch, ha sido en ocasiones propuesto como contrapunto a Baschet, como constructor de objetos sonoros experimentales. Sus creaciones, singulares y atractivas, exploran muchas familias de instrumentos distintos -percusión, cuerda, viento, voz-, para explorar dimensiones tímbricas, afinaciones alternativas microtonales, espaciales y gestuales. Aun así, y sin menospreciar en modo alguno el aspecto escultórico de los instrumentos de Partch ni sus concepciones musicales, hay que recordar que él mismo insistía cándidamente en que todo este abanico de desarrollos constructivos y tonales constituyen una solución a medida de sus necesidades e inquietudes musicales. Partch hacía mucho hincapié en que no esperaba que nadie excepto sus colaboradores tuviera que utilizar ni desarrollar los instrumentos ni los sistemas tonales que inventó. Más bien se trataba de dar un ejemplo fehaciente y estimulante de la posibilidad que cada uno se construya su propio conjunto sonoro. Podemos considerar que en este aspecto coincide con François Baschet, pero divergen en el sentido que éste se esfuerza a disponer todos sus conocimientos para animar a que otras personas los desarrollen -tanto en el campo instrumental como en el de la escultura-, y se dedica a crear una variadísima gama de objetos sonoros pensados para que los pueda tocar todo el mundo.

Veamos donde están las bases históricas y conceptuales que permitieron a los hermanos Baschet desarrollar tales propuestas. Después de participar activamente en la resistencia francesa durante la segunda Guerra Mundial, se dedicaron al estudio concienzudo de todas las fuentes históricas disponibles sobre teoría acústica, desde los clásicos griegos a Chadlni, Rayleight, Bouasse, y de todo lo que se relacionara con la organología. Y se dedicaron a la tarea de aplicar los conocimientos que adquirían a un nuevo tipo de objeto sonoro, uniendo los mundos de la física acústica, de la música y de la escultura. Modelando forma y sonido fueron pioneros de lo que ellos mismos bautizaron como "Escultura Sonora", y que constituyó un gran impulso para lo que posteriormente hemos llamado Arte Sonoro.

Estos inicios se dieron en el contexto, y con una sensibilidad semejante a los posicionamientos de escucha propuestos des del mundo 
de la música electroacústica, el trabajo con los sonidos del paisaje sonoro y las concepciones experimentales y otras nuevas ideas de después de las vanguardias de la primera mitad del siglo XX. Bernard Baschet trabajó con Pierre Shaffer en el Groupe de Recherches Musicales de París en el "Tratado el Objeto Sonoro" (Shaffer, P., 1966). La avidez de esa época hacia nuevas sonoridades y nuevas maneras de concebir la música, se manifestó en los hermanos Baschet en la búsqueda de las posibilidades de lo acústico, palpable y realizable de manera instrumental. Desde 1954 hasta hoy en día, han consolidado determinadas configuraciones y aplicaciones, para usos y usuarios, o intérpretes, que fueron evolucionando en función de las necesidades que ellos mismos observaban como artistas y fruto de colaboraciones con músicos y compositores.

Su novedoso enfoque para la comprensión de la física acústica, de los agentes y procesos involucrados, las capacidades y las combinaciones posibles entre estos elementos- aportan una comprensión singular de los instrumentos conocidos y los sonidos producidos, y los que todavía están por inventar. Una comprensión con una combinatoria abierta tanto por el lado de la física hipotética y posible, como por el lado de la interacción musical como hecho comunicativo, social. Hoy en día, estas concepciones -modulares, fractales, rizomáticas- todavía no se han agotado tras sesenta años de investigación, desarrollo y aplicación.

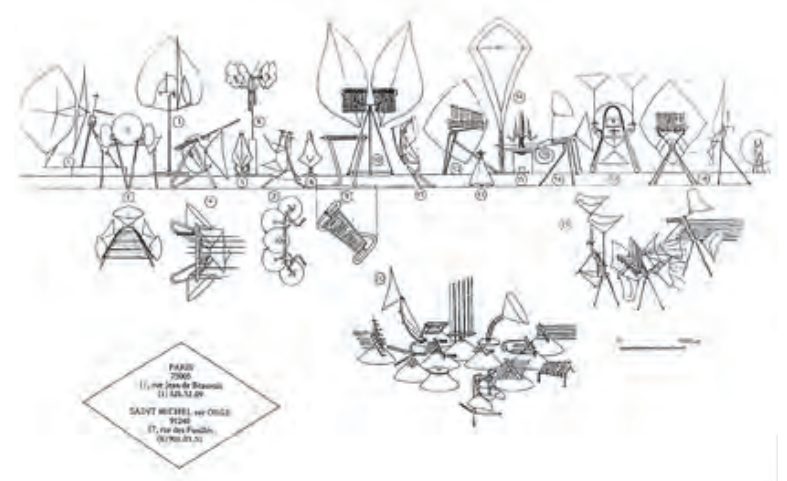

Figure 1. Dibujo de los hermanos Baschet. Por catalogar. 


\section{Martí Ruiz \& Robert Ruiz - Escultura Sonora Baschet}

Muchas de ellas se pueden considerar percusiones, desde idiófonos innovadores, a estructuras complejas que exploran todo tipo de registros y texturas sonoras, percusiones multitímbricas, melódicas, accesorios modulares para añadir resonancias y reverberaciones. La idea de inventar aplicaciones para transmitir las vibraciones internas de los materiales al aire, encontramos una gran variedad de formas con un enfoque escultórico del trabajo en metal, cartones y fibras, para la construcción de difusores en infinitas variaciones formales, planchas tensadas, plegadas, torsionadas, recortadas, cónicas, que modulan el sonido a la vez que lo hacen audible. Estos difusores característicos se unen a otros sistemas acústicos de altavoces inflables, cilindros y tubos plegables.

Para resumir el abanico de aplicaciones puestas en juego por las ESB mencionaremos la existencia de las variaciones recombinadas de los principios de pianos y teclados, cuerdas -guitarras, violines, violoncelos, contrabajos, salterios, arcos y slides-steel, arpas- e incluso instrumentos de viento. Destacan innovaciones como resonadores acústicos para la voz -familia de la Tôle à Voix- así como el trabajo también extenso de molinos y fuentes sonoras, estructuras que pueden combinar la participación, con automatismos físicos eólicos e hidráulicos, que abren otra vía de aproximación hacia el arte ambiental.

Especialmente las piezas pensadas en términos más instrumentales permiten la interpretación de de todo tipo músicas: arreglos de composiciones conocidas o tradicionales, así como nuevas músicas compuestas o improvisadas y experimentales. En numerosos casos para películas, en colaboraciones con artistas como Jean Cocteau, Alexander Calder y Toru Takemitsu.

Los hermanos Baschet han esbozado una clasificación de su propia obra en: Esculturas, Instrumentos, Estructuras y elementos pedagógicos. Aun así, en sus textos y hablando con ellos, nos insisten que se trata de una clasificación aproximada en base a la función o emplazamiento que se le dé a un objeto, y la casi totalidad de sus creaciones puede asumir cualesquiera de estas cuatro funciones.

Habitualmente han rehusado establecer estrictamente esta clasificación, dado que precisamente han intentado borrar dichas fronteras conceptuales. A causa de esta naturaleza múltiple en numerosas ocasiones los Baschet han tenido que luchar para que sus 
creaciones fueran aceptadas como instrumentos en contextos musicales y como esculturas en contextos expositivos.

Esta interdisciplinariedad, enfrentada a una mentalidad clasificadora demasiado recelosa, les llevó incluso a protagonizar litigios memorables análogos al famoso proceso Brancusi. En el caso del gran escultor rumano, sus piezas debían pagar para entrar en los Estados Unidos como materiales industriales, al no ser reconocidas como esculturas por los "críticos" funcionarios de aduanas, incapaces de valorar la abstracción vanguardista de lo que tenían ante sus ojos. En el caso Baschet, al trasladar sus piezas para ser expuestas en la galería Waddell y en el Moma de Nueva York, se encontraron con que la ley norteamericana establecía que una obra de arte no podía tener ninguna utilidad ni aplicación, de manera que las piezas Baschet debían tributar como instrumentos musicales, o sea productos comerciales de consumo y no como obras de arte. Ante esta clasificación impositiva, Alfred Bar, director del Moma, impulsó una campaña respaldada por otros artistas e intelectuales para cambiar la ley y actualmente podemos encontrar la "Enmienda Baschet", que permite que una escultura ofrezca alguna utilidad instrumental.

\section{Participación y Accesibilidad universal en la Escultura Sonora} Baschet

El desarrollo de los primeros prototipos y modelos definitivos Baschet -algunos de ellos clasificables como esculturas, otros como instrumentos musicales- permitían que cualquiera persona pudiera hacerlos sonar sin necesidad de una aproximación técnica previa. Estos objetos sonoros experimentales, fueron expuestos como una invitación para que los visitantes pudieran hacerlos sonar. Por ello, desde muy al principio, las ESB repararon en la importancia accesibilidad, en facilitar su uso a toda persona que quisiera hacerlas sonar.

Entre sus más destacados hallazgos en la investigación de sistemas y materiales generadores de sonido y su modulación, destaca la familia de los llamados "Cristales Baschet". Esta familia, no solo integra una gama de instrumentos cromáticos y diatónicos, sino que se encuentra en el cenit de la combinación de investigación acústica y la voluntad de 
accesibilidad. El principio del Cristal, aplicado a instrumentos y esculturas, permite que cualquier persona genere un sonido puro y bien definido sin necesidad de entrenamiento técnico previo, con una gran respuesta dinámica a la acción del tacto, siendo por ello apreciado tanto por músicos especializados como por todas las personas que acceden al potencial de una acción sonora muy rica y expresiva. (Figura 2)

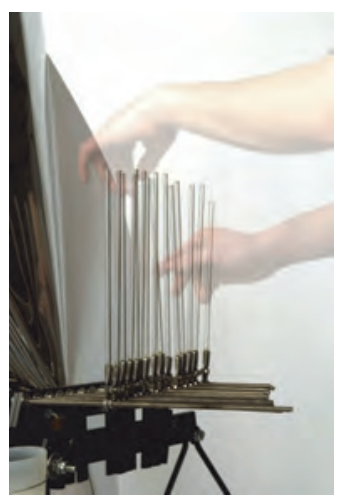

Figure 2. Detalle de las varillas de vidrio de un Cristal Trombón. Foto Vicent Matamoros, 2010.

La elección del sonido como eje de trabajo, lleva consigo un potencial de observación y contemplación implícito, así como una dimensión comunicativa que conduce la obra de los hermanos Baschet a desarrollar una especie de "filosofía de la participación". El conjunto de la ESB se basa en hacer posible que cuantas más personas tengan la oportunidad de experimentar y gozar del sonido, y a la vez plantea oportunidades para la colaboración en situaciones creativas o pedagógicas entre personas procedentes de ámbitos muy distintos. Empezando por ellos mismos: dos hermanos que trabajan en colaboración respetando sus diferencias y sumando sus capacidades, para llegar a un punto significativamente distinto de lo que producirían sus trabajos por separado. Partiendo de esta relación, sus colaboraciones se ramifican en todas direcciones, inicialmente con músicos, intérpretes y compositores, para desarrollar los primeros experimentos y las primeras muestras y conciertos como en su primera muestra en 1963 en el Musée des Arts Décoratifs de París y con exposiciones sorprendentes e interactivas cualificadas como Hands $\mathrm{On}$. Se requiere que el visitante a la exposición interactue. Las piezas tienen unas propiedades que el 
visitante puede y debe explorar, para que la obra se manifieste en su naturaleza sonora. Esta filosofía participativa diríamos que fluye huyendo del clásico concepto expositivo "se ruega no tocar" para invitar con un provocador "Please Play!"

En todo su trayecto intelectual, creativo y de producción artística, los hermanos Baschet manifiestan el propósito de generar un arte para todos los seres humanos sin excepción. Un arte del cual nadie pueda estar excluido, del cual ninguna persona por ninguna condición singular pueda dejar de disfrutar. Un arte no elitista, no "selectivo"; un arte que -visto desde los actuales logros en derechos de las personaspodríamos calificar como "arte inclusivo", flexible, que proporciona oportunidades para que cada persona pueda acceder y participar a su manera.

En algunos casos, la obra de los hermanos Baschet, se genera a partir de un propósito explícito de facilitar el acceso a la obra por parte de algún colectivo de personas con discapacidad. En este sentido hay que destacar su enorme curiosidad y su atrevimiento hacia nuevos retos. Esto les lleva en 1966 a aceptar la propuesta de David y Eléonore Hays de participar en el National Theatre for the Deaf ("Teatro Nacional para los Sordos") de Nueva York. Empezaron las experiencias con los alumnos de mecánica de la New York School for the Deaf, inventando aplicaciones para que las vibraciones sonoras pudieran ser percibidas por el oído interno de personas con daños neurológicos, con apéndices de contacto especialmente diseñados para mandar las vibraciones directamente al cráneo. Para personas con sordera profunda, diseñaron estructuras que pudieran hacer vibrar el suelo, a través de los cuales, los ritmos y las duraciones de las frecuencias mas graves pudieran ser experimentados táctilmente. Estas estructuras también pueden ser utilizadas, lógicamente, por todas las personas sin discapacidad.

Esta trayectoria inclusiva se enriquece con exposiciones masivas como la Exposición Universal de Osaka en 1970. De esta manera, con la participación de literalmente millones de personas, los Baschet contaban con la observación de posibles necesidades y estrategias para resolverlas sin menoscabar la naturaleza sonora y plástica de su obra. Paralelamente a las exposiciones, esta actitud lleva a concebir actividades de difusión de todo tipo, desde giras de conciertos a proyectos de construcción protagonizados por colectivos distintos en varios países. (Figura 3) 


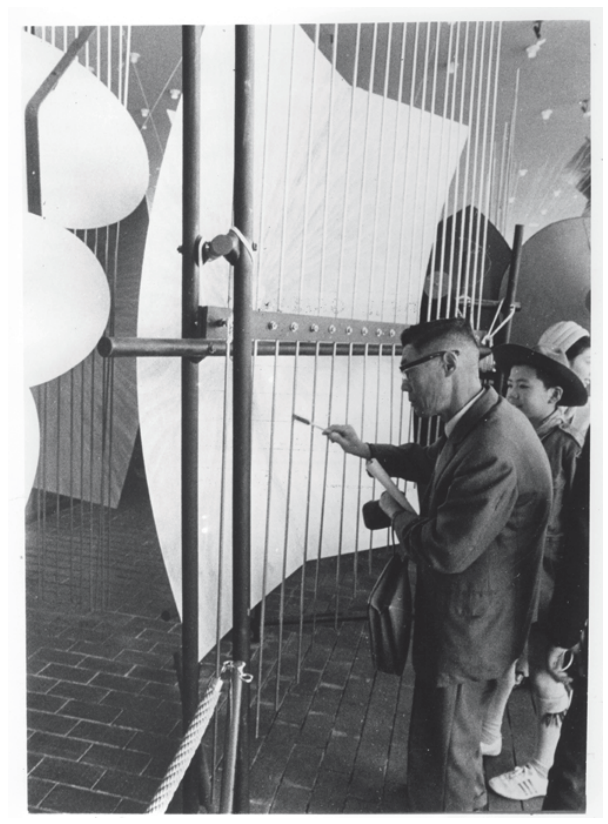

Figure 3. Osaka, 1970. Autor desconocido.

Asimismo, François Baschet, empieza a trabajar en proyectos que permitan no solo la interpretación sonora, sino que inviten a quien lo desee a tomar parte del proceso de construcción de los objetos, aprendiendo el arte de la modificación de los generadores de sonido y su disposición plástica. Publica su libro "Sound Structres" (Baschet,F. 1999, Op.cit.) y otro libro - "Klang Objekte”- sobre la construcción de fuentes, molinos y recursos sonoros activos e interactivos (Baschet, F., Villeminot, A., 1993), de carácter muy práctico, destinado a estudiantes de formación profesional. También proyecta y prueba reiteradamente prototipos de kits de autoconstrucción, una especie de mecano musical, con los que cada cual pueda experimentar con los principios acústicos en la recombinación de unos elementos básicos preestablecidos, a imagen y semejanza de los modelos escultóricos e instrumentales mayores. 


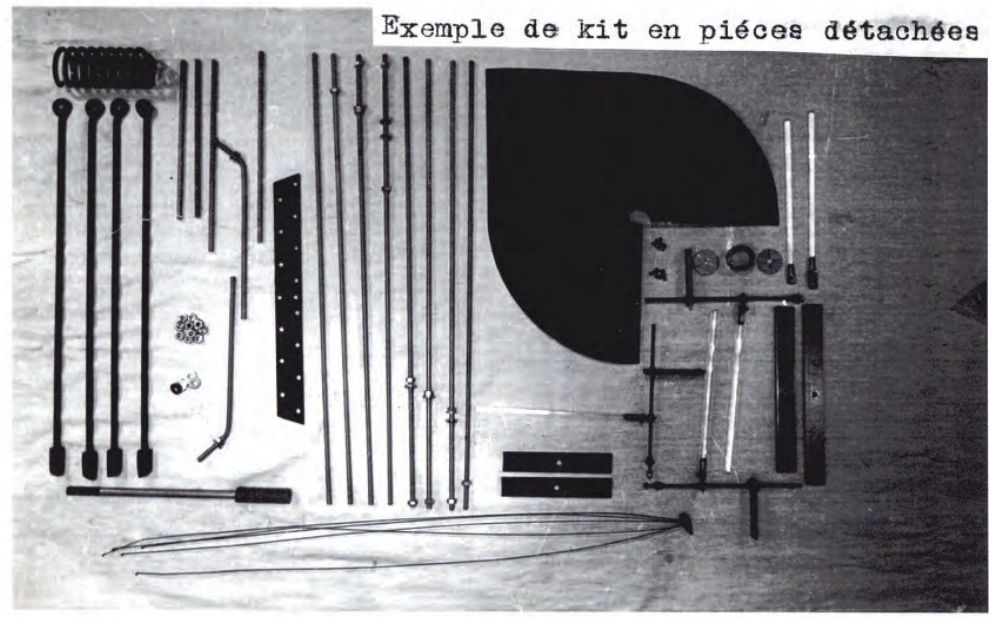

Figure 4. Ejemplo de Kit desmontado. Fotografía por catalogar. Gentileza de François Baschet.

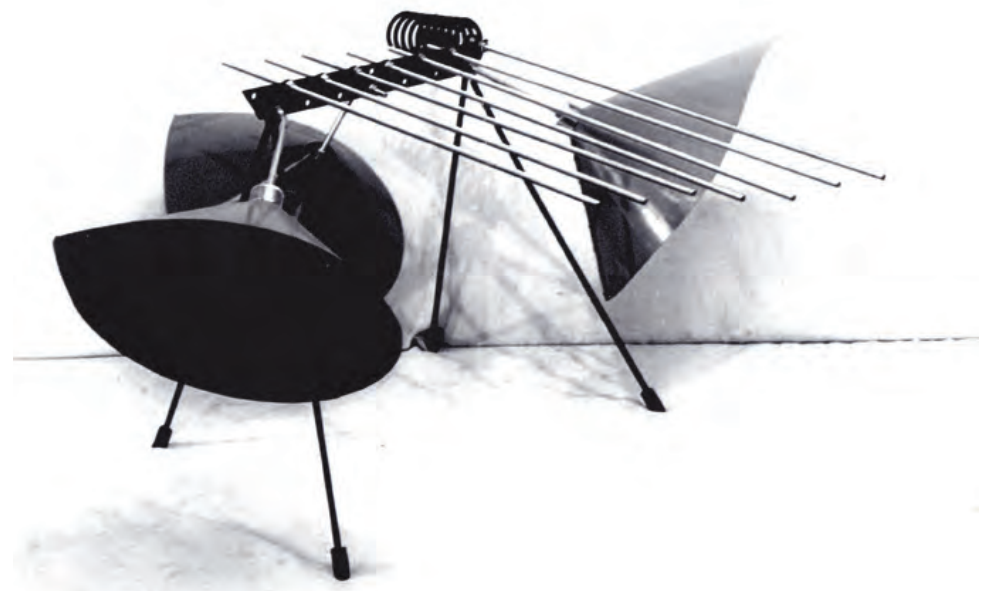

Figure 5. Ejemplo de Kit montado en una de sus posibles configuraciones. Fotografía por catalogar. Gentileza de François Baschet. 


\section{Martí Ruiz \& Robert Ruiz - Escultura Sonora Baschet}

En 1975 la fundación del Museo Guggenheim de Nueva York les propone participar en un programa educativo piloto Learning trhough the Arts, destinado a la reinserción de personas con dificultades de integración social. A partir de esta experiencia, y en colaboración con Alain Dumont y Vincent Baschet, y otros pedagogos empiezan a trabajar en el conjunto de estructuras sonoras del Instrumentarium Pedagógico Baschet (IPB). Un proceso de diseño que tardará diez años en ser considerado completado. Se trata de un conjunto de 14 piezas concebidas como una paleta sonora. Cada una está pensada para ofrecer sonidos diversos entre ellos, sin necesidad de una técnica concreta, y escapando del riesgo de que ningún prejuicio sobre las capacidades con instrumentos convencionales generen desconfianza, evitando un freno muy extendido entre quienes no se consideran músicos. Fueron diseñados para un transporte fácil y poder participar en experiencias en todo tipo de centros en varios países.

La gama de sonidos posibles está dispuesta para poder yuxtaponerse, como lo hace la música moderna, sin arreglo a una tonalidad determinada, sino por otro tipo de criterios que se pueden desarrollar trabajando directamente con los sonidos, tal como hace también la música electroacústica. El concepto fundamental que se manifiesta en el conjunto del IPB es el de favorecer el despertar musical, a través de un recurso con el que poder experimental a un nivel pre musical, para canalizar las experiencias hacia una educación de la musicalidad acorde con el propio proceso de cada uno, nunca sujeto a ideas preconcebidas. Es decir, primero la experiencia y después los conceptos y su organización.

El desarrollo de los objetos se produce en paralelo la creación una metodología pedagógica -un corpus de actividades y estrategias- que ayude a conducir la experiencia propuesta sin inhibir la intuición de cada usuario o intérprete. Las actividades buscan llegar a despertar las capacidades musicales partiendo de escuchar los sonidos que cada uno puede investigar sobre las piezas del IPB, pasando por la escucha lo que tocan otras personas, hasta la experiencia del sonar conjunto, improvisado o auto-organizado. Las condiciones que el IPB proporciona son adecuadas para todo tipo de personas de todas las edades y condiciones físicas y mentales. 
Este planteamiento supone una alternativa para todas la personas que sienten limitaciones ante las pedagogías académicas de la música, que siguen metodologías muy marcadas hacia el desarrollo de un determinado tipo de capacidades y competencias con códigos muy específicos. Cristina Vidal-Quadras de Lewin Richter ha trabajado con el IPB desde 1974 en Singapore, Hong-Kong, Melbourne, Bogotá, Sevilla y Barcelona, en varios aspectos de la enseñanza escolar musical interdisciplinaria (artes plásticas, lengua, teatro, danza y terapia). VidalQuadras declara en la página oficial de internet de François Baschet:

Siempre creí que la intuición era fuente de enseñanza creativa. Sufrí, como profesora de música, el tedio de programas de enseñanza inadaptados. En esa época de mi vida, mi trabajo de pedagoga musical me aburría. Debía conformarme a un programa arcaico, en un momento en que la expresión cultural mundial vivía una revolución general. Yo buscaba un método que incluyera la interactividad y la participación de los estudiantes. Al descubrir las estructuras sonoras Baschet, encontré las herramientas que me hacían falta.

Fue en 1974 que me encontré con Bernard Baschet en su taller. Tuve allí la ocasión de estar en contacto y de utilizar, a mi ritmo, las formas extraordinarias, los materiales y todas las vibraciones de aquellos instrumentos, de aquellas esculturas, un universo maravilloso y onírico. Al mismo tiempo, fui iniciada a los métodos terapéuticos y a la filosofía libertaria de Bernard Baschet: "No tenemos un método de trabajo". ${ }^{1}$

El aumento progresivo de la demanda por parte centros de educación especial, escuelas, institutos de acceder a las prácticas con el IPB dan lugar a la creación de la asociación Structures Sonores et Pedagogie, en 1981, dedicada a la construcción, comercialización del IPB así como de actividades de formación para educadores que pudieran aplicar y extender los métodos propuestos. Fueron convocados por la Cité de la Musique, el IRCAM o el Conservatoire National Superieur. Bernard Baschet y Romain Pomedio trabajaron con dedicación durante ocho años con chicos autistas. Magali Viallefont realizó la tesis doctoral 
Qu'apporte la practtique musical à la gestualle des handicappés. El canal de televisión franco-alemán Arte produjo Sprachloss, un documental muy significativo, precioso testimonio del trabajo con el IPB de Bernard Baschet y Pomedio.

Paralelamente a los desarrollos con el IPB, las colaboraciones de François Baschet con escuelas, institutos y centros de formación profesional han dado buenos resultado también en el Estado Español, con la experiencia de Fuentes de Madrid 88. En Cataluña con las premiadas experiencias de investigación y construcción con alumnos de Secundaria del Instituto IES Castellar de Vallès, en colaboración con el profesor de Ciencias Miquel Calvet.

Todo ello configura el rico marco de acción del conjunto de la ESB, que no se limita a lo convencionalmente asociado al arte, a la música o al diseño, sino apostando por la investigación y la pedagogía como manifestación de un pensamiento inclusivo destacable.

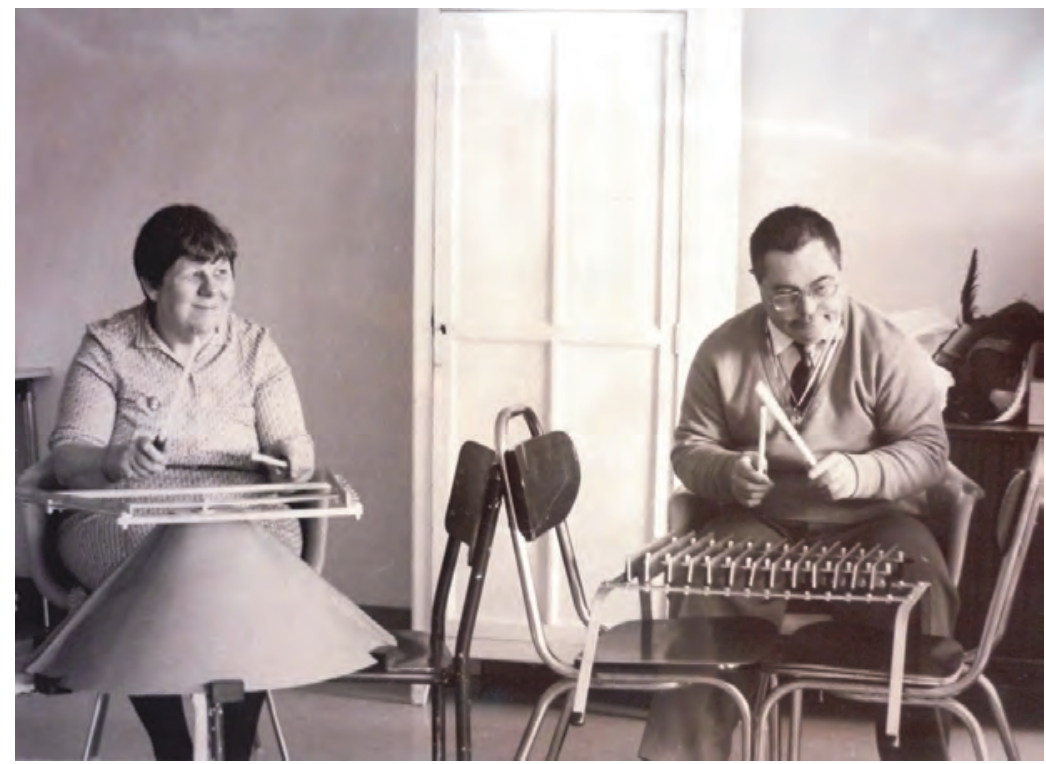

Figure 6. Foto inédita por catalogar, autor desconocido. Facilitada por Bernard Baschet y SSP, circa 1970. 


\section{Introducción a los Conceptos Básicos del Universal Design}

Conviene ahora recordar algunos de los aspectos clave del enfoque del Universal Design -Diseño Universal o Diseño para todos-, para poder efectuar un análisis como el propuesto en el presente artículo.

En linea con los avances en los derechos civiles y los grandes movimientos para acercarnos a la igualdad social en todos los terrenos durante el siglo XX, en los que la podemos incluir los posicionamientos de las hermanos Baschet, hemos querido abrir una mirada que englobe los principios de lo que se ha llamado Universal Design (UD), y que consideramos un conjunto de propuestas e intenciones valiosas, que por fortuna han ido emergiendo, tomando forma $\mathrm{y}$ ampliando sus implicaciones en cada vez mas ámbitos de acción. La intención de UD es la de dar accesibilidad al mayor número de personas sin discriminación alguna por sus condiciones y capacidades, a oportunidades para una desarrollo personal digno y equitativo.

Ron Mace, y sus colaboradores (arquitectos, diseñadores de productos, ingenieros e investigadores en diseño de entornos) definieron el Universal Design como:

El diseño de productos y entornos utilizables por todas la personas, en la mayor amplitud posible, sin la necesidad de posteriores adaptaciones o diseños especializados. (Conell et al., 1997)

En un inicio, esta perspectiva nació de la necesidad de construir edificios y espacios públicos para que fueran accesibles a las personas con discapacidad, empezando en 1973 en Carolina del Norte, y extendiéndose al resto de estados con la ley Americans with Disabilities Act de 1990: ADA, en 1990, sobre derechos de accesibilidad de estas personas a estos entornos.

Sin embargo, y lógicamente, la preocupación por el acceso de estas personas, generó entornos y edificios accesibles a personas que, sin discapacidad, hubieran podido tener dificultades para acceder a ellos por causa de otras condiciones personales. 
En el Estado Español, la Ley 51/2003 define los conceptos de «accesibilidad universal» y «diseño para todos» en los siguientes términos: ${ }^{2}$

c) Accesibilidad universal: la condición que deben cumplir los entornos, procesos, bienes, productos y servicios, así como los objetos o instrumentos, herramientas y dispositivos, para ser comprensibles, utilizables y practicables por todas las personas en condiciones de seguridad y comodidad y de la forma más autónoma y natural posible. Presupone la estrategia de «diseño para todos»y se entiende sin prejuicio de los ajustes razonables que deban adoptarse.

d) Diseño para todos: la actividad por la que se concibe o proyecta, desde el origen, y siempre que ello sea posible, entornos, procesos, bienes, productos, servicios, objetos, instrumentos, dispositivos, o herramientas, de tal forma que puedan ser utilizados por todas las personas, en la mayor extensión posible.

De esta forma la legislación española concreta una forma de asumir el UD en nuestro contexto jurídico de manera complementaria al propósito de accesibilidad universal permitiendo y propiciando los procedimientos de UD basados los iniciales principios de acción.

Tenemos pues que destacar con entusiasmo que los principios pensados inicialmente para dar mayor grado de accesibilidad en lo arquitectónico, se hayan considerado relevantes para otro tipo de diseños y servicios. En esta expansión hay un hecho contrastado ampliamente y que resulta imprescindible no pasar por alto porqué atañe a todo el mundo: Una mayor accesibilidad no solo constituye un progreso para las personas a quien va destinada originalmente la adaptación, sino que el resto de personas también pueden verse beneficiadas por ella. El camino de la inclusión y la atención a la diversidad favorece a todos en mayor o menor medida. Esto genera un marco con una voluntad no segregadora.

Estos principios han sido ampliamente difundidos desde su formulación por Ron Mace y sus colaboradores, en 1997: 
1. Uso equitativo: Lo diseñado proporciona los mismos significados para todos/das, eliminando posibles estigmatizaciones garantizando la equidad y a través de diseños atractivos para todos los/las usuarios/as.

2. Flexibilidad en el uso: Posibilidad de elección de formas de uso. 3. Uso simple e intuitivo: No implica complejidades innecesarias y ofrece retroalimentación positiva durante y después de las tareas.

4. Información perceptible: Aporta contrates entre lo esencial y lo secundario a través de información multi-modal, redundancias.

5. Tolerancia al error: lo diseñado minimiza efectos aleatorios y advierte de posibles errores.

6. Bajo esfuerzo físico: Lo diseñado ayuda a mantener posiciones adecuadas, proporciona una utilización a partir de un esfuerzo físico razonable y minimiza las acciones repetitivas y continuada.

7. Tamaño y espacio para el uso apropiado: Aporta líneas claras de visión, posición cómoda y posibilidad de atenciones individualizadas. (Conell et.al. Op.Cit)

Existen recursos para la evaluación de la medida en la que un producto, un instrumento musical, por ejemplo, se ajusta a estos siete principios; recursos pensados para la evaluación de la adecuación de productos a los siete principios del UD. Para efectuar nuestro análisis tentativo, nos basaremos en algunos aspectos propuestos por la North Carolina University como indicadores de cualidades como algunos puntos de referencia.

Las coincidencias democratizadoras entre los ideales de los Hermanos Baschet con la línea de lo propuesto inicialmente por Mace parece que confluyen en tanto que los principios del UD se extiende internacionalmente, con el paso del tiempo e implementándose en ámbitos como el Universal Instructional Design o el Universal Design for Learning. Es decir que las actividades y los recursos para el aprendizaje se plantean desde los mismos principios de UD.

El siguiente hito que debemos destacar en este proceso histórico, por las implicaciones enormes que tiene en el Estado Español, es la aparición por ley de los principios de UD en el marco de las enseñanzas universitarias. Vemos con esperanza esta ampliación del marco de 


\section{Martí Ruiz \& Robert Ruiz - Escultura Sonora Baschet}

aplicación, cómo desde las Universidades y la administración pública se quiere promover unas condiciones de igualdad de oportunidades, en todo los terrenos que sea posible. De alguna manera podemos ver en estos cambios, coetáneos de tantas otras realidades antagonistas actuales, como una línea progresista en la que se puede inscribir totalmente los principios fundamentales de ESB. I el IPB. Sería muy interesante estudiar cronológicamente la relaciones de influencias recíprocas que se hayan podido suceder entre estos movimientos de lucha contra la exclusión social, por la igualdad social, la accesibilidad universal, y las actividades llevadas a cabo por los Hermanos Baschet. A nosotros nos parece ver en ella el signo de los tiempos, hacia una sociedad cooperativa, tolerante y civilizada, que respeta la diversidad.

En este sentido, vamos a tomar el diseño y los usos del IPB para constatar hasta qué punto llega la coincidencia de criterios con el UD, dando por sentado que los hermanos Baschet empezaron sus exposiciones participativas en los años sesenta, sus actividades deliberadamente inclusivas en 1975 y el diseño del IPB no acabó hasta 1985, todo ello antes de la formulación legal impulsada por Mace en los años setenta para la arquitectura y extendida a todos los ámbitos en 1990.

\section{Algunas cualidades del Instrumentarium pedagógico Baschet, consideradas desde la perspectiva de los principios del UD}

Las 14 piezas del Instrumentarium, con las acciones y actividades que permiten, reúnen un gran potencial combinatorio que lo hace altamente accesible, facilitador de la participación de toda persona y, por tanto, posee un alto valor -a nuestro entender- para la creación de entornos inclusivos de práctica musical e inclusivo. Particularmente si se entiende este Instrumentarium no pieza a pieza sino como conjunto. Este primer ensayo analiza el conjunto, contando con las propiedades de cada pieza, pero sin entrar en detalles en términos de diseño industrial ni de las actividades que permite o no permite cada pieza por separado. (Figura 7) 


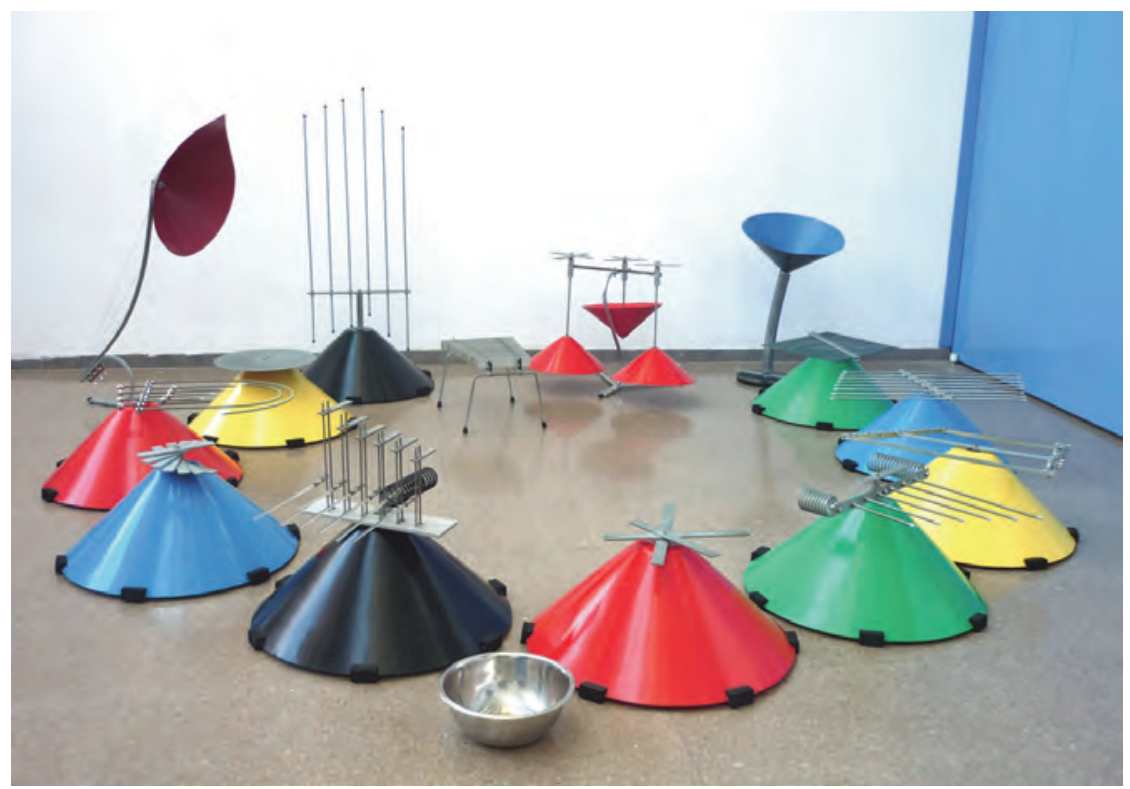

Figure 7. 14 piezas que conforman el Instrumentarium Pedagógico Baschet, gentileza de Andreu Ubach. Foto: Martí Ruiz.

Tomamos el IPB como tema de reflexión específico dentro del campo de la ESB por ser, a nuestro entender, un destacado ejemplo de propuesta inclusiva en lo que al Arte Contemporáneo se refiere. Sus concepciones respecto a la función social del arte no solo les llevaron a ser pioneros de un arte cuyo público no es un tipo de persona en concreto, sino que conciben un arte que pueda hacerse cercano y apropiado por cualquier persona, sea cual sea su bagaje cultural. Esta concepción participativa, de la escultura sonora y del arte en general podría haber quedado en este punto como un hito en esta macrotendencia hacia la interactividad, hacia la transversalidad, y lo multidisciplinario. Pero su postura radicalmente democratizadora les llevó a ahondar en las posibilidades de lo relacional al combinar las grandes exposiciones $H A N D S O N$ y las giras de conciertos, con la publicación de libros y la generación de recursos y actividades, lúdicas 


\section{Martí Ruiz \& Robert Ruiz - Escultura Sonora Baschet}

y pedagógicas, para extender y compartir sus hallazgos. De este posicionamiento llevado hasta las últimas consecuencias aparece el IPB, con una plena consciencia de sus implicaciones: Bernard Baschet asegura que en cuanto empezaron a trabajar cada vez más en su dimensión pedagógica e inclusiva, sabían que determinados ambientes y grupos de galeristas, coleccionistas y críticos dejarían de interesarse y de darles repercusión mediática, pero que aun así sabían que valía la pena. En parte fue así. A nuestro juicio, el gran reconocimiento internacional todavía no ha llegado. Pero como intuían los hermanos Baschet desde el principio de su compleja, expansiva y paciente carrera artística, hoy en día nuevas generaciones reconsideran la función social del arte, las relaciones entre arte y ciencia, y tanto las ESB como el IPB cada vez son más conocidos.

Como hemos visto, el proceso de diseño y adecuación del IPB duró prácticamente diez años, de 1975 a 1983. Durante este proceso se buscaron una formas y disposiciones singulares, configuraciones distintas de las utilizadas en el resto de la ESB. Los principios acústicos Baschet para obtener distintas sonoridades con un grupo limitado de materiales y formas físicas, se ponen al servicio de unos condicionantes de accesibilidad, resistencia y simplicidad.

El espíritu investigador y lúdico de los Hermanos Baschet se había podido transmitir a millones de personas que asistían a sus exposiciones y descubrían el sonido de sus Esculturas. El IPB nació para conectar con la curiosidad habitualmente característica de la infancia. Admirados al ver como algunos principios de la pintura abstracta habían sido extendidamente asimilados en la educación plástica infantil, disponiendo las herramientas para experimentar con libertad. Los Baschet entendieron que su vocación participativa debía aprovechar esta apertura pedagógica para una propuesta de calado menos anecdótico que una exposición. Fundir el juego y el descubrimiento de unos sonidos con una pedagogía activa, que permitiera a cada persona tomar consciencia de sus capacidades y de las posibilidades del sonido a partir de sus propias experiencias. En Palabras de Bernard Baschet: "Hemos querido poner colores sonoros a disposición de los niños y darles libertad de tocar sin reproducir." (Baschet, B., 1988, citado por Bousquet, F. y Ubach, A., 2008, p.133) 
El conjunto del IPB pensado para dar acceso a los niños, con el tiempo se ha demostrado absolutamente apropiado para cualquier otra franja de edad. Por ello, podríamos considerar que la su accesibilidad fomenta situaciones inclusivas, con grupos de participantes o usuarios con capacidades y características muy dispares. "...éste permite responder a las expectativas de usuarios diferentes, desde la primera infancia a las personas de mayor edad, pasando por los adolescentes y los adultos, con diferentes niveles de estructuración personal, y en el seno de diversas instituciones". (Baschet, B., 1988, citado por Bousquet, F. y Ubach, A. p.133) Así como el trabajo con "Medios especializados, personas con necesidades educativas especiales"(Baschet, B., 1988, citado por Bousquet, F. y Ubach, A. p.142)

La amplia accesibilidad y sus atractivas cualidades le confieren un alto grado de capacidad de facilitar la participación de todos/as, con actividades que hoy en día podríamos llamar "multinivel". Esta particularidad hace del Instrumentarium un conjunto muy abierto. Lejos de ser un recurso especialmente diseñado para personas con discapacidad, que quizá podría tener un uso en una contexto segregado, se muestra como un conjunto verdaderamente inclusivo, siguiendo la estela de la experiencia de las exposiciones de participativas HANDS ON con "Públicos heterogéneos". (Bousquet, F., Ubach, A., Op.cit., p.143)

Esta línea de pensamiento, de permanente replanteamiento de las posibilidades, como hemos mencionado, se manifiesta tanto en las características formales del IPB como en la metodología propuesta por la SSP en una "sucesión de actividades renovadas constantemente descubrimiento, exploración, producción, composición, codificación e interpretación-..." (Bousquet, F., Ubach, A., Op.cit., p.139)

La intención de propiciar el despertar de las capacidades musicales, puede dar paso a otros aprendizajes interpretativos, juegos interdisciplinarios y de educación de la escucha. Así lo atestigua la notable suma de instituciones enumeradas por F. Bousquet, colaborador de los Hermanos Baschet, formador y actual constructor del IPB: más de 500 instituciones educativas, de carácter asistencial, musicales, etc., han adquirido el IPB. ${ }^{3}$ Actualmente la SSP continua realizando las formaciones para el uso del IPB y mantiene contacto con todas las instituciones y particulares que lo usan. 
El conjunto está pensado como la suma de texturas sonoras, de posibilidades de modulación del sonido. Todos los generadores de vibraciones son metálicos. La mayoría de piezas cuentan con un un difusor en forma de cono de fibra y resina, o de cartón rígido, muy resistentes, de colores vivos y contrastados.

Para quienes no hayan podido escuchar y tocar el IPB, describimos brevemente cada una de las piezas.

1. Estrella: Tres láminas horizontales colladas asimétricamente generan seis longitudes vibrantes que producen sonidos llenos no muy largos, con ataque definido. (Figura 8)

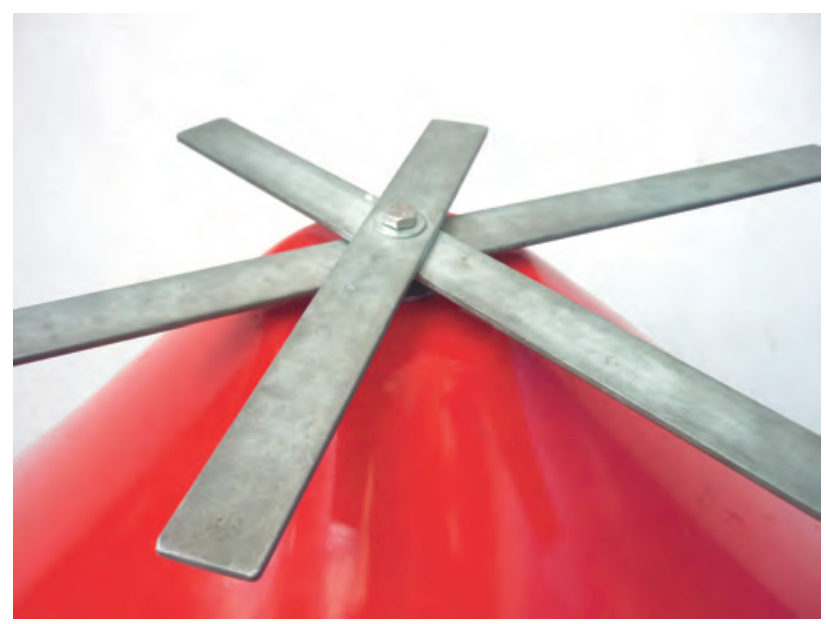

Figura 8. Detalle de Estrella. Foto Martí Ruiz. Pueden escuchar una muestra en http://www.structuresonore.eu/tabid/66/Default.aspx

2. Disco: Un disco metálico relativamente flexible, dispuesto en horizontal, collado asimétricamente. Puede generar sonido largos y profundos como un gong. Permite la modulación en altura de los sonidos al tensionar y doblar el disco. ${ }^{4}$

3. Candelabro: Seis barras largas dispuestas en vertical generan sonidos largos y complejos, un poco como campanas. Los extremos cortos del 
las barras, que sobresalen por debajo del puente producen seis sonidos más cortos -pero profundamente reverberados por simpatía- de alturas muy distintas. ${ }^{5}$

4. Doble Muelle: Teclado multitímbrico horizontal compuesto por 6 barras corta de diferentes longitudes, y una lámina collada asimétricamente formando dos longitudes vibrantes de sonidos cortos, conectadas a dos muelles que pueden ser percutidos, o vibrar libremente para añadir reverberación al resto de sonidos. Se puede parar la vibración de los muelles y constatar táctilmente la acumulación de energía acústica en las reverberaciones de muelles. ${ }^{6}$ (Figura 9)

Figure 9. Detalle de Dos Muelles. Foto Martí Ruiz.

5. Barras curvas: Teclado multitímbrico horizontal compuesto por dos barras largas curvadas que generas sonidos largos, junto con otras 8 barras cortas de diferentes longitudes -4 con pesos en los extremos y 4 en puntos nodales- generan sonidos complejos con ataques reverberados por la simpatía del conjunto. ${ }^{7}$ 
6. Barras rectas: Teclado horizontal compuesto por 8 barras de longitud media, dispuestas para producir sonidos de diferente altura moderadamente reverberados. ${ }^{8}$

7. Escalera: Seis láminas de longitudes decrecientes, colladas en espiral simétrica, ofrece dos teclados helicoidales iguales, de sonidos densos, llenos de frecuencias medias, con ataques notables y una resonancia corta. ${ }^{9}$ (Figura 10)

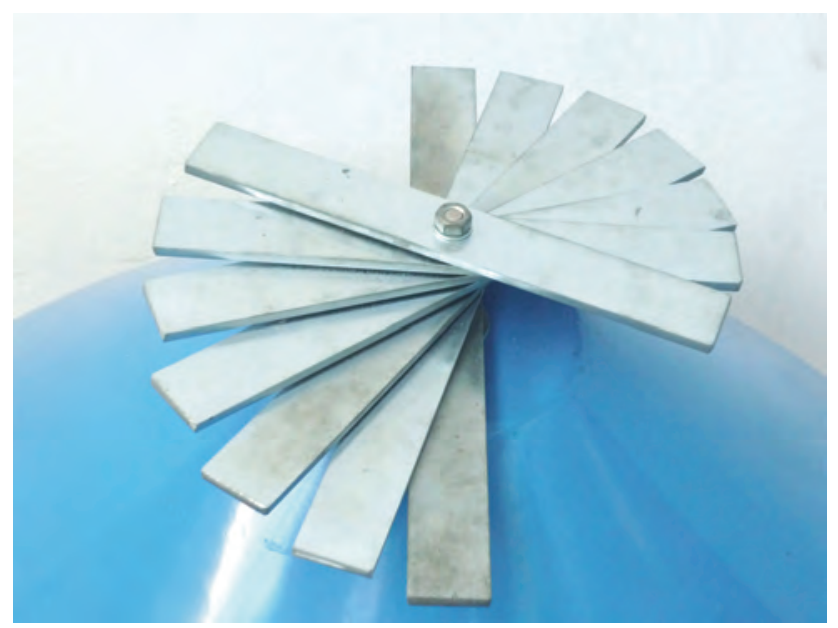

Figure 10. Detalle de Escalera.

8. Cuerdas: Sistema semejante al arpa o salterio horizontal de 8 cuerdas metálicas, reverberadas por simpatía, con ataque variable según el percutor, plectro o dedos, afinable, con capacidad para "vibratos" al tensar el marco puente. Ofrece sonidos largos, brillantes y limpios. ${ }^{10}$ 9. Arco: 3 cuerdas metálicas fijadas a un arco flexible que se pueden tocar como un arpa, como un berimbau o frotando con un arco. De todos modos produce sonidos largos, muy sensibles a la tensión variable que se puede aplicar al arco para cambiar la altura de notas con orgánicos glissandi. ${ }^{11}$ 
10. Parilla: 25 barritas finas de metal horizontales, con pequeñas diferencias de longitudes reparten el ascenso o descenso de la frecuencias en pequeñas fracciones. Cada sonido se enriquece por la reverberación del conjunto. ${ }^{12}$

11. Muelle: Un muelle largo muy flexible y una lámina en la base, sonando a través de un cono de cartón suspendido en el extremo. El sonido del muelle largo y reverberado se puede detener al tacto. La lámina de sonido corto suena reverberada a través del muelle. Ofrece una gran variedad de sonidos en función de la forma de hacerlo sonar -percutiéndolo o frotándolo con las manos, con baquetas de distintos materiales, etc-. Añade el factor de la movilidad, dado que la base es muy pesada y el extremo del muelle con el cono puede bascular y girar libremente, desplazando ostensiblemente la direccionalidad del sonido. ${ }^{13}$

12. Silvante: 13 láminas de dural de longitudes decrecientes, suspendidas para vibrar libremente al ser estimuladas por el extremo estrecho, produciendo sonidos brillantes de altísima frecuencia y notable longitud. No necesitan cono difusor. ${ }^{14}$

13. Tres Cruces: Tres pares de láminas en cruz, conectados cada uno a un difusor independiente, ofrece los sonidos mas secos y cortos del conjunto. ${ }^{15}$

14. Cristal: Seis varillas de vidrio encastadas al sistema de doble barra metálica del Cristal Baschet. Obtenemos sonidos largos y limpios, sin ataque, gran rango dinámico en función de la intensidad de la presión al frotar las varillas con los dedos mojados. Los sonidos son reverberados simpáticamente por el conjunto y por un muelle, que puede ser percutido, así como los contrapesos del sistema metálico. Afinación determinable y muy estable. ${ }^{16}$

Una vez descritas las principales características del Instrumentarium Baschet vamos a examinarlo, considerando sus características en base a los siete principios de UD.

\section{Uso equitativo}

El conjunto está pensado para ser usado musicalmente, y para facilitar situaciones de aprendizaje, de sensibilización. Desde usos extremadamente básicos, facilita evoluciones y desarrollos interpretativos más sofisticados a los que se puede ir accediendo. 
El conjunto facilita usos puramente lúdicos, escénicos, y de aprendizaje del sonar y de las características de objeto sonoro. Desde el punto de vista constructivo, muestran los principios acústicos con esquemática claridad y facilitan la comprensión de los acontecimientos acústicos.

La gran variedad tímbrica y de tipos de acciones a realizar, abre muchas posibilidades entre las que elegir, siendo muy fácil, por contraste, que al menos alguna de las piezas y sus sonidos resulten atractivos para aproximarse y disponerse a interactuar.

\section{Flexibilidad en el uso}

Puede usarse de acuerdo con las condiciones ideadas y ampliamente investigadas por la SSP y todos sus usuarios, y también de cualquier otro modo. Como objetos sonoros, cada uno de ellos, e incrementando sus potenciales al añadir piezas hasta el conjunto de 14, manifiestan su potencial ante cualquier interacción táctil.

"Se pueden tocar con las manos y también con la ayuda de diversos mediadores (percutor, pelota, pincel, cepillo, hoja...)" (Bousquet, F., Ubach, A., Op.cit., p.130)

Algunas de las piezas se pueden afinar de acuerdo con criterios tonales y de textura, se pueden modificar algunas sonoridades tapando las partes generadoras de la vibración con ropas, añadiendo objetos entre las cuerdas, encima de las barras y láminas, deslizando a lo largo de las cuerdas, y en función de las dimensiones y el materiales de elemento percutor utilizado.

\section{Uso simple e intuitivo}

Todos los elementos utilizados son esenciales e imprescindibles.

No requiere ninguna instrucción determinada para usarlos. Una persona o grupo de personas que no fueran introducidas por las actividades propuestas habitualmente, rápidamente haría su lectura de los elementos dando también resultados personales, que al fin y al cabo es para lo que fueron ideadas.

El uso puede ser especialmente simple por sonar al mas mínimo contacto, con una gran sensibilidad dinámica. El conjunto precisamente busca motivar esa interacción intuitiva, que conduzca a cada usuario a su propio uso según el contexto. La metodología propuesta por la SSP así como toda la filosofía de la participación de la ESB buscan 
amplificar esta aproximación, accesibilidad, a la intuición musical.

La no-correspondencia formal con instrumentos de música conocidos así como la accesibilidad directa al mundo sonoro permiten una desinhibición rápida en el participante, que accede a una expresión sonora directa a través del instrumento.

(Bousquet, F., Ubach, A., Op.cit., p.131)

El sonido rico y claro del Cristal se produce fácilmente, cualquier persona que tenga un mínimo de capacidad motriz, puede generar esos sonidos imposibles de conseguir con ningún otro instrumento acústico. Esto es interesante tanto para músicos especializados, para maestros, para cualquier tipo de estudiante o intérprete usuario, con o sin discapacidad. Los principios de las percusiones, las cuerdas, están dispuestos meditadamente para tener el mismo potencial inclusivo.

La variedad de formas y disposiciones de los elementos generadores del sonido posibilita el uso de una amplia variedad de gestos y, "Así, la variedad de gestos inducidos por los teclados favorece el desarrollo psicomotor: horizontal, vertical, curva, circular, eje central, organización continua o particular". (Bousquet, F., Ubach, A., Op.cit., p.133)

Todas las formas cumplen con una función acústica o estructural. No hay ningún elemento añadido para decorar. Todos los sistemas que requieren un difusor, utilizan los conos de fibra como soporte; el Muelle, necesita un soporte pesado para permitir la movilidad del cono, las láminas suspendidas del Silvante requieren solamente de unas patas que las sostengan para vibrar libremente.

Son elementos eminentemente interactuadores, una muestra de unos cuantos principios básicos, siempre listos para la interacción, suenan sea cual sea la aproximación que se realice. Como objetos sonoros intrigantes, particularmente dispuestos, abren sus posibilidades con una claridad total. Son un punto de partida.

\section{Información perceptible}

Las formas simples, reducidas a lo esencial, resultan visualmente llamativas por su diversidad, sus diseños y colores contrastantes, geometrías rectas y curvas, abstractas, y todas ellas funcionales. Las 


\section{Martí Ruiz \& Robert Ruiz - Escultura Sonora Baschet}

dimensiones de cada pieza le dan presencia perceptible, abarcable al tacto con una escala de proximidad y confianza. Incluso en el caso de no poder verlos, las formas, las texturas y las disposiciones de los elementos es accesible y comprensible.

La resistencia de los conos permite también experimentar la vibración táctilmente, tanto si se trata de un usuario con alguna, mucha o ninguna deficiencia auditiva.

\section{Tolerancia al error}

Todos los elementos vibrantes están dispuestos para ser accesibles y sonar con cualquier interacción física con ellos. No hay otra cosa que hacer con las estructuras que ponerlas en funcionamiento. La metodología propuesta -des de la apretura a la escucha y los usos, La observación del fenómeno sonoro, la participación de el mismo- hacen que la idea misma de error no quepa. En algunos usos musicales de interpretación preacordada, y en caso de la libre improvisación colectiva, simple pueden producirse fenómenos o juicios estéticos que uno pueda considerar como un error, eso pertenece al dominio de la música y sus prácticas de ensayo o interpretación, pero no porque el IPB pueda usarse erróneamente. Las funciones acústicas son inmediatas, y no cabe la posibilidad de un uso sin resultados, como sí podría pasar por ejemplo manejando erróneamente una cámara de fotos, de manera que no consigamos captar el aspecto de lo que fuere.

Solamente en el caso Cristal puede suceder que se intente tocar con las manos secas, eso difícilmente produciría ningún efecto. Aun sí, si se dispone un recipiente con agua cerca del Cristal, hay un altísimo número de posibilidades, en función de las capacidades intelectivas del usuario, de hacer sonar el Cristal sin ninguna indicación.

Las partes metálicas no están pintadas ni modificadas, de manera que su tacto y temperatura indican su rigidez. Todos los cantos están redondeados y los extremos de las barras cubiertos por tapones de plástico redondos.

Es poco probable que un usuario se haga daño con el uso o el mal uso. Las varillas de cristales, tienen una resistencia elástica gracias a la lámina acerada que la sostiene, de manera que puede resistir tirones fuertes y golpes. Aún así, es cierto que para cada usuario cabe observar que si hay que tomar alguna precaución por seguridad con respecto al Cristal. 
Si se sigue una introducción guiada, se consigue progresivamente que la toma de contacto con las distintas características de los materiales facilite la formación de una consciencia las posibilidades y los riesgos de cada pieza. Así, con el uso, se descubre el umbral de intensidad con que se puede golpear o frotar una estructura, una información sobre la presión que va unida su consecuente manifestación sonora.

\section{Bajo esfuerzo físico}

Todas las estructuras, decíamos, se pueden usar con un esfuerzo mínimo. Cualquier pequeño gesto aplicado suena, pudiendo trabajar con intensidades débiles, de movimientos y resultados sutiles.

No hay necesidad de hacer esfuerzos. En función de limitaciones de movilidad se puede usar una u otra estructura, y el tamaño de las piezas facilita levantarlas o inclinarlas si es necesario para facilitar una postura cómoda, relajada, que no requiera gestos fatigantes. Se pueden utilizar elementos percutores blandos o ligeros, o tocar con las manos.

\section{Tamaño y espacio para el uso apropiado}

"Están concebidas para ser fácilmente almacenables, desmontables y transportables" (Bousquet, F., Ubach, A., Op.cit., p.130)

Una vez montados, sigue tratándose de un conjunto móvil así que se puede disponer cada pieza como sea mas conveniente, para ser usados en disposiciones personalizadas. Se pueden alzar sobre bancos, cubos o cajas. Pueden ser usados por varias personas a la vez. Los elementos generadores de sonido están dispuestos para ser accesibles en varias posiciones, sentados o tumbados, y en casi todos los casos desde los 360 grados. No hay piezas pequeñas. Las varillas de vidrio están suficientemente separadas como para frotarlas agarrándolas con la mano entera, e incluso frotando con otra parte del cuerpo.

\section{Conclusiones}

Después de esta lectura y reflexión, constatamos que podemos recopilar $\mathrm{y}$ extraer algunas conclusiones, exponer nuevas perspectivas e interrogantes, tanto a nivel pedagógico, constructivo y artístico.

Consideramos muy adecuada esta doble lectura porque permite presentar la ESB y el UD, como dos caminos cruzados, o dos manifestaciones o facetas de unos mismos principios democratizadores 


\section{Martí Ruiz \& Robert Ruiz - Escultura Sonora Baschet}

igualitarios, de atención a la diversidad, que permiten vislumbrar un horizonte prometedor y que se pueden retroalimentar mutuamente.

Constatamos la posibilidad de aplicar exitosamente -como en el caso Baschet, avant la letre- los principios del UD al terreno de los instrumentos musicales, y de otras propuestas interactivas. Constatamos también que se pueden generar condiciones de aprendizaje estimulantes, eficaces y atractivas, desde el arte, desde lo lúdico, personalizables e inclusivas.

La experiencias acumuladas por la historia del IPB constituyen un referente vivo y vívido en lo que refiere a integración social. Podemos aprender de estas iniciativas para enriquecer el resto de campos de la actividad humana en las que haya que implantar o ampliar la inclusividad, la accesibilidad universal.

Consideramos que en gran medida, el IPB cumple con los siete principios del UD. Aunque no se diseñó siguiendo todos sus los parámetros, por imposibilidad cronológica, en términos generales sí cumple con los siete principios por la mera naturaleza del proyecto que representa. Siendo esto así, nos preguntamos, si sería necesario mejorar algunos aspectos del IPB para cumplir completamente con todos los parámetros de los siete principios del UD.

Consideramos la conveniencia de impulsar nuevos estudios. Valdría la pena realizar una serie de estudios pormenorizados evaluando una por una las piezas del IPB, y exponer a Bernard Baschet y la SSP, los resultados, con propuestas concretas que pudieran aumentar el valor educativo en el UD. Estos estudios, deberían abarcar los desarrollos en la pedagogía del arte y estudiar el impacto social, para poder modificar o ampliar aspectos físicos de las piezas, de su uso y metodologías.

Para ello, sería muy interesante poder estudiar los informes de las experiencias que la SSP viene realizando desde el inicio de sus actividades, como por ejemplo las memorias redactadas por Cristina Vidal-Quadras de Lewin Richter. Sería óptimo coordinar esos estudios internacionalmente, en colaboración con universidades e instituciones especializadas en los diversos ámbitos puestos en juego en el IPB y obviamente con la misma SSP.

Al mismo tiempo, entendemos que muchos de estos principios se podrían ver como unas directrices paralelas, sensiblemente sugerentes para la utilización del IPB. 
En lo que atañe a la posibilidad actual de creación de nuevas estructuras sonoras, -y desde el conocimiento de los recursos usados por Baschet que nos aporta la tesis doctoral en curso por Martí Ruiz "Escultura Sonora Baschet: archivo documental, clasificación de aplicaciones para el desarrollo de formas acústicas"-, humildemente nos podríamos plantear añadir algunas estructuras nuevas al IPB, como proyecto a pensar desde los principios del UD:

Diseñar alguna estructura de planchas resonadoras para enriquecer el uso de la voz con el conjunto del IBP, en la línea de la familia instrumental de la Tôle à Voix Baschet. Esta idea surge de la misma noticia del uso de una de estas Tôle à Voix durante las actividades con el IPB, en el taller de Bernard Baschet, sede de la SSP. Dada las características de estas planchas metálicas, haría falta estudiar su modificación para adaptarse al UD plenamente, y reducir su hipotética peligrosidad y optimizar su accesibilidad y manejabilidad.

Podría concebirse algún nuevo elemento incluso de carácter portátil? Actualmente, en el Taller de Escultura Sonora Baschet de la UB, con colaboradores de François Baschet, Jordi Casadevall y Andreu Ubach, entre otros, estamos trabajando en aplicaciones portátiles de los principios Baschet, prototipos inéditos en la historia de la ESB. Además del entusiasmo de François ante el éxito de la aplicación de los principios para nuevas finalidades, constatamos que son muy atractivos para todos los públicos, notablemente manejables, especialmente para niños. ¿Cabría pues la posibilidad de diseñar algunas de estas estructuras para añadir el factor de la movilidad, para enriquecer el trabajo de la espacialidad y el movimiento para los usuarios del IPB, y las nociones de plurifocalidad, tan llamativamente desarrolladas por Llorenç Barber?

Constatamos además, desde el punto de vista de la aprendizaje de la organología y las actividades de construcción, que en el sentido de la transmisión del saber, -del aprendizaje de lo técnico, lo funcional, lo constructivo-, acumulado por los Baschet, el IPB y el conjunto de la ESB- muestra los principios acústicos con una claridad meridiana: enseña, descubre el enfoque de las funciones acústicas del objeto sonoro, descifra el enfoque teórico y aplicado tan característico de Baschet. El IPB no solo sirve para los usos para los que fue pensado, sino que muestra su enfoque de acústica modular que define cualquier 


\section{Marti Ruiz \& Robert Ruiz - Escultura Sonora Baschet}

instrumento: define los tipos de elementos que pueden entrar en vibración, las distintas formas de generar esa vibración, las distintas maneras de alterar estas vibraciones -modularlas en frecuencia, intensidad, expresividad-, y las distintas formas de hacerlas audibles: empezando por de la misma superficie del objeto idiofónico, hasta las sofisticadas formas de transmisión de la vibración hasta pabellones o formas capaces de amplificar y difundir esa vibración al aire o a un medio resonante.

Es cierto que el IPB no recoge todas esas posibilidades imaginables. Solamente utiliza las combinaciones que consideraron mas apropiadas para sus intenciones. Precisamente es esta concepción Baschet de las funciones acústicas, lo que nos facilita imaginar el conjunto de esas posibilidades de construcción e interacción en sus ilimitadas variaciones. Se trata del camino mismo, de la evolución de los objetos sonoros acústicos, desde su prehistórico atávico inicio, perpetuando y redefiniendo las concepciones teóricas, a menudo preservadas por unos pocos. Desde la ESB, y claramente desde el IBP, se da acceso a un gran público que históricamente no ha tenido la ocasión de usar y comprender el uso de las estructuras acústicas, de un modo también nuevo, hospitalario y libre. Y especialmente, por esta diversidad de personas que pueden usar el IPB, mayor es la concienciación hacia la necesidad y lo oportuno de incrementar la accesibilidad, la inclusividad de los soportes, instrumentos y estrategias de comunicación y creación.

Podemos repensar el IBP, podemos repensar otros instrumentos ya existentes, y podemos inventar otros nuevos. Desde el IPB, la información sobre la acústica nos llega inseparable de sus formas de uso, y remarcan un camino hacia otras configuraciones facilitadoras, en función de los pasos que queramos hacer como sociedad cultural.

Y entendemos que cuantas más oportunidades se brinden a colectivos más diversos, mayor será la diversidad resultante de enfoques y aportaciones. Se trata de la comunicación una serie de propósitos y de unos lenguajes -los técnicos constructivos y los lenguajes sonoros nacidos del uso del IPB- que se pueden comprender desde cualquier cultura local, por lo que la sinergia intercultural podría avanzar por caminos empíricos contrastables, sin renunciar a la comunicación noverbal. 
Para terminar, des del punto de vista de la pedagogía de las artes, constatamos la conveniencia de utilizar algunos principios de evaluación objetivables. Desde el punto de vista del Laboratori d'Art Sonor, consideramos favorablemente la posibilidad de usar los propósitos y los parámetros del UD -y su extensión en el UDL, Universal design for Learning-, en nuestra programación docente, en el diseño de nuestros proyectos e investigaciones de construcción. Esto nos da la oportunidad de atender a parámetros clave para estructurar y poner en valor la variadísima cantidad de observaciones a realizar con respecto al uso y los aprendizajes posibles a través del conjunto de la ESB.

En el ámbito de lo creativo abundan intangibles que no necesitan de ninguna evaluación, pero en el ámbito de la pedagogía del arte, entendemos que hoy en día, una postura comunicativa cuanto más inclusiva y multinivel posible sería deseable -especialmente cuando se trate de propuestas interactivas- para no perpetuar la fractura entre artes cultas y artes populares, así como ayudar a acercar el mundo de la cultura y el de la educación.

Con estos principios y criterios en mente, podemos mantener cierto rigor metodológico entorno del ámbito de la intuición y la creatividad, herramientas para la reflexión y la investigación. Desde este punto entendemos que podemos contribuir a una mejora en la calidad de vida culturalmente y favorecer el impacto de las sinergias arte-ciencia en la sociedad.

\section{Notas}

1 (Vidal-Quadras de Lewin Ritcher, C. «Esculturas sonoras Baschet: Cuerpo, Espíritu, Sonido» http://francois.baschet.free.fr/vidal_quadrases.html).

2 (letras c y d del artículo 2 de dicha ley, que encontraran en el Boletín Oficial del Estado http://www.boe.es/boe/dias/2003/12/03/pdfs/A43187-43195.pdf)

3 (http://www.structuresonore.eu)

4 Pueden escuchar una muestra en http://www.structuresonore.eu/tabid/69/Default.aspx

$5 \mathrm{http}: / /$ www.structuresonore.eu/tabid/66/Default.aspx

$6 \mathrm{http}: / / \mathrm{ww} w$. structuresonore.eu/tabid/70/Default.aspx

$7 \mathrm{http}: / / \mathrm{ww} w$. structuresonore.eu/tabid/76/Default.aspx

$8 \mathrm{http}: / /$ www.structuresonore.eu/tabid/77/Default.aspx

$9 \mathrm{http}: / /$ www.structuresonore.eu/tabid/71/Default.aspx 
10 http://www.structuresonore.eu/tabid/67/Default.aspx

11 http://www.structuresonore.eu/tabid/65/Default.aspx

12 http://www.structuresonore.eu/tabid/73/Default.aspx

13 http://www.structuresonore.eu/tabid/74/Default.aspx

14 http://www.structuresonore.eu/tabid/75/Default.aspx

15 http://www.structuresonore.eu/tabid/64/Default.aspx

16 http://www.structuresonore.eu/tabid/68/Default.aspx

Pueden leer más acerca de las características, historia y usos del IPB en

http:/www.er.uqam.ca/nobel/baschet/introduction/index.html

\section{Referencias}

Baschet, B. (1988). L'eveil musical de tout petit. Cahier du CENAM.

París, Edition Centre national d'action musicale.

Baschet, F. (1999). Les Structures Sonores, The Sound Sculptures of

Bernard and François Baschet, Chelmsford, UK, Soundworld

Publishers.

Baschet, F., Villeminot, A. (1993). Klang Objekte. Starnberg, Eberwald. Bousquet, F., Ubach, A. (2008). Sensibilización Musical con Estructuras

Sonoras Baschet. Aproximación a una metodología para el uso continuado del Instrumentarium Baschet en la Escuela Primaria.

Ministerio de Educación, Política Social y Deporte, Secretaría de

Estado de Educación y Formación. Edita Secretaría General

Técnica, Subdirección General de Información y Publicaciones.

Dentro de AA.DD. La competencia artística: Creatividad y apreciación

crítica. (2008). Ministerio de Educación, Política Social y

Deporte, Secretaría de Estado de Educación y Formación. Edita

Secretaría General Técnica, Subdirección General de

Información y Publicaciones.

Conell, B. R., Jones, M., Mac, R., Mueller, J., Mullick, A., Ostroff, E. et al. (1997). The Principles of Universal Design. U.S, The National Institute on Disability and Rehabilitation Research.

Department of Education. NC State University, The Center for Universal Design.

Schaeffer, P. (1966). Traité des Objets Musicaux (versión abrégée)

Editions de Seuil. Trad. del francés Araceli Cabezón de Diego. 
Madrid, Alianza Editorial (Alianza Música), (1998).

Martí Ruiz es Doctorando, Becario de investigación de la Universitat de Barcelona y Profesor de la Universitat de Vic.

Robert Ruiz es Dr. en Psicología y Profesor Titular en la Universitat de Vic.

Contact Address: Carrer Sagrada Família, 7. 08500 Vic, Barcelona. España. Email: gibrel18@gmail.com,robert.ruiz@uvic.cat 


\section{B.RP:AC}

Instructions for authors, subscriptions and further details:

http://brac.hipatiapress.com

\section{El Bulli: Contemporary Intersections Between Food, Science, Art and Late Capitalism.}

Maria Domene-Danés ${ }^{1}$

1) Indiana University, Henry Radford School of Fine Arts, Department of Art History, United States of America.

Date of publication: June 3rd, 2013

To cite this article: Domene-Danés, M. (2013). El Bulli: Contemporary Intersections Between Food, Science, Art and Late Capitalism. BRAC Barcelona Research Art Creation 1(1), 100-126. doi: 10.4471/brac.2013.04

To link this article: http://dx.doi.org/10.4471/brac.2013.04

\section{PLEASE SCROLL DOWN FOR ARTICLE}

The terms and conditions of use are related to the Open Journal System and to Creative Commons Non-Commercial and Non-Derivative License. 
BRAC - Barcelona Research Art Creation. Vol. 1 No. 1, June 2013 pp.

$100-126$

\section{El Bulli:}

Contemporary Intersections

Between Food, Science, Art and

Late Capitalism.

Maria Domene-Danés

Indiana University

\section{Abstract}

Ferran Adrià, head of the Catalan restaurant and now foundation elBulli, participated in the exhibition of contemporary art Documenta 12 in 2007. My paper analyzes this event as the intersection of three elements: Adrià's work and performance as chef, the incorporation of science and technology into cuisine in what is known as Adrià's 'techno-cuisine', and the crossing between contemporary art and food. To do so, I describe some of Adrià's dishes and examine the ways in which they relate to the artistic field. Rather than addressing the polemic question of whether a chef can ever be considered an artist or not, my essay reflects on the significance of Adrià's approximation to the contemporary art world in relation to the blurring of artistic frontiers and other cultural and social fields. I approach Adrià's case as an example of what Fredric Jameson calls the 'dedifferentiation' of spaces, disciplines, and social spheres that result from the economic forces of late capitalism.

Keywords: Ferran Adrià, Documenta, dedifferentiation, late capitalism.

2013 Hipatia Press

ISSN 2014-8992

DOI: $10.4471 /$ brac. 2013.04

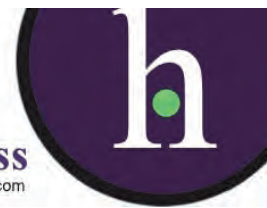


BRAC - Barcelona Research Art Creation. Vol. 1 No. 1, June 2013 pp.

$100-126$

\section{El Bulli:}

Intersecciones Contemporáneas Entre Comida, Ciencia, Arte y Capitalismo Tardío

Maria Domene-Danés

Indiana University

\section{Resumen}

Ferran Adrià, chef principal del restaurante catalán y ahora fundación elBulli, participó en 2007 en la exposición de arte contemporáneo Documenta 12. Mi trabajo analiza este evento como la intersección de tres elementos: el trabajo y performance de Adrià como cocinero, la incorporación de la ciencia y la tecnología en la cocina en lo que se conoce como la "tecno-cocina" de Adrià, y el cruce entre arte contemporáneo y comida. En mi análisis, describo algunos de los platos de Adrià así como su relación con el campo artístico. En lugar de centrarme en la cuestión polémica sobre si un chef puede considerarse un artista o no, mi ensayo reflexiona sobre el significado de la aproximación de Adrià al mundo del arte contemporáneo en relación a la disolución de fronteras artísticas y de otros campos culturales y sociales. Me acerco al caso de Adrià como un ejemplo de lo que Fredric Jameson llama la "desdiferenciación" de espacios, disciplinas y esferas sociales producida por las fuerzas económicas del capitalismo tardío.

Palabras claves: Ferran Adrià, Documenta, desdiferenciación, capitalismo tardío. 
erran Adrià is head of the Catalan restaurant and now foundation elBulli. He is not only one of the most influential chefs, especially known for his 'techno-cuisine'; Adrià is also the only chef who has ever been invited as another artist at Documenta, thethe only chef who has ever been invited as another artist at Documenta, the contemporary art exhibition that is held in Kassel, Germany, every five years. He participated in Documenta 12 (2007), and he converted elBulli in another venue of the artistic event. ${ }^{1}$

As a result of this transformation from chef into "artist," Adrià began to be often portrayed in the media as a new Salvador Dalí. A quick search of pictures of him on the Internet shows the drawing of a parallel between the two artists (Figures 1, 2, and 3).
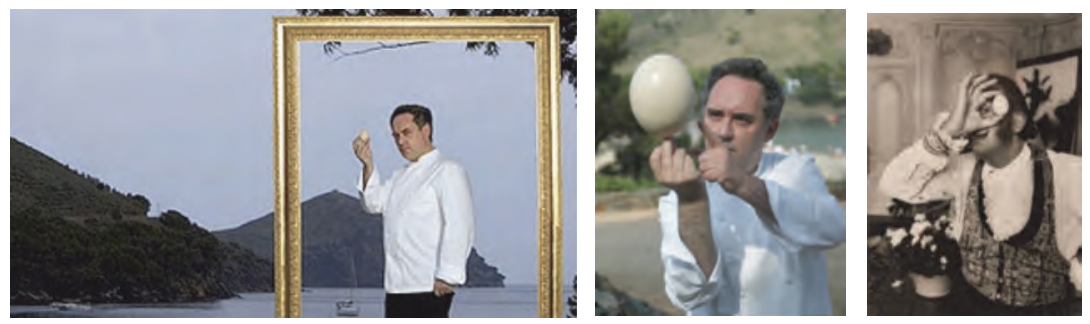

Figure 1, 2. Ferran Adrià in Cala Montjoi (Roses)

Figure 3. Václav Chochola, Salvador Dali with Egg, 1969

In these pictures, Adrià is photographed 'playing' with an egg, exactly like Dalí in Chochola's famous photo. The egg plays a double role: it functions as a universal symbol of cuisine and it associates Adrià directly to Dalí, as eggs are a playful and architectonical recurrent element of the latter's imagery. Moreover, the Fundació Gala i Salvador Dalí in Figueres and the Casa-Museu Salvador Dalí in Portlligat, both buildings decorated with egg-like elements, are located in the same small area as the restaurant/foundation elBulli, which is in Cala Montjoi, Roses. 
Adrià's cuisine and his persona embody a contemporary intersection between food, science, art and market. In this essay, I will not address value question of whether a chef can ever be considered an artist or not. Rather, I will reflect on the significance of his approximation to the contemporary art world in relation to the blurring of artistic frontiers and other cultural and social fields. I will approach Adrià's case as an example, to borrow Fredric Jameson's terminology, of the 'dedifferentiation' of spaces, disciplines, and social spheres that result from the economic forces of late capitalism. ${ }^{2}$ At the same time, I will describe some of Adrià's dishes to see the ways in which they relate to the artistic field. Finally, I will also explore the motivations that were behind the invitation to participate in Documenta.

Interactions between contemporary art and food are not new. Leaving aside earlier connections between art and food in many still-lifes, we can think of contemporary representations of food such as Andy Warhol's Campbell Soup cans or Claes Oldenburg's hamburgers and hot dogs, and installations and performances based on food, such as Paul McCarthy's performances, Alison Knowles's giant salads, Rirkrit Tiravanija's meals in art galleries and museums, and Gordon MattaClark's restaurant Food in New York (Figures 4-9). Yet, these examples consist of multisensory artistic projects that engage in food in different ways: food as commodity f or mass consumption, as a experience of the abject, or as practices of relational aesthetics. Indeed, we can also
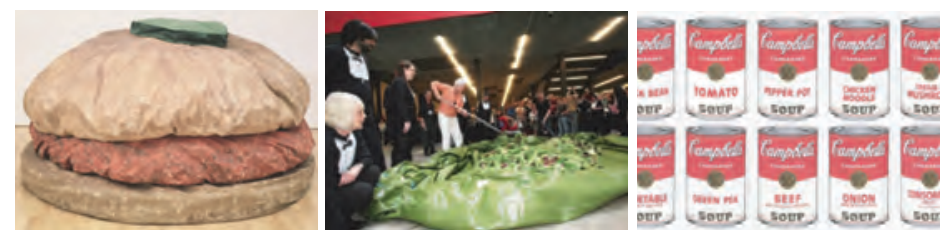

Figure 4. Claes Oldenburg, Floor Burger (Giant Hamburger), 1962.

Figure 5. Alison Knowles, Make a Salad, 1962 (Reenactment, Tate Modern, 2008).

Figure 6. Andy Warhol, Campbell's Soup Cans, 1962. 

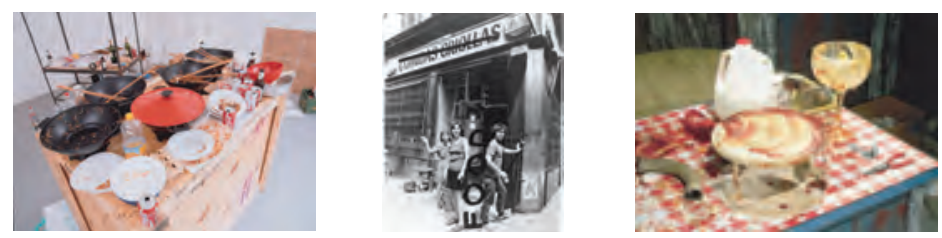

Figure 7. Rirkrit Tiravanija, Pad Thai, 1991-96

Figure 8. Robert Frank, Still from FOOD (short movie on Gordon Matta-Clark and Carol Goodden's conceptual restaurant founded in 1972 in New York City).

Figure 9. Paul McCarthy, Bossy Burger, 1991. Performance, video, and installation at Rosamund Felsen Gallery, Los Angeles.

mention a work much closer to Adrià: Catalan artist Antoni Miralda and his Centre Internacional de la Cultura del Menjar (International Center for the Food Culture), an online project devoted to the investigation of gastronomy, science, technology, and art. ${ }^{3}$

In the case of Adrià, however, we have a cook with no direct relation to the art world who was invited to a highly influential artistic event. It is worth remembering that developments in cuisine have a utilitarian component. As Italian artist Maurizio Cattelan pointed out in an interview with Adrià in the art magazine FlashArt in 2009: "I must start from the principle that vanguard cuisine comes from the need to feed. And this is the big difference in relation to the other artistic fields."4 And yet, what contribution does Adrià make to the contemporary art scene? What theoretical, conceptual and ideological frames connect his work to the sphere of the aesthetic? In fact, can we still think of the aesthetic as a separate field? These are some of the questions that I will attempt to address in this essay.

\section{Who is Ferran Adrià?}

Ferran Adrià (Santa Eulàlia, Barcelona, 1962), head of the restaurant elBulli ${ }^{5}$, was considered the best chef in the world from 2006 to 2009 
by the prestigious list The San Pellegrino World's 50 Best Restaurants. ${ }^{6}$ Yet, he was downgraded to number two in 2010, when restaurant Noma in Copenhagen reached the top position. In 2011, elBulli closed its doors to reinvent itself and they plan to reopen again in 2014 in the form of an interdisciplinary foundation devoted to leading scientific investigation and food culture.

elBulli was a restaurant located in the North-East of Catalonia, in an area close to the border with France. For many years, elBulli, or El Bulli, was a restaurant owned by a German couple and accommodated North-European visitors during the tourist boom of 1960s. In 1984, at age twenty-two, Adrià joined the kitchen staff of elBulli as a line cook.

Eighteen months later, he became the head chef. In 1990, Adrià and Juli Soler, who had already been the restaurant's manager for many years, became co-owners.

During the first three years, Adrià was very influenced by the French nouvelle cuisine. But after this period, he began to invent and cook his own recipes and his cuisine became associated with molecular gastronomy, even if he prefers to describe his cuisine as 'deconstructivist' and 'technoemotional'. ${ }^{7}$ As he points out, "[m]y goal is to provide unexpected contrasts of flavor, temperature and texture. Nothing is what it seems. The idea is to provoke, surprise and delight the diner. [...] The ideal customer doesn't come to elBulli to eat but to have an experience."

Catalan cuisine is in principle not an easy ground for molecular or scientific experimentation. Catalan cooking is based on fresh food such as fish from the Mediterranean; meats from the interior, especially pork; and seasonal vegetables, with special emphasis on corn, garlic, and olive oil. Its basic premise is to maintain the essential tastes without overprocessing them.

During the 80 s and early 90 s, Catalan cuisine was highly influenced by French nouvelle cuisine, but in the late 90s many restaurants began to further experiment with new forms of cooking, even if these were still based on the essential foods of traditional cuisine. It is worth mentioning that most of the considered best restaurants in Spain have emerged in Barcelona and the northern part of Catalonia, where we find seven restaurants with two or three Michelin stars. ${ }^{9}$ This is indicative of 
Catalonia's high creativity in the field of cuisine and also its success in developing a cultural and gastronomic tourist industry.

Following this trend, Adrià's beginning as a leading chef and coowner of elBulli around the mid-1980s were clearly influenced by nouvelle cuisine. The dishes from this period are characterized by the use of local ingredients which were considered 'poor' or 'peasant food', but which were cooked and presented in a highly sophisticated form. Yet, traditional local styles of preparing food were also applied to expensive food like seafood. Traditional and local cuisine "informed elBulli's early explorations of the traditional food of Catalunya, of the rest of Spain, of Italy and finally of the whole Mediterranean." 10

Currently, Adrià's dishes are inspired by fusion cuisine and are highly influenced by Japanese cuisine. From the Nippon Island, he has borrowed not only many ingredients but especially kaiseki cuisine, "a style of formal dining with many courses that are finely balanced in taste, texture, cooking technique and presentation. In fact, the Japanese emphasis on the spirituality, ritual and sequence of eating, which values the experience of the whole meal and the flow of courses over individual dishes, had a deeper influence on the food of elBulli than the use of Japanese ingredients." 11 Indeed, the search for new techniques of cooking, new concepts, and new ingredients is the most important act of creativity. Fusion cuisine has fully immersed Adrià's world in globalization. In this sense, Adrià's dishes have little to do with his beginnings at elBulli's kitchen, when the essential ingredients were local. Now the most 'local' ingredients and references are connected to the rest of Spain, mainly with Castilla and Andalucía. Therefore, Adrià's vision of the 'global' is reflected in the fusion of two instances: the different worldcuisines and the Spanish cuisine rather than the Catalan one. For instance, he uses Andalucian olive oil, ham, and olives; and he mimics Andalucian style when he deepfries fish (with a very sophisticated technique). On the other hand, dishes such as the one called 'earthy', made of several tiny bites of earthy-like dishes, were inspired by Japanese landscapes (Figure 10). Not surprisingly, Adrià was named international 'brand ambassador' for Spain by the country's Ministry of Tourism, in an attempt to make high cuisine another attractive asset for Spain. ${ }^{12}$ 


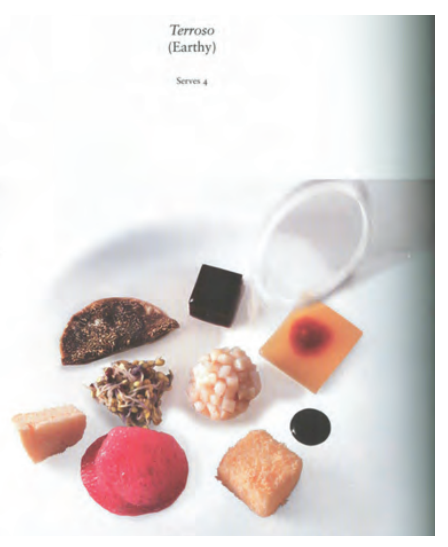

Figure 10. "Earthy".

Perhaps we can also read Adrià's cuisine in political terms and observe that his ideological position would correspond to the construction of the image of a Spain with regional variations rather than the image of a differentiated Catalonia. This relates to one of the fiercest controversies in which he was involved. One of his fervent competitors was Santi Santamaria, former chef of the three-star Michelin restaurant El Racó de Can Fabes, who publicly criticized Adrià's cuisine. ${ }^{13}$ Santamaria's restaurant presented the opposite type of cuisine: it was based on high quality local ingredients, which were cooked with traditional techniques so that the food was little processed. Gastronomist Colman Andrews directly connects Santamaria's cuisine with his Catalan pride. He says that "Santamaria today is proudly, politically Catalan, and is a vocal articulate defender of regional traditions, culinary and otherwise, and of the natural environment of rural Catalonia."14 Andrews describes Santamaria as "a sturdy medium-sized bear of a man with a generous smile, a balding pate and the shadow of a beard and mutton chop whiskers sometimes framing his rounded face." 15

In this sense, Andrews' presumably gracious description of Santamaria can be viewed as an ideological and determinist analogy between certain physical and behavioral features, and localist and 
stubborn Catalan nationalism. Thus, it is implicit in Andrew's statement that Adrià embodies the opposite values: Adrià is invited to participate in Documenta at least in part because he represents a multicultural and global frame, which is conveniently connected to the tourist picture of Spain. ${ }^{16}$ In short, while Santamaria's sort of 'political' cuisine is seen as 'traditionalist', Adrià can be regarded as an 'innovative' chef and global artist.

\section{Molecular Cuisine or Techno-emotional Food ${ }^{17}$}

Adrià was the fist Catalan chef to explore the new possibilities of 'techno-cuisine'. Molecular gastronomy is today a highly influential force in contemporary haute cuisine. ${ }^{18}$ Strictly speaking, all cooking processes are molecular, since cooking changes the molecular structure of food, especially with the application of heat. Applied to contemporary haute cuisine, however, it refers to the reduction of recipes to global formulas, in which ingredients from the same physicochemical family can be interchanged to invent new recipes.

Nicholas Kurti, a Hungarian physicist and professor at Oxford, and Hervé This, a French physical chemist who works at the Institute National de la Recherché Agronomique, invented Molecular and Physical Gastronomy in 1992. Molecular Gastronomy is, in short, the study of the physical and chemical processes that occur while cooking. As This points out,

Nicholas Kurti and I sought to promote the notion of molecular gastronomy [...] Chemistry and physics, judiciously applied, can tell us how to preserve the tenderness of meats, how to master the chemical reactions that give the crust of roasted meat its wonderful flavor [...]. Time honored maxims,proverbs, old-wives' tales, folk believes, and culinary rules are millstones round our necks that weight us down when they are false and wings that carry us aloft when they are true. Hence the importance of molecular gastronomy, whose primary objective is first to make an inventory of such rules and then to select those that have withstood careful analysis. Culinary art has everything to gain by separating the wheat from the chaff of empirical observations." 19 
More specifically, as de Solier points out, "Kurti and This suggest that dishes are neither solid nor liquids, but 'complex disperse systems', and have developed their own scientific language called 'CDS formalism', which aims to provide a global description of the physical microstructure of a dish by translating its recipe into a scientific formula." ${ }^{20}$ For example, the 'Chantilly cream' is translated into a global formula by:

$\mathrm{O} / \mathrm{W}+\mathrm{G} \Rightarrow(\mathrm{G}+\mathrm{O}) / \mathrm{W}$

That is, an oil (in this case milk) dispersed (divided) in water, plus gas (or whipping), leads to a whipped cream. This translation of recipes into formulas is called 'modeling dishes'. ${ }^{21}$ With modeling dishes, one skilled chef can interchange elements from the same family of foods, or also called the 'physicochemical system.' For instance, one can substitute liquid milk for a solid cheese to make a cheese Chantilly. In Kurti and This, this method is called 'generalization'.22

Adrià's molecular cuisine is famous for the invention of the so-called spherifications, foams and airs, as well as liquid nitrogen cooking. Every year the restaurant would close during a six-month period and a team of about twelve chefs devoted themselves to investigating at elBulli Taller (literally, workshop), which opened in 2000 and was located in Barcelona. ${ }^{23}$ The creations developed at the Taller brought science into the kitchen by using chemicals and laboratory instruments to produce 'strange' food. Before 2003, elBulli team discovered most of their pseudo-scientific creations by chance and by trial and error, but in 2003 two chemists were hired as permanent staff of the new Science department in the Taller. Andrews ironically describes elBulli Taller as a place where

he [Adrià] and his team prepare food on flameless induction hobs and, worse, sometimes with cold, in tubs of liquid nitrogen; they use machines that don't look familiar and implements that don't seem to belong in the chef's tool kit, such as electric screwdrivers and oversized syringes. The Taller, in particular, is rumored to be some kind of high-tech laboratory, full of science-fiction paraphernalia. ${ }^{24}$

Andrews' narrative is especially interesting to situate the work of Adrià and the Taller in a terrain in between science and sorcery. On the 
one hand, Andrews emphasizes the scientific side of Adrià's work and presents it as something serious, contrasted, and rigorous (Figure 11).

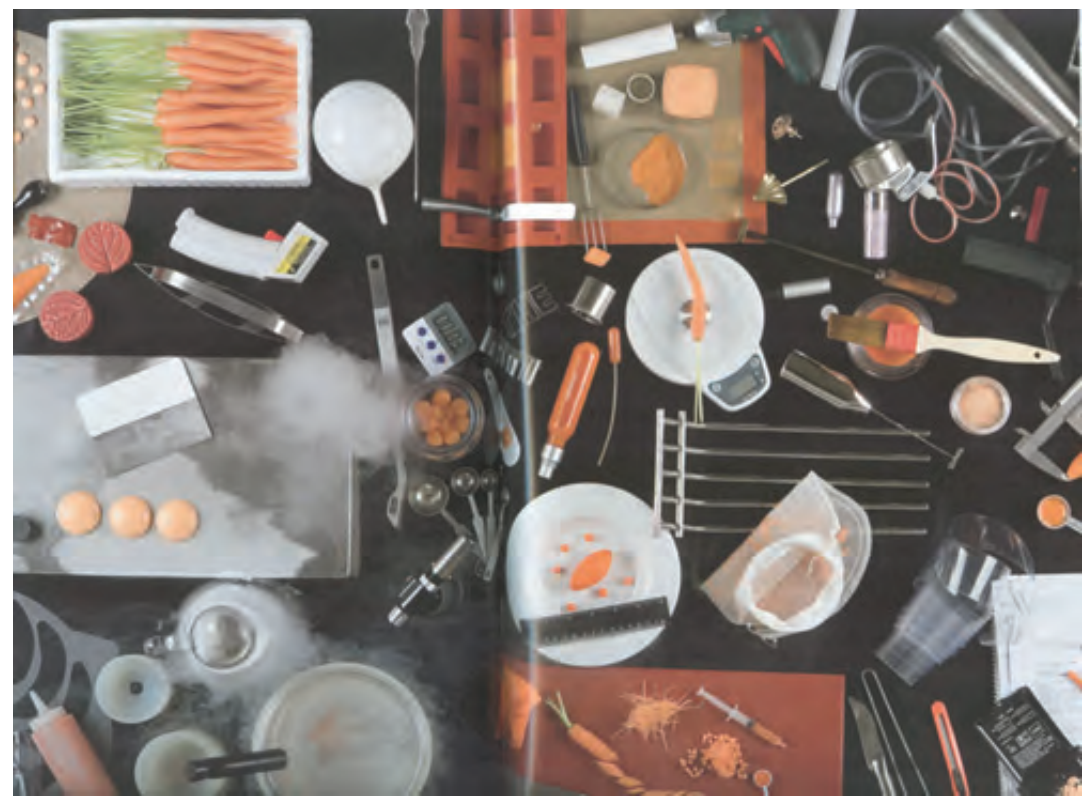

Figure 11. "Still Life" created by elBulli Taller.

But, on the other hand, he emphasizes mystery and offers to the reader a sense of magic, secrecy, and geniality. The balancing between the two poles is perhaps the strongest aspect of Adrià and his creations. Yet, Adrià's success is also due to his willingness to make his recipes public. Sharing his recipes, which are published in books and on the Internet, is a way of proving that, behind the mysterious forms and the cryptic science, his creations are feasible, enjoyable, and healthy. ${ }^{25}$

One of Adrià's most famous inventions are the so-called spherifications (Figure 12), which are the product of dissolving calcium carbonate in an edible liquid of some kind, such as melon, pea, or carrot juice, while feeding droplets of this mixture into a solution of calcium 
alginate. Then, a chemical reaction solidifies the epidermic layer of the drop, keeping the interior totally liquid. A refinement of this procedure came with the use of liquid nitrogen to freeze the eatable liquid solution mixed with calcium carbonate into molds before bathing them in the alginate solution. With this process, the food could take many other shapes, not only spherical (Figure 13).
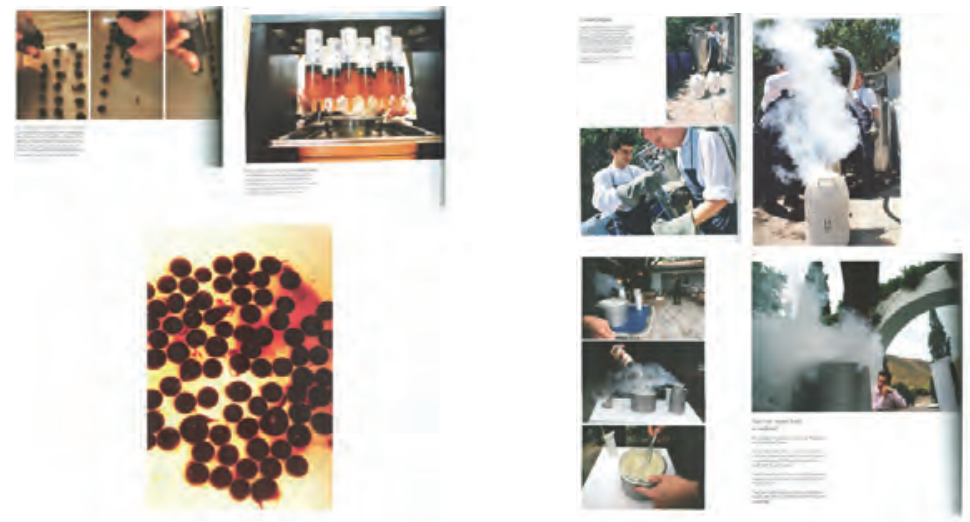

Figure 12. Spherification Process.

Figure 13. Cooking with Liquid Nitrogen.

No scientific creation by Adrià has been as successful and imitated as the foams and airs (Figure 14). The idea came to Adrià in 1991 when he paid attention to the residual foam left by freshly squeezed fruit juice. ${ }^{26}$ Foams are no more than mousses lightened with air instead of cream. To achieve this, Adrià and his team tried several ways of injecting air into food. Finally, they could do it with the help of an Austrianmade siphon with nitrous oxide capsules as propellants used in Austrian coffeehouses. $^{27}$

The first air was produced in elBulli Taller in 2003 "by emulsifying a foam, [previously liquefied with a Turmix], ${ }^{28}$ injecting the maximum amount of air and consequently a foam that, due to its volatility, we call 'air'." 29 


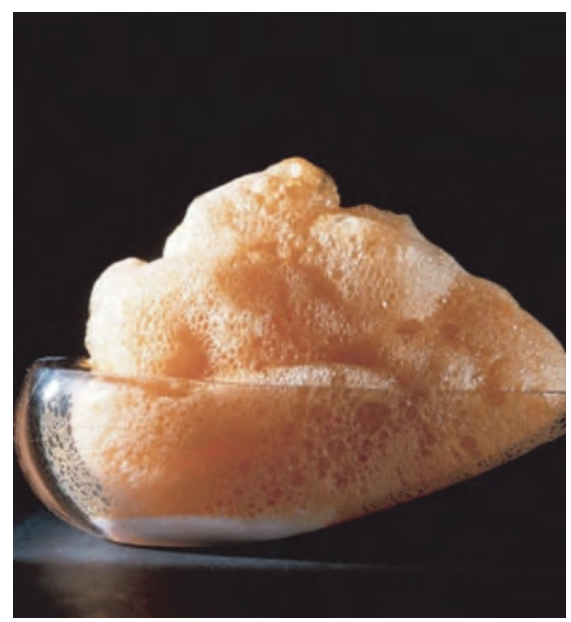

Figure 14. "Carrot Air".

In short, the main role of science in Adrià's cuisine marks a difference in relation to the rest of highly renowned chefs. Scientific experiments held every year at elBulli Taller by chemists and the application of sophisticated technologies to the creation of 'new' dishes, elevated elBulli and its chef to a level above the simple act, or art, of cooking. As de Solier points out, "the science of molecular gastronomy transforms culinary knowledge and practice from the realm of the layperson into an abstract system of scientific expertise." 30 The notion of 'abstract system' is a key aspect to understand the role of Adrià as an 'artist' who participated in Documenta 12.

\section{elBulli's Participation in Documenta 12}

elBulli was invited to participate in Documenta 12 in 2007. elBulli became Documenta's Pavilion G during the 100 days of the art event (Figure 15). Therefore, the 50 clients dining at elBulli each night during this period were not considered guests, but visitors of the Documenta. Moreover, the director of the Documenta, Roger M. Buergel, randomly chose every day two visitors at the Documenta and invited them to have 
diner at elBulli. ${ }^{31}$ They were invited to fly from Kassel to Catalonia, have diner at elBulli, spend the night in a hotel, and come back the next day. Adrià served each evening to his 50 diners a 35-course diner specially prepared on the occasion of Documenta.

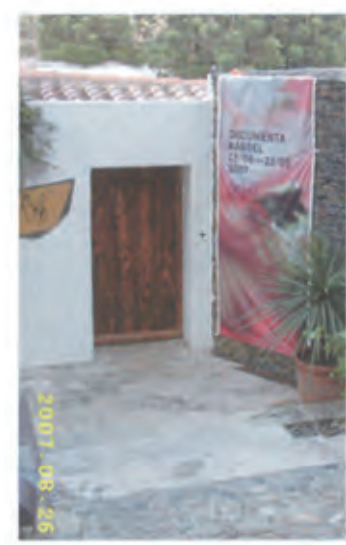

During the one hundred days that documenta 12 lasted, there was a large banner at the entrance to the elBulli restaurant identifying it as one of the pavilions of the exhibition.

Figure 15. Documenta's Pavilion G, 2007.

According to Buergel, "almost single-handedly, Ferran managed to transform the way in which we perceive food. This was the key to his participation in Documenta 12. Of course, the transformation of human perception is an old modernist game. In 2007, one might suppose or even wish the game to be over. But it is not." 32 Thus, to Buergel, the artistic aspect in Adrià's creations is the perceptual trick. Almost all of Adrià's dishes are not what they appear to be, or they are even nothing recognizable, responding to what Adrià calls 'techno-emotionalcuisine'. For instance, dishes conventionally served hot are turned into 


\section{Maria Domene-Danés - El Bulli Contemporary Intersections}

ice creams, caviars are made of spherified fruit juices, pasta is made with thin endless cheese noodles, and cold drinks are served hot. One could argue that Adrià's dishes are based on a sort of anti-synesthetic game.

But, is this experimentation with form sufficient to explain the inclusion of Adrià into the art world? While this was one of the main alleged reasons to present him as an artist, his participation could also respond to a series of marketing needs which were related in turn to the anxieties of European cultural elites that were eager to keep the modernist impulse alive and discover 'new', 'groundbreaking' forms of artistic engagement while professing class status through their culinary experiences. As Manuel Borja-Villel ${ }^{33}$ points out, "Ferran's participation [in Documenta] was an example of the narcissism and self-satisfaction inherent in the mounting of the show", which "speaks to a certain dilettantish extravagance on the part of the curator, who, in my way of seeing, considers this political venue as something merely festive and communal." 34

Yet, rather than condemning Adrià or the curator, some characteristics of his cuisine can be analyzed as catalyzers of cultural crossing not only between art and food but also between modernism and postmodernism. That is, Adrià's creations can be translated into examples of both modernist and poststructuralist or deconstructivist theories, as his production navigates in between the two.

\section{Is elBulli Modernist?}

Adrià's maximum is defined with the sentence 'creativity means not copying', which he acquired after attending a talk by chef Jacques Maximin in Nice in $1987 .{ }^{35}$ Thus, Adrià's culinary principle is based on rupture and originality, which are central ideas within modernism and are intrinsically linked to the notions of authorship and creative genius.

The modernist project is also manifested in the universalist aim of molecular cuisine to establish common truths, which will provide the foundations for the evolution of gastronomy. ${ }^{36}$ Kurti and This's venture engages with the work of Brillant-Savarin, who was the first to connect 
food and science in early nineteenth-century France. We owe to these men the invention of molecular gastronomy. ${ }^{37}$ The translation of recipes into formulas by molecular cuisine and its consequent method of 'generalization' (invented by Kurti and This) is also used by Adrià and his team to develop a system of symbols (Figure 16). Thus, as de Solier affirms, "molecular gastronomy is no postmodern science."38

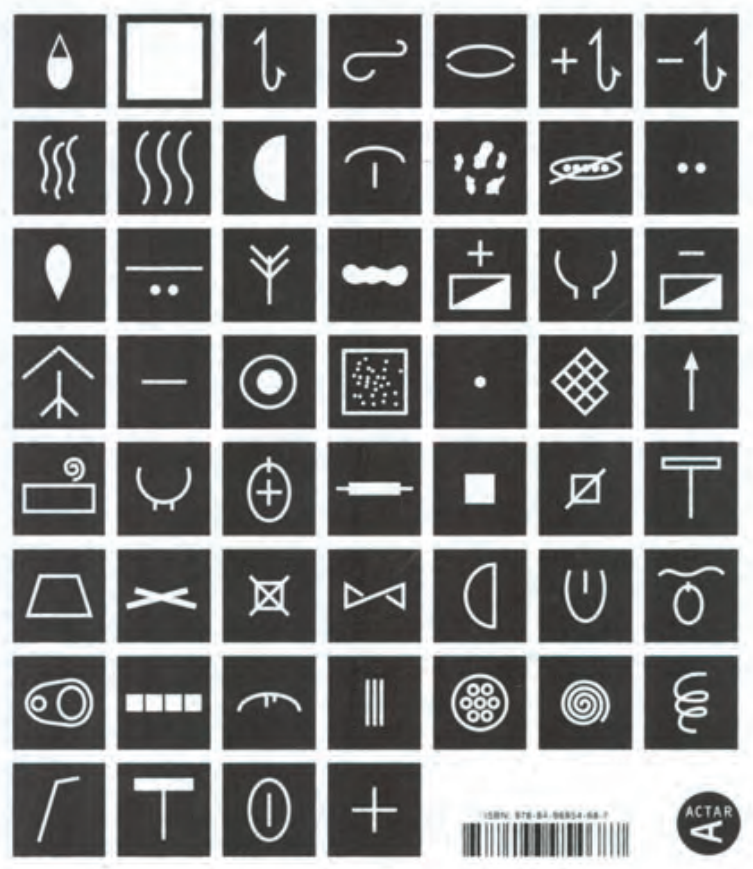

Figure 16. elBulli’s Symbols.

On the other hand, the aspect and textures of some of Adrià's dishes suspiciously resemble abstract expressionist paintings, especially the image of the dish published in Documenta 12 catalog (Figure 17). Or, in one particular dish he pays direct homage to European Informalism (Figure 18). According to anthropologist Gary Alan Fine, creativity is 
fundamental to the chef's status, since cooking is a form of aesthetic production and a sensory experience, and not a mere technique. ${ }^{39}$ In this sense, Fine's approach to high cuisine, especially Adrià's, is very similar to Buergel's artistic view of Adrià's 'old' perceptual tricks and games.
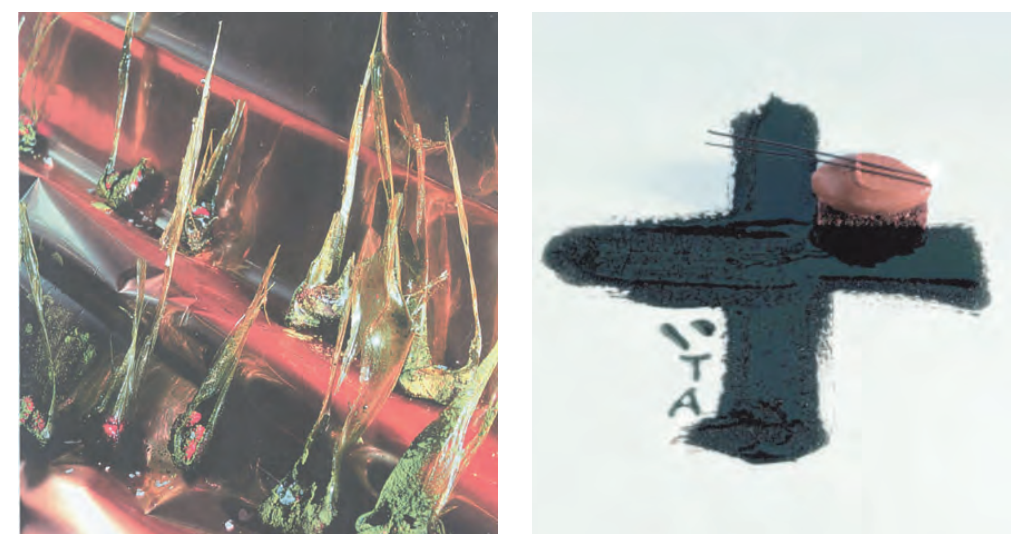

Figure 17. elBulli's Image for Documenta's Catalog, 2007.

Figure 18. elBulli's Homage to Antoni Tàpies.

\section{Is elBulli Postmodernist and Deconstructivist?}

Adrià argues that, beyond perceptual games and surprises, his cuisine is a language for the dialogue between the chef and the diner. Through this dialogue, Adrià expects to 'deconstruct' traditional culinary meanings. Adrià suggests that "deconstruction in kitchen consists of using (and respecting) already known harmonies, transforming the texture of ingredients, as well as their shape and temperature." 40 Deconstruction is the task of questioning the concepts that are self-evident and that structure our knowledge to open up other possibilities of approaching the world. ${ }^{41}$ As philosophical thinking it aims to go beyond the sensorial, and it is unclear whether food and cuisine can ever depart from this sensorial realm. 
However, as Parasecoli (2001) fervently defends, the idea of deconstruction helps us understand Adrià's world. According to Parasecoli,

the concepts Adrià translates and materializes into food are, by his own admission, amazingly close to those developed within the literary and philosophical movement generally known as deconstruction: the same provocative use of estrangement, intended to make the most familiar structures, classifications, and conceptual systems totally unfamiliar; the same intense effort to subvert any absolute set of assumptions, to relentlessly fray the signifying differences in the canonized and mythicized culinary discourse. ${ }^{42}$

Still, while deconstruction avoids authority and uniqueness in favor of simulation and pastiche, Adrià's 'deconstructivist' approach to cuisine emphasizes originality, authorship, and uniqueness. Following Parasecoli again, "the common point between cooking style and the deconstruction method would be the play with textures, shapes, and temperatures of ingredients in order to enhance the 'spirit' of a dish, to display all of its connections to memory and to other recipes." 43 Therefore, going back to Buergel's justification on why Adrià was invited at Documenta, one realizes that what Adrià and Parasecoli call deconstruction, Buergel calls it perceptual games. In the end, it remains unclear whether deconstructing cuisine means creating something new or dismantling the inherited knowledge that structures our food and our cuisine.

\section{Food for Thought, Thought for Food or the Endogamy of Class Elite}

Adrià's participation in Documenta 12 led to the publication in 2010 of the book Food for Thought, Thought for Food, edited by Vicent Todolí and Richard Hamilton (Figure 19). ${ }^{44}$ The aim of this book was to justify Adrià's fragile position as a contemporary artist who nevertheless remains within the sphere of high cuisine. The main argument of the contributors to the book was to present Adrià as andespite his own reluctance to being labeled one, and to portray the menu of his restaurant as a collective and participative work of art. 


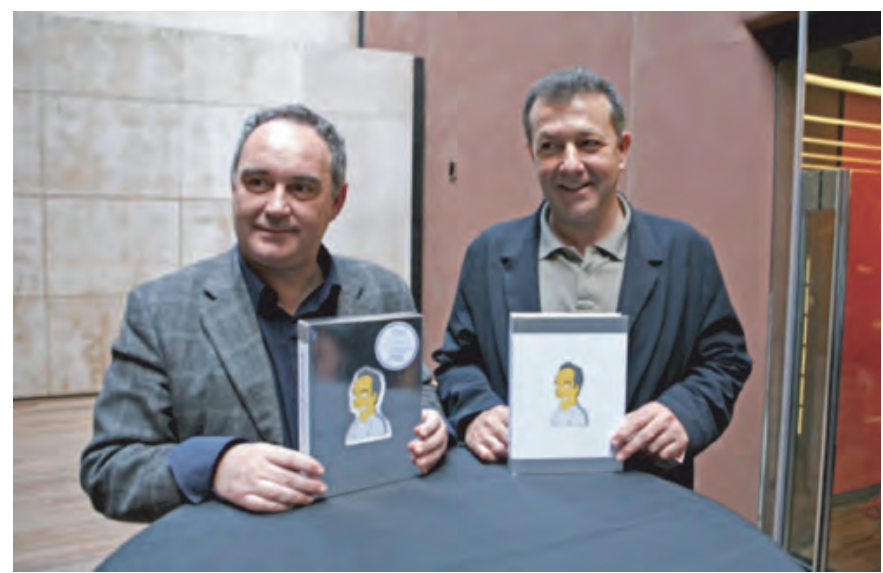

Figure 19. Promotional Pictures for Food for Thought, Thought for Food. Adrià and Todolí.

For instance, Richard Hamilton's text argues that inviting Adrià to participate in Documenta 12 was a completely appropriate decision. Hamilton compares Adrià's work with several 'postmodern artists [who] have approached the subject of food obliquely', such as Marcel Broothaers, Claes Oldenburg, Alison Knowles, Dieter Roth, and Daniel Spoerri. ${ }^{45}$ Adrian Searle's article, in turn, is a journal-style report of his one-day experience at elBulli Taller in Barcelona. Searle describes the process of conception and production of the dishes, and constantly compares it to the process of artistic creation.

The book offers a wide understanding of how Adrià's formal participation in Documenta materialized, and it contains detailed illustrations of the thirty-five creative dishes that composed the menu (Figure 20). And yet, the argument of the whole book and the passionate explanations of the editors and contributors do not quite succeed in convincing skeptical readers, and one does not find a strong theoretical base to justify the presentation of high cuisine as art. We still have to answer the question: where does the impulse to define Adrià's cuisine as art come from?

At the same time, commodities have also incorporated cultural value. 


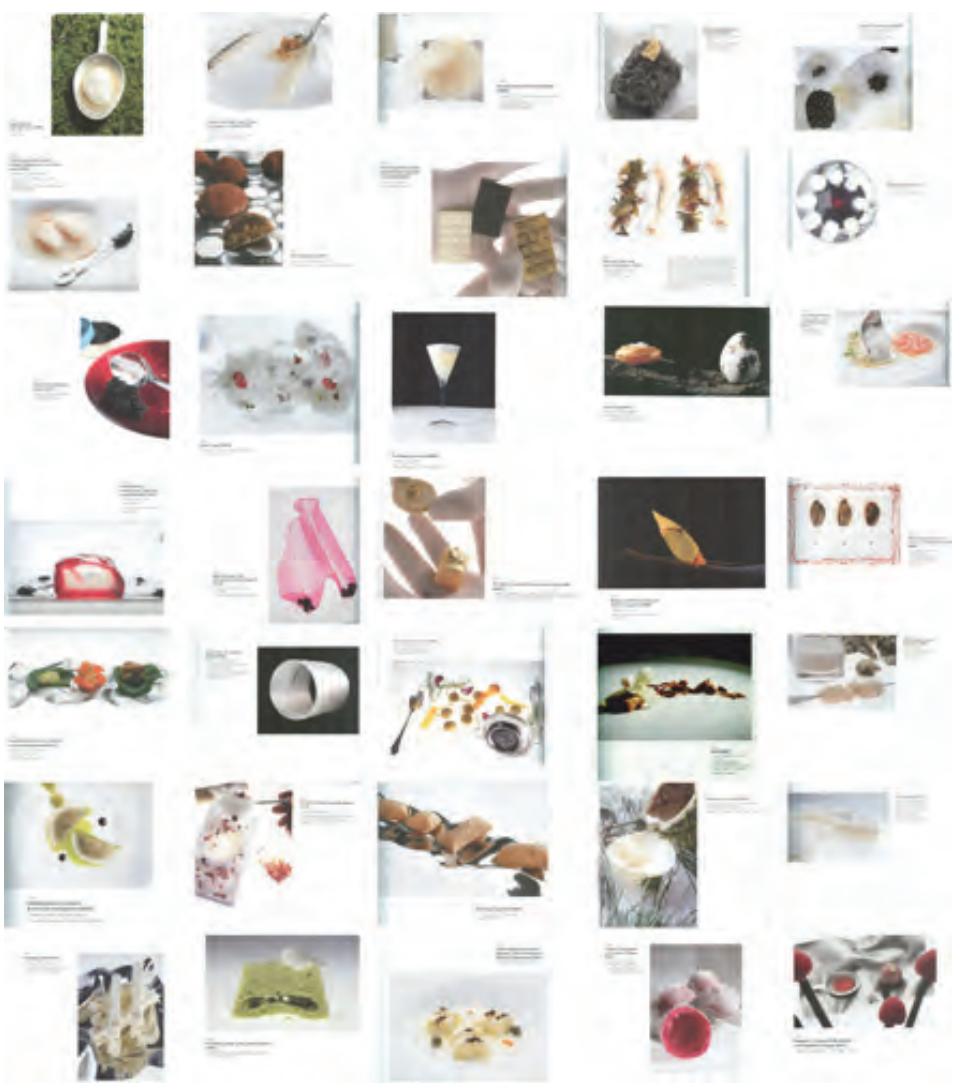

Figure 20. Documenta's Menu.

\section{elBulli as an Example of Postmodern 'Dedifferentiation'}

The case of elBulli is maybe another, rather extreme example of the general blurring between the market and cultural production, or what Jameson has termed the 'dedifferentiation' of social spaces in late capitalism. In our contemporary times, the difference between culture and the market has disappeared, as everything has been transformed into capital, from art to food to all type of personal and social experiences. 
In a post-Fordist economy in which the desires of the customer detemine the design of production, marketing has become a crucial aspect of the commodity. Commodities differentiate themselves through the work of marketing, which involves all type of cultural and immaterial knowledges that can help create special qualities for commodities.

The paradox is that the more commodities must differentiate themselves in our consumerist and postmodern society, the more dedifferentiated the spheres of society become. As Jameson points out, postmodernity, in which 'the end of art" 46 takes place, "is marked by a dedifferentiation of fields, such that economics has come to overlap with culture: that everything, including commodity production and high and speculative finance, has become cultural; and culture has equally become profoundly economic or commodity oriented."47 For Jameson, the emergence of the so-called happenings during the 1960s, whose very deployment was also political because of their critique of the relation between high culture and state power, was the first attempt to abolish the boundaries between art and life. ${ }^{48}$ 'The end of art' was strictly linked to the end of the sublime and the end of the auteur, and it went hand by hand with the appearance of Theory (mainly structuralism and post-structuralism). However, a parallel phenomenon was the emergence of what Jameson calls the 'Beautiful', which conformed the other face of postmodernism, at the other side of Theory. The Beautiful relates to the decorative, and it is a source of "pleasure and gratification". ${ }^{49}$ Thus, both Theory and the Beautiful are part and parcel of 'the end of art'. Following Jameson again,

we must add a significant qualification to this identification to postmodernism with Kant's and Burke's conception of the Beautiful: this has to do with education, the public sphere, and the cybernetic or informational age; and it requires us to underscore a remarkable historic development in our own time, namely the immense expansion of culture and commodification into all these fields-politics and economics, for example- from which it was so rightly differentiated in the daily life of the modern period. ${ }^{50}$

Thus, this 'acculturation' of daily life and the corresponding 'commodification' of culture can explain the relationship between two 
separate phenomena such as elBulli and Documenta. This double process of 'commodification' of culture and 'acculturation' of daily life can be particularly observed in Adrià's foams and airs (see figure 15). As de Solier points out, "elBulli's molecular gastronomy dematerializes the substance of food [especially in foams and airs], making literal Marx's metaphor of modernity: 'All that is solid melts (or in this case, is siphoned) into air'." 51 But Adrià's foams and airs can be read not only as a metaphor for modernity, but also, and more specifically, as a metaphor of our current stage of modernity, namely postmodernity. This stage, as Jameson has shown, is that of finance capitalism. The airs and foams are a perfect portrait of the transformation from material production (the so-called 'Fordist' model) into immaterial finance capital (or also called 'post-Fordist' model). Adrià's molecular gastronomy is another example of the general dematerialization of production under finance capitalism. Like the immaterial components of marketing and the dedifferentiation between art and decoration, cuisine turns into another free-floating signifier with no "proper" sphere or "authentic" tradition.

\section{Concluding Remarks}

The performative experience of dining at elBulli (performative because some of the dishes were finished at the guests' table, and sometimes special guests could eat in the magnificent kitchen while it was in full action), the aesthetic achievement of Adrià's dishes, the will to confuse and transform human perception, and the centrality of science in his creations, the 'dedifferentiation' of social fields, along with an intense process of marketing, are some of the guidelines to interpret Adrià's invitation to Documenta 12.

However, we must still ask the question of Adrià's contribution to the contemporary art scene. Given that his dishes do not seem to assume any artistic practice or discourse beyond the perceptual games provided by his highly sophisticated creations, we must question whether his food experiences connect in any strong way with the artistic tradition of "before" the end of art. In other words, even if finance capitalism has blurred all differences and categories, the lack of reference to a previous 
conception of art turns him into a simple celebration of the current state of things. Adrià's food, even if it is aesthetically complex and visually attractive, does not pursue the creation of a vision or a comment on the world beyond the sensorial experience of food. In the end, his art and food are simply sustained by the global 'airy' economy and one cannot help wonder what would happen to his creations if some day this airy economy finally collapsed.

\section{Notes}

${ }^{1}$ In 2000, El Bulli modified its spelling and became elBulli. This change aimed to modernize the restaurant's logo by imitating the spelling of trendy technologies such as iPhone, iBook, or iPod. This not only indicated a marketing strategy but also reflected the restaurant's effort to connect to new technologies. For more information, see Andrews Colman (2010). Reinventing Food. Ferran Adrià: The Man Who Changed the Way We Eat. London: Phaidon. Since this paper mainly focuses on the period of 2007, when Adrià was invited at Documenta, I will use the most recent name elBulli.

2 Jameson, Fredric (1998). The Cultural Turn. Selected Writings on the Postmodern, 1983-1998. London: Verso, (73).

${ }^{3} \mathrm{http}: / / \mathrm{www}$. foodculturemuseum.com/ [last accessed April 28, 2013].

${ }^{4}$ Cattelan, Maurizio (2009). "Ferran Adrià" Flash Art 267, 39.

${ }^{5}$ In its restaurant form, elBulli was composed of Ferran Adrià (elBulli's main chef and co-owner), Albert Adrià (Ferran's brother and elBulli dessert's chef), Juli Soler (coowner and PR), Oriol Castro (Creative Team alongside with Adrià brothers), Pere Castells and Î́ngrid Farré (scientific department).

${ }^{6} \mathrm{http}: / /$ www.theworlds50best.com/ [last accessed April 28, 2013].

7 Technoemotional cuisine is based on scientific experimentation and the invention of perceptual games. Even if this type of cuisine is defined as "deconstruction," its application in cuisine is very far from the philosophical context in which it emerged.

8 Andrews, Colman (2010). Reinventing Food. Ferran Adrià: The Man Who Changed the Way We Eat. London: Phaidon, (201).

${ }^{9}$ This guide awards one to three stars to a small number of restaurants of outstanding quality. Two restaurants have three stars: Sant Pau (Sant Pol de Mar) and El Celler de Can Roca (Girona), and five Catalan restaurants have two stars: Les Cols (Olot), Miramar (Llançà), Can Fabes (Sant Celoni), Lasarte, Àbac, Enoteca and Moments (Barcelona). This is a high percentage in relation to the rest of the world (except for some regions of France). Source: http://ca.wikipedia.org/wiki/Guia_Michelin\#Les_estrelles_Michelin [last consulted March 4, 2013].

${ }^{10}$ Adrià, Albert; Adrià Ferran; Soler, Juli (2008). A Day at elBulli. An Insight into the Ideas, Methods and Creativity of Ferran Adrià. New York: Phaidon Press Ltd, (136).

${ }^{11}$ Adrià, Albert; Adrià Ferran; Soler, Juli, (136). 


\begin{abstract}
12 Andrews, Colman. (293).
${ }^{13}$ See footnote 22 .

${ }^{14}$ Andrews, Colman. (277).

15 Andrews, Colman. (277).

16 The Patronat de Turisme Costa Brava Pirineu de Girona (Costa Brava Girona Pyrenees Tourist Agency) partially funded Adrià's participation in Documenta.

17 The term 'techno-emotional' was first coined by journalist Pau Arenós in the Spanish periodical El Periódico. Source: Andrews, Colman. (219).

18 de Solier, Isabelle (2010). Liquid Nitrogen Pistachios: Molecular Gastronomy, elBulli and Foodies. European Journal of Cultural Studies, 13, 2, 155-170 (156)

19 This, Hervé (2006). Molecular gastronomy: exploring the science of flavor. New York: Columbia University Press, (11-12). For more information, see Crow, James Mitchell; Campos-Seijo, Bibiana (2009). Interviews: Hervé This and Ferran Adrià Talk Chemistry and Cooking. Chemistry World 6, 10, 40; Friel Blanck, Jaime (2008). Molecular Gastronomy: Overview of a Controversial Food Science Discipline. Journal of Agricultural and Food Information, 8, 3, 77-85; and Raisfeld, Robin; Rob Patronite (2006). Ferran Adrià, Molecular Gastronomist. New York, 39, 38, 83.

${ }^{20}$ de Solier, Isabelle (158).

21 de Solier, Isabelle (158).

22 de Solier, Isabelle (158).
\end{abstract}

${ }^{23}$ During each six-month period, more than 5000 experiments were conducted at elBulli Taller. Around 100 were selected to eventually become part of the next menu. (Andrews, 203).

${ }^{24}$ Andrews, Colman (201).

25 During the last three years, an intense controversy emerged on whether Adrià's recipes could be harmful for people's health. Late chef Santi Santamaria, owner of El Racó de Can Fabes, accused Adrià of 'poisoning' his customers. But the two restaurants, both with three Michelin stars at that moment, have always been competitors and Santamaria, who died in February of 2011, had always been on the losing side. For more information, see Chapter 14 in Andrews, Colman; and Santamaria, Santi (2009). La cocina al desnudo [The Kitchen Stripped Bare]. Madrid: Ediciones Temas de Hoy, SA. ${ }^{26}$ Andrews, Colman. (234).

${ }^{27}$ In particular, the 'Isi Siphon' was the one used at elBulli. It is a sort of pressurized container in which foams can be created by aerating a liquid under pressure. Source: Adrià, Ferran; Adrià, Albert; Soler, Juli (525).

28 Electric blender. The name comes from the Spanish brand that popularized the appliance.

${ }^{29}$ Ferran Adrià quoted in Andrews (237).

${ }^{30}$ de Solier, Isabelle (156).

31 The chief curator was Roger Buergel and the exhibition's head commissioner was Ruth Noack (also Buergel's wife).

32 Hamilton, Richard; Todolí, Vicent (2009). Food for thought, thought for food. Barcelona: ACTAR, 77. For more information, see also Pitman, Joanna (2009). Lovely mousse, but is it art? A profile of the great chef Ferran Adrià. The spectator (July 11), 16.

33 In 2007, Borja-Villel was the chief curator at the Museu d'Art Contemporani de Barcelona (MACBA) and is currently the director of the Museo Nacional Centro de Arte Reina Sofía in Madrid (MNCARS). 


\section{Maria Domene-Danés - El Bulli Contemporary Intersections}

${ }^{34}$ Quoted in Andrews, Colman (270).

${ }^{35}$ Adrià, Ferran; Adrià, Albert; Soler, Juli (40).

${ }^{36}$ de Solier, Isabelle (157).

${ }^{37}$ See footnote 37.

38 de Solier, Isabelle (158).

39 de Solier, Isabelle (160).

${ }^{40}$ Qtd. in de Solier, Isabelle (163).

41 See, Culler, Jonathan D (1982). On Deconstruction: Theory and Criticism after Structuralism. Ithaca, N.Y.: Cornell University Press.

42 Parasecoli, Fabio (2001). Deconstructing Soup: Ferran Adrià's Culinary Challenges Gastronomica 1, 1, 60-73 (63).

${ }^{43}$ Parasecoli, Fabio (67).

44 Book's editors are Vicent Todolí (the Tate Modern's former Director) and Richard Hamilton (Renowned British Artist). Book's contributors are Roger Buergel (director of Documenta 12), Ruth Noack (exhibition's head commissioner and also Buergel's wife), Marta Arzak (Director of Interpretation at Bilbao's Guggenheim Museum and also daughter of Basque leading chef Juan Mari Arzak, first Spanish chef who achieved three Michelin Stars), Josep Maria Pinto (elBulli cataloguer), and Adriane Searle (The Guardian's art critic). However, the idea of the book was Adrià's. He wanted to evoke Brillant-Savarin's nineteenth-century book on gastronomic philosophy, and conceive the book as the new 'physiology of taste'. Source: Andrews, Colman (272).

${ }^{45}$ Hamilton, Richard; Todolí, Vicent (54).

46 See, Danto, Arthur C. (1997). After the End of Art: Contemporary Art and the Pale of History. Princeton, N.J.: Princeton University Press.

47 Jameson, Fredric (73).

48 See, Kaprow, Allan (2003 [1996]). Essays on the Blurring of Art and Life. Berkeley, CA.: University of California Press.

49 Jameson, Fredric (86).

${ }^{50}$ Jameson, Fredric (86).

51 de Solier, Isabelle (164).

\section{References}

Andrews, C. (2010). Reinventing Food. Ferran Adrià: The Man Who Changed the Way We Eat. London, England: Phaidon.

Adrià, A., Adrià F., \& Soler, J. (2008). A Day at elBulli. An Insight into the Ideas, Methods and Creativity of Ferran Adrià. New York, N.Y: Phaidon Press Ltd.

Campos-Seijo, B. (2009). Interviews: Hervé This and Ferran Adrià Talk Chemistry and Cooking. Chemistry World, 6(10), 40.

Cattelan, M. (2009). Ferran Adrià. Flash Art (267), 39.

Culler, J. D. (1982). On Deconstruction: Theory and Criticism after 
Structuralism. Ithaca, N.Y.: Cornell University Press.

Danto, A. C. (1997). After the End of Art: Contemporary Art and the

Pale of History. Princeton, N.J.: Princeton University Press.

Friel Blanck, J. (2008). Molecular Gastronomy: Overview of a

Controversial Food Science Discipline. Journal of Agricultural and

Food Information, 8(3), 77-85.

Guillén, M. (2011). Food Cultura. Retrieved from

http://www.foodculturemuseum.com

Hamilton, R. (2009). Food for thought, thought for food. Barcelona, Spain: ACTAR.

Jameson, F. (1998). The Cultural Turn. Selected Writings on the

Postmodern, 1983-1998. London, England: Verso.

Kaprow, A. (2003). Essays on the Blurring of Art and Life (2nd ed.).

Berkeley, CA.: University of California Press.

Parasecoli, F. (2001). Deconstructing Soup: Ferran Adrià's Culinary

Challenges. Gastronomica 1(1), 60-73.

Pitman, J. (2009, July 11). Lovely Mousse, But is it Art? A Profile of the Great Chef Ferran Adrià. The spectator pp. 16.

Raisfeld, R. (2006). Ferran Adrià, Molecular Gastronomist. New York, $39(38), 83$.

Santamaria, S. (2009). La cocina al desnudo [The Kitchen Stripped Bare]. Madrid, Spain: Ediciones Temas de Hoy, SA.

Solier, I. de (2010). Liquid Nitrogen Pistachios: Molecular Gastronomy, elBulli and Foodies. European Journal of Cultural Studies, 13(2), 155-170.

This, H. (2006). Molecular Gastronomy: Exploring the Science of Flavor. New York, N.Y.: Columbia University Press.

Woodward, S. (2012). The World's 50 Best Restaurants. Retrieved from http://www.theworlds50best.com 
Maria Domene-Danés: PhD Candidate. Henry Radford School of Fine Arts. Department of Art History. Indiana University. Bloomington. United States of America.

Contact Address: Henry Radford School of Fine Arts, Indiana University, 1201 E. Seventh Avenue, Office 132 Bloomington, IN 47405, United States of America. Email: mdomened@umail.iu.edu $1201 \mathrm{E}$. 


\section{B.RP:AC}

Instructions for authors, subscriptions and further details:

http://brac.hipatiapress.com

\section{La Cascarilla Cerámica como Material Escultórico}

Carmen Marcos Martínez¹.

1) Departamento de Escultura, Facultad de Bellas Artes de San Carlos. Universidad Politécnica de Valencia, España.

Date of publication: June, 3rd 2013

To cite this review: Marcos, C. (2013). La Cascarilla Cerámica como Material Escultórico (Review of the doctoral thesis). Barcelona, Research, Art, Creation, 1 (1), 127-129. doi: 10.4471/brac.2013.05.

To link this article: http://dx.doi.org/10.4471/brac.2013.05

\section{PLEASE SCROLL DOWN FOR ARTICLE}

The terms and conditions of use are related to the Open Journal System and to Creative Commons Non-Commercial and Non-Derivative License. 
BRAC - Barcelona Research Art Creation. Vol. 1 No. 1, June 2013 pp.

$127-129$

\section{Reviews (I)}

Petrillo, L. (2013). La cascarilla cerámica como material escultórico. (Tesis doctoral no publicada). Universidad de Barcelona, Barcelona, España.

La tesis que citamos fue defendida en la Facultad de Bellas Artes de Barcelona el 22 de enero de 2013, y tuvimos el honor de formar parte del tribunal.

Quisiéramos dibujar el contexto histórico e investigador en el que se puede inscribir esta investigación. En 1996 Mr. David Reid impartió un taller que organizamos en el Departamento de Escultura de la Facultad de Bellas Artes de Valencia, titulado "Fire Technologies in the Making of Sculpture", en el que se realizaron moldes experimentales aglutinados con materias orgánicas, con refractarios alternativos, con moldes no refractarios. Una de las reflexiones finales del curso de Mr. David Reid fue comentar que teníamos "entre manos" un material exquisito, la cáscara cerámica que usábamos como material de molde perdido, y por tanto lo rompíamos, lo tirábamos, pero que al fin y al cabo era una cerámica, una cerámica de grandes cualidades. Desde entonces no hemos parado hasta encontrar un sentido y expresión escultórica a la propuesta del maestro. Dos Congresos de Investigadores en Fundición Artística después (2006 y 2009, celebrados ambos en la Facultad de Bellas Artes de Valencia), la tesis de D. Lucido Petrillo recoge y presenta la cáscara cerámica como material escultórico, desarrollo completo de su participación precisamente en el II Congreso con un artículo titulado "Experiencias y estudio de resistencias de la

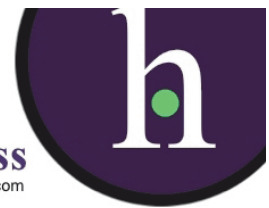


cascarilla cerámica para su uso como material escultórico". Este congreso se completaba con una exposición de esculturas entre las cuales tanto la de D. Lucido como la de quien suscribe estas líneas eran propuestas escultóricas en cáscara cerámica.

Toda la tesis tiene un marcado carácter empírico-experimental. Está estructurada en cinco capítulos de contenidos, de los cuales los tres primeros se centran en someter al material que ya conocemos, a la cáscara cerámica, a una revisión de reconocimiento, que incluye análisis de componentes, pruebas de resistencia teniendo el sílice coloidal PW50 (nombre comercial del sílice coloidal suministrado por Comercial Química Massó) como aglutinante central de la investigación, y procedimientos escultóricos tradicionales. En esta primera parte de la tesis consideramos una aportación especial la elección del uso del PW50, dado que hasta fecha muy reciente, el sílice coloidal citado y empleado habitualmente en las fundiciones artísticas era el Hispasil 17.31 .

De esta primera parte de la tesis destacamos las imágenes de microscopía realizadas con el SEM sobre secciones de diferentes muestras de cáscara cerámica por ser en si una aportación científica de relevante interés que el seno de la Universidad puede viabilizar para incrementar y mejorar el campo de conocimiento de la Escultura.

Resultan de gran interés los capítulos IV y $\mathrm{V}$, en los que la tesis muestra sus aspectos más puramente creativos. Cierto que los capítulos previos preparan y abonan el terreno para poder desarrollar con fluidez y "tranquilidad" técnica los dos siguientes, pero pensamos que la amplitud y complejidad de la primera parte de la tesis ha restado tiempo de explorar las verdaderas posibilidades creativas de la investigación en si. El capítulo IV, que aborda los tratamientos superficiales de la cáscara cerámica resulta a todas luces innovador, desde la mezcla de la barbotina de primera capa con otros materiales, como las limaduras de hierro y/o bronce, hasta el uso de esmaltes y acabados cerámicos industriales, comerciales. El capítulo V, titulado "Experiencias de la aplicación de la cáscara cerámica como material escultórico", es el que da sentido a todo lo investigado de forma más empírica en los capítulos anteriores. Se trata de crear esculturas con los diversos procedimientos ensayados y con las premisas técnicas que marcan una calidad de trabajo buena. Se presentan trabajos de creación propia, pero también de 
compañeros e incluso de sus dos directores de tesis, con lo cual se ha alcanzado una mayor riqueza y profundidad, tanto formal como estilística. Muchas de estas piezas presentadas han participado en exposiciones colectivas, con lo que consideramos se ha cerrado el ciclo de comunicación que es inherente al acto creativo.

Como valoración final nos gustaría expresar nuestra comunión con el planteamiento de esta tesis doctoral. Desde nuestros inicios como profesora asociada en la Universidad Politécnica de Valencia, en los que nuestra actividad profesional compaginaba la creación escultórica en el taller personal con las clases en la universidad, hemos entendido que docencia, creación e investigación van unidas. Creemos en una investigación en la que la técnica apoye y estimule lo creativo, un hermanamiento entre investigación técnica y creación escultórica.

Carmen Marcos, Universidad Politécnica de Valencia carmemarcos@gmail.com 